\title{
A MONETARY POLICY \\ STRATEGY IN GOOD \\ AND BAD TIMES \\ LESSONS FROM THE RECENT PAST
}

by Stephan Fahr, Roberto Motto, Massimo Rostagno, Frank Smets and Oreste Tristani 


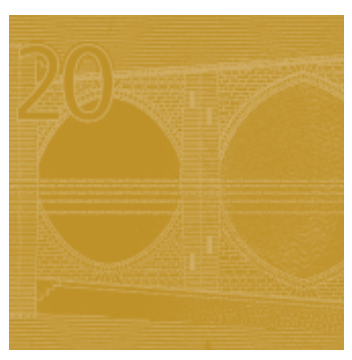

\author{
A MONETARY POLICY STRATEGY \\ IN GOOD AND BAD TIMES
}

LESSONS FROM THE RECENT PAST '

by Stephan Fahr, Roberto Motto, Massimo Rostagno, Frank Smets and Oreste Tristani ${ }^{2}$
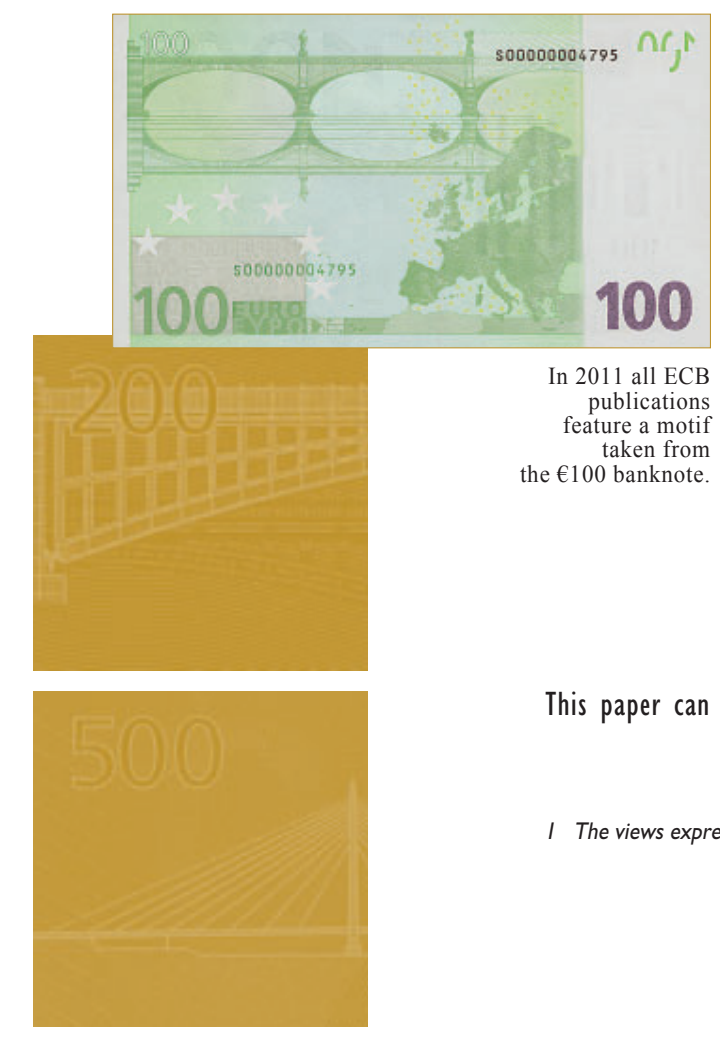

NOTE: This Working Paper should not be reported as representing the views of the European Central Bank (ECB). The views expressed are those of the authors and do not necessarily reflect those of the ECB.

This paper can be downloaded without charge from http://www.ecb.europa.eu or from the Social Science Research Network electronic library at http://ssrn.com/abstract_id=|8|4928.

I The views expressed in this paper are our own and not necessarily those of the European Central Bank or its Governing Council. We thank G. Amisano, G. Kiss, H. Pill, J. Pisani-Ferry, G. Tabellini, J. Ulbrich, J.-P. Vidal and W. White

for helpful comments. We gratefully acknowledge $P$. Gertler's and $K$. Holzheu's research assistance.

2 All authors: European Central Bank, Kaiserstrasse 29, D-603II Frankfurt am Main, Germany; e-mails: Stephan.Fahr@ecb.europa.eu; Roberto.Motto@ecb.europa.eu; Massimo.Rostagno@ecb.europa.eu; Frank.Smets@ecb.europa.eu; 
(C) European Central Bank, 2011

\section{Address}

Kaiserstrasse 29

60311 Frankfurt am Main, Germany

Postal address

Postfach 160319

60066 Frankfurt am Main, Germany

Telephone

+496913440

Internet

http://www.ecb.europa.eu

Fax

+496913446000

All rights reserved.

Any reproduction, publication and reprint in the form of a different publication, whether printed or produced electronically, in whole or in part, is permitted only with the explicit written authorisation of the ECB or the authors.

Information on all of the papers published in the ECB Working Paper Series can be found on the ECB's website, http://www. ecb.europa.eu/pub/scientific/wps/date/ html/index.en.html

ISSN 1725-2806 (online) 


\section{CONTENTS}

Abstract

Non technical summary

1 Introduction

2 A tale of the last 15 years

2.1 The great moderation and the financial crisis

2.2 Booms and busts in asset and credit markets

3 The economy and the strategy

3.1 Questions and methodology

3.2 First answer: the economy did not cooperate

3.3 Second answer: the strategy did steer the economy

4 The financial crisis

4.1 From the financial turmoil to the Great Recession

4.2 A VAR analysis

5 Conclusions

References

Annex

Figures

Appendix 
We evaluate the ECB's monetary policy strategy against the underlying economic structure of the euro area economy, in normal times and in times of severe financial dislocations. We show that in the years preceding the financial crisis that started in 2007 the strategy was successful at ensuring macroeconomic stability and steady growth despite shocks to the supply side and to the transmission mechanism which complicated the policy process. Emphasis on monetary indicators in the ECB's monetary policy strategy - the monetary pillar - was instrumental in avoiding more volatile and less predictable patterns of inflation and growth. After the collapse of financial intermediation in late 2008, the strategy of the ECB was to preserve the integrity of the monetary policy transmission mechanism by adopting a comprehensive package of non-standard policy measures. According to our quantitative evaluation of the impact of the non-standard policy package, which notably did not include entering commitments regarding the future path of the policy rate, the liquidity interventions decided in October 2008 and in May 2009 were critical to preserving price stability and forestalling a more disruptive collapse of the macro-economy.

JEL classification codes: E3 I; E44; E5 I; E58

Keywords: Monetary Policy; Monetary transmission; Credit, Supply factors; Financial crisis; Non-standard policy measures 


\section{NON TECHNICAL SUMMARY}

The outbreak of the financial turmoil in 2007 and the subsequent financial crisis with the collapse in trade and economic activity in 2008 have led to a rethinking of monetary policy frameworks. In this paper, we focus mainly on two aspects of this debate. First, the financial boom and bust episode of the new millennium has questioned the appropriateness of what is sometimes called the "Jackson Hole consensus". According to this consensus central banks should only respond to asset prices and financial imbalances to the extent that they affect the inflation forecast. Second, the financial crisis has led to an unprecedented use of non-standard monetary policy tools to avoid that liquidity problems turn into solvency problems with an eventual breakdown of the monetary transmission mechanism. The notion that the policy-controlled short-term interest rate is the sole tool of monetary policy has therefore been questioned.

We provide evidence that the period between 1999 and 2007 was very successful for the euro area macroeconomy. Inflation was stabilised around values that had not been experienced on a sustained basis even in those member states which had been most successful in preserving the value of their currencies in the course of the previous decades. We show that inflation control was not purchased at the price of higher volatility in real activity or reduced growth prospects. In fact, real per capita income growth in the euro area matched the performance of other prominent industrialised economies which are viewed as the most dynamic from a global perspective.

But macroeconomic stability in the year leading up to the Lehman crisis masked growing underlying imbalances in the financial sector. During the decade prior to the financial crisis, low and stable inflation and low volatility in economic activity co-existed with highly procyclical asset price movements and pronounced cycles in money and credit creation. Low real and nominal volatility and falling external finance premia in those years led to a secular rise in private debt, which itself contributed to the sharpness of the correction in the most recent recession.

The boom-bust cycle that resulted from this association between the macroeconomic and the financial side of the economy has challenged the prescription - which is central to the most extreme characterisation of the Jackson Hole consensus - that central banks should only react to asset prices and financial imbalances to the extent that they affect the short-term inflation forecast. Using the fully-specified structural model of Christiano, Motto and Rostagno (2010), we investigate this proposition. We first show that both supply side and financial shocks have been important drivers of business cycle and asset price fluctuations in the euro area. The former produced a de-synchronisation of inflation and real activity, which complicated the appropriate setting of monetary policy; the latter influenced asset price formation in directions that are atypical and seriously interfered with the transmission of monetary policy. On the basis of this analysis, we then demonstrate that against those underlying conditions - an excessive focus on short-term inflation developments can exacerbate the boom-bust behaviour and destabilise the economy.

Using counterfactual policy simulations, we argue that a forward-looking, pre-emptive strategy needs to be balanced by safeguards which insure central bankers against policy myopia. In our policy simulations, reaction to credit developments can represent such a safeguard. The monetary pillar of the ECB's monetary policy strategy alerts policy to rising imbalances in the monetary sector. Monetary imbalances are well-correlated with financial imbalances. In turn, financial imbalances are typically a distinct feature of the macro-economy at those critical time junctures, when the central bank is called upon to draw its balancing line between short-term risks and its long-term stability objective. In the formulation of those difficult balancing acts, monetary analysis can promote a longer-term perspective which can help overcome policy myopia.

In the last section of the paper, we analyse the financial crisis and the ECB's response to it. The measures collectively referred to as the "Enhanced Credit Support" were activated to overcome those financial market impairments which were restraining credit creation and the transmission of the policy easing being pursued through interest rate reductions to the broader economy. We put these measures in the context of the 
academic literature and conduct a preliminary assessment of their effectiveness. We find that the ECB intervention was important to avoid disorderly de-leveraging in the banking sector and instrumental in sustaining credit creation and averting downside risks to price stability. Our results are also consistent with the hypothesis that the non-standard measures introduced by the ECB - which, notably, do not include entering commitments regarding the future path of the policy rate - contributed to providing support to the euro area economy. An important lesson from the financial crisis experience is therefore that by taking on a financial intermediation role in markets that are impaired, central banks can complement their more traditional interest rate policy and ensure its proper transmission. These non-standard policies are different from policies of quantitative easing which typically aim at substituting for the traditional interest rate policy in an environment where the latter is constrained by the lower bound. 


\section{Introduction}

The outbreak of the financial turmoil in 2007 and the subsequent financial crisis and collapse in trade and economic activity in 2008 following the default of Lehman Brothers have led to a rethinking of monetary policy frameworks. Recent contributions to this debate are Bean et al (2010) and Mishkin (2010).

In this paper, we focus mainly on two aspects of this debate with reference to the euro area and US experience over the last fifteen years. First, the financial boom and bust episode of the new millennium has questioned the appropriateness of what is sometimes called the "Jackson Hole consensus". According to this consensus central banks should only respond to asset prices and financial imbalances to the extent that they affect the inflation forecast. ${ }^{2}$ Other observers, amongst whom White (2006) and Rajan (2005), had warned that price stability may not be sufficient for financial stability and suggested that central banks should lean against the emergence of financial imbalances by tightening the monetary policy stance.

The European Central Bank (ECB)'s monetary policy strategy with its medium-term orientation and emphasis on monetary and credit analysis explicitly allows for looking beyond the short-term price developments and taking into account the medium-term implications of booming asset prices and credit markets for price stability. ${ }^{3}$ As argued by Trichet (2009), excessive money and credit growth in 2004 and 2005 was an important factor in not reducing the main refinancing rate below 2 percent in 2004 and underpinned the need to start a normalisation process from low interest rates in 2005. In Section 3 of this paper, we examine some of the sources of the boom and bust episodes in the euro area and argue that in line with the ECB's monetary policy strategy responding to money and credit developments helps stabilising both inflation and output. We, therefore, argue that an enhanced role of money and credit in monetary policy strategies is one of the important lessons from the crisis. ${ }^{4}$

Second, the great recession has led to an unprecedented use of non-standard monetary policy tools for two reasons. First, central banks had to intervene in financial markets to avoid that liquidity problems turned into solvency problems with an eventual breakdown of the monetary transmission mechanism. Malfunctioning interbank and other financial markets called upon central banks to take on a more active financial intermediation role. They also highlighted the fact that there was no longer a single market rate due to the collapse of normal arbitrage activities. Second, because monetary policy had to be eased beyond what is possible by reducing short-term interest rates close to their lower bound at zero, a number of central banks had to pursue alternative policies of quantitative and credit easing. The notion that the policy-controlled shortterm interest rate is the sole tool of monetary policy has therefore been questioned.

The ECB's broad and flexible operational framework with a large number of counterparties and a broad set of collateral allowed for a quick and pervasive expansion of its intermediation role in the interbank market, which was first demonstrated when tensions arose on 9 August 2007..$^{5}$ In Section 4, we discuss and evaluate some of the non-standard policy measures the ECB has taken to address the malfunctioning in financial markets. We discuss these measures in the context of the academic literature and conduct a preliminary assessment of their effectiveness. We find that the ECB intervention was important to avoid disorderly de-leveraging in the banking sector and instrumental in sustaining credit creation and averting downside risks to price stability. Our results

2 See, for example, Bernanke and Gertler (1995) and the response by Cecchetti et al (2000).

3 See, for example, Trichet (2004) and Issing (2002).

4 Another important lesson of the crisis that we do not examine is the need for a new macroprudential policy framework.

5 See Cassola, Durré and Holthausen (2010) for a thorough review. 
are also consistent with the hypothesis that the non-standard measures introduced by the ECB - which, notably, do not include entering commitments regarding the future path of policy - contributed to providing support to the euro area economy.

Before addressing those two issues in the rest of this paper, we first review in Section 2 the euro area experience of the last fifteen years in terms of nominal, real and financial stability. This provides the background and illustrates the 'facts' we try to explain in the paper. For comparison, we contrast the euro area evidence with that in the United States. We show that during the decade prior to the financial crisis low and stable inflation and low volatility in economic activity have co-existed with highly procyclical asset prices. In the late 1990s this took mostly the form of rising stock prices, buoyant investment and rising credit, whereas in the middle of the last decade rising house prices and mortgage debt with falling external finance premia were the main features. The secular rise in private debt associated with the low real and nominal volatility and the falling external finance premia contributed to the sharpness of the correction in the most recent recession. An important feature of the euro area experience is that medium and long-term inflation expectations have been strongly anchored throughout the last fifteen years including the period of the financial crisis. This has contributed to limit the consequences of adverse shocks.

\section{A tale of the last 15 years}

In this section, we briefly review the developments in inflation, economic activity and financial markets over the past fifteen years in the euro area and the US. In Section $2 . I$ we first document how, following a period of great moderation, the financial crisis has affected the level and the volatility of inflation and economic activity. The next subsection (2.2.) then describes the underlying behaviour of financial markets. ${ }^{6}$

\section{I The great moderation and the financial crisis}

The Treaty creating the monetary union establishes price stability as the primary objective of monetary policy in the euro area. To provide a clear yardstick against which the public can hold the European Central Bank (ECB) accountable and with a view to anchoring medium- to long-term inflation expectations, the Governing Council of the ECB adopted a quantitative definition of price stability in 1998. This definition reads: 'Price stability shall be defined as a year-on-year increase in the Harmonised Index of Consumer Prices (HICP) for the euro area of below $2 \%$. Price stability is to be maintained over the medium term.' Following a thorough evaluation of the monetary policy strategy in 2003, the Governing Council clarified that it aims to keep HICP inflation 'below, but close to, $2 \%$.'

Figure 2.I plots HICP inflation over the past 15 years, as well as various survey- and market-based measures of medium-term inflation expectations. The average annual inflation rate in the euro area between January 1999 and September 2010 has been $1.97 \%$, about $0.65 \%$ lower than average inflation in the same 16 countries of the current euro area in the pre-EMU decade. More importantly, medium-term inflation expectations as measured by Consensus Economics or the ECB's Survey of Professional Forecasters have consistently been very close to 1.9\%. Moreover, as shown in Smets (2010) and Orphanides (2010), differences across forecasters as, for example, captured by the standard deviation, have systematically narrowed since the start of EMU up until the outbreak of the crisis.

6 The review in Section 2 is very selective. One of the important developments over this period that we do not focus on is the process of real and financial globalisation.

7 One of the reasons for keeping inflation close to 2 percent was to allow for a buffer in the presence of the lower bound on nominal interest rates. See Section 3 for a detailed analysis of the ECB's monetary policy strategy. 
This stability of inflation expectations can also be observed in other major economies. For example, Figure 2.2 compares the 5-year ahead spot and 5-year forward, 5-year ahead break-even inflation rates (BEIRs), as measured by the difference between nominal and indexed bond yields for the euro area and the United States. The euro area in this respect compares well with the experience in the United States. ${ }^{8}$

With the exception of the most recent period in which inflation briefly reached 4 percent in 2008 and subsequent negative rates in 2009 due to highly volatile energy and commodity prices, annual inflation has fluctuated around 2 percent in a relatively narrow band. Figure 2.3 shows that the volatility of headline inflation in the EMU period has fallen significantly compared to the pre-EMU period. This occurred because of a strong stabilisation of core inflation ${ }^{9}$ and in spite of the surge in energy inflation volatility. An additional factor contributing to low inflation volatility is the negative correlation between core and energy inflation observed in the euro area. This negative correlation absorbed some of the increased volatility of energy inflation and is a special feature of the euro area data in the post-EMU period. The ECB's clear focus on headline inflation may have contributed to the negative correlation as potential cost-push factors are offset through anchored inflation expectations.

Figure 2.4 shows the evolution of the variance of headline inflation over time in 36-month moving windows and its decomposition. It reveals the sharply increased volatility of inflation rates during the most recent crisis episode. This is, however, mainly due to the sharp rise in the volatility in energy and food price inflation.

The stabilisation of headline inflation at low levels in the euro area has not been at the expense of a reduced growth performance. ${ }^{10}$ As shown in Figure 2.5, the average annual growth in real per capita incomes in the EMU period was I.I percent, compared with 1.2 percent for the United States. Output per capita for the euro area and the US is about II\% higher than in the first quarter of 1999, although the growth dynamics between the two regions differed over time. The US took a stronger hit after the burst of the dot-com bubble, but performed especially well in 2004-2005 when the euro area suffered from subdued growth performance. This strong growth performance compared to the euro area was mainly due to large differences in TFP developments in the years 2002 to 2004 as documented in Figure 2.6. Section 3 further elaborates on the consequences of supply shocks for the economy and particularly for inflation and monetary policy. Remarkably, both regions went through a similar contraction of about $5 \%$ on an annual basis during the acute period of the financial crisis, demonstrating in an impressive way its global implications, which is evidenced in the trade collapse towards the end of 2008 and beginning of 2009.

Figure 2.7, adapted from Benati and Goodhart (2010), shows how the financial crisis has put a (temporary) end to the long period of low nominal and real economic volatility in industrial countries. The period before the financial crisis, known as the great moderation, was the result of a number of factors that can be combined into three groups: a) structural change, e.g. better inventory management (McConnel and Perez-Quiros, 2000) or financial innovation and better risk sharing (Blanchard and Simon, 200I), b) improved macro-economic policies, such as the establishment of stability-oriented monetary policies, and c) good luck, i.e. the absence of large

8 The stability of inflation expectations has also been documented using more rigorous econometric techniques in Beechey et al (2010) and Ehrmann et al (2009). Galati et al (2010) investigates whether the financial crisis has affected the stability of inflation expectations.

9 Core inflation is defined here for comparability reasons as headline inflation excluding processed and unprocessed food and energy prices.

10 The EU treaty on monetary union indicates price stability as primary objective, but in addition states that '[w]ithout prejudice to the objective of price stability, it shall support the general economic policies in the Community' [Lisbon Treaty 127(I)]. These general economic policies have as its task 'to promote throughout the community a harmonious development of economic activities, a continuous and balanced expansion, an increase in stability, an accelerated raising of the standard of living [...]' [Article II9(I)]. The ECB is able to contribute to these objectives through its pursuit of price stability. 
shocks such as the oil price crises of 1974 and 1979." The relative importance of these factors has been hotly debated, but all three factors are likely to have contributed to a reduction of volatility. ${ }^{12}$

A number of additional observations are worth making. First, there is no apparent clear trade-off between output and inflation volatility in the cross-section of industrial countries shown in Figure 2.7. This may be partly due to the fact that the shocks have been different across countries. Nevertheless, both output and inflation volatility have been relatively small in the euro area compared to other countries. However, to the extent that the stability-oriented monetary policy of the ECB has been successful in anchoring inflation expectations and avoiding inflation or deflation scares, it may also have supported an inward shift of the output/inflation volatility trade-off. Smets (2010) illustrates this mechanism by performing a counterfactual simulation of the recent recession using the ECB's New Area Wide Model. This simulation shows that a higher sensitivity of long-term inflation expectations to actual headline inflation would have deepened the most recent recession significantly and led to a longer period of deflation, in particular in the light of the lower bound on interest rates. Notwithstanding the differences in policy objectives and the role played by inflation expectations and differences in labour market institutions the trade-off between inflation and the unemployment gap, the socalled Phillips curve, appears to be very similar over the past 15 years in the euro area and the United States (see Figure 2.8). It appears that different features of labour market institutions and price-setting compensate each other to deliver a similar sacrifice ratio. However, the range of inflation and unemployment gap outcomes is smaller in the euro area than in the US. The figure also reflects the fact that the flattening of the Phillips curve may have been a temporary phenomenon of the last years of the great moderation.

Second, there has been a uniform outward shift in the volatility of output and inflation following the financial crisis. In the euro area this shift in inflation volatility has generally been lower than that of output compared to other countries. A closer look at the dynamic evolution of inflation and output growth volatility is presented in Figure 2.9 by employing a 5 -year window for computing volatilities from 1995 until the present. The chart indicates that the turn of the century led in the euro area and the US to an increase in output growth volatility, associated with the burst of the dot-com bubble in 200 I, but inflation volatility remained constant. If anything, inflation volatility slightly declined for the euro area, whereas it increased somewhat for the United States. The 1999-2003 window marks the first period entirely under the auspices of the ECB. Thereafter and up until 2007 inflation volatility and output growth volatility declined. The traditional stabilisation trade-off became a "tradein" for the euro area. In the United States output volatility was reduced as well, but inflation volatility remained at its previous levels. Most recently, with the inception of the strong rise in energy prices in 2007 and 2008, volatilities in both areas increased, first for inflation, and later for output growth with the financial crisis.

In conclusion, while the volatility of headline inflation and economic activity has increased quite dramatically over the past three years, average headline inflation and medium-term inflation expectations have remained closely anchored to the ECB's definition of price stability. This in turn has contributed to stabilising both nominal and real volatility. The low macro-economic volatility during most of the early part of the new millennium may have contributed to a reduction in the perception of risk and an increase of leverage and debt, which subsequently exacerbated the depth of the financial crisis. In the next section, we turn to some of the developments in financial markets.

\subsection{Booms and busts in asset and credit markets}

The previous section described how the last fifteen years has been characterised by price stability. Over the same period, signs of instability existed within the financial sector which eventually led to the most recent

II See Bernanke (2004) for an overview of the factors behind the great moderation from a policy perspective. The break in volatility in real GDP was first documented by McConnell and Perez-Quiros (2000).

12 See, for example, Stock and Watson (2004). 
crisis. Figure 2.10 shows the development of aggregate asset prices normalised to nominal GDP in the euro area and the US since 1995. ${ }^{13}$ This measure of aggregate asset prices includes stock market prices as well as residential and commercial property prices weighted by their relative sectoral size. ${ }^{14}$ It vividly captures the two boom-bust episodes in this period. The developments of aggregate asset prices in the US and the euro area are amazingly synchronised, with the euro area exhibiting slightly lower amplitude due to the relatively lower share of stock prices in the index.

The two boom and bust phases that the US and the euro area experienced over the past fifteen years have clearly been different in nature with different implications for the rest of the economy. Figure 2.1I directly compares the two phases through the lens of corporate bond spreads, separated into financial and non-financial corporations. These spreads indicate the special nature of the recent crisis in comparison to the burst of the dot-com bubble in 200I. Spreads between BBB rated securities of non-financial corporations and AAA government bonds in the euro area increased persistently to above 200bps during the burst of the dot-com bubble, whereas financial securities remained well contained. ${ }^{15}$ During the financial crisis, instead, BBB rated financial spreads have reached up to 2700 basis points over AAA rated government bond yields, whereas nonfinancial spreads have a pattern reflecting a deeper than usual recession.

There are however many similarities between the two boom periods. As shown in Figure 2.12 for the euro area, in both boom periods the rise in stock prices was associated with increasing shares of credit and investment in GDP in the corporate sector and supported by a fall in the external finance premium. The reverse pattern is visible when stock prices fall, illustrating the pro-cyclicality of the financial system. The latter effect is in line with models where collateral valuations are relevant for credit supply such as in the financial accelerator models of Bernanke, Gertler, Gilchrist (1999) or Christiano, Motto, Rostagno (2010). Higher stock prices increase the net worth of borrowers and thereby relax the external finance constraint.

Another complementary interpretation is that higher stock prices and a booming economy increase the risktaking capacity of the financial sector and thereby lead to lower risk premia, in turn reinforcing the economic boom. This process then goes in reverse when first signs of a slowing economy become apparent. Recent research has emphasised the importance of such a risk-taking channel as a driver of the business cycle. For example, Adrian and Shin (2010) argue that value-at-risk ( $\mathrm{VaR})$ constraints on the banking sector will lead to a procyclical pricing of risk. Recent evidence on the impact of the monetary policy stance on the price of risk and credit standards in a number of financial markets provides support for such an interpretation. ${ }^{16}$

Figure 2.13 plots M3 corrected for portfolio shifts and the external finance premium. The chart further confirms the negative correlation between the external finance premium and monetary indicators. As discussed in Section 3, the monetary analysis of the ECB can be used to identify signals of the monetary-financial side that affect the economy. ${ }^{17}$ At the same time, it has to be acknowledged that monetary policy is not the most efficient instrument to deal with such financial imbalances.

Another feature of Figure 2.13 worth mentioning is the secular decline in the external finance premium from 1995 till 2007 and the sharp rise thereafter. The decline in the external finance premium up until 2007 also

13 The source of these aggregate asset price developments is BIS (2010).

14 For the link between asset price booms and money and credit growth, see Borio and Lowe (2002) and Detken and Smets (2004).

15 Two short-lasting spikes can nevertheless be identified, which led the spreads to rise by more than 200bps above the AAA government bond yields.

16 See, for example, Jiménez et al (2009), Bekaert, Hoerova and Lo Duca (20l0), Maddaloni et al (2010), Gambacorta and Marquez (2010).

17 See Detken, Gerdesmeier and Roffia (2010) for an overview of methodological improvements in assessing asset price bubbles through monetary analysis. 
compares well with the widespread finding that the equity premium has fallen over the same period, as surveyed in the meta-analyis by van Ewijk, de Groot and Santing (2010). This coincides with a secular decline in long-term interest rates, which may partly be the result of the global savings glut which started with the Asian financial crisis in 1997. A complementary explanation of the fall in risk premia is the greater macro-economic stability during that period. To the degree that greater stability has been achieved through better institutional setups and policies, it may provide sound reason for the fall in risk premia. But to the degree that smaller shocks are behind this stability, it may have led to mis-pricing and overly positive asset valuations. ${ }^{18}$

The fall in risk premia, long-term interest rates and macro-economic uncertainty may also have played a role in the rise in leverage across sectors in the euro area and the US, also over longer periods. Figure 2.14 shows the evolution of private and government debt in the euro area since 1999 and the US since 1950. Three observations are worth making. First, according to the national financial accounts overall private and government debt in both the euro area and the United States exceeded 300 percent of GDP ahead of the financial crisis. Second, in the euro area, the share of government and corporate debt is relatively larger than in the US, but the rapid growth of debt in the first half of the 2000's in the US was mainly due to the increase in household debt. Over the short and long run it was net financial debt (excluding equity) that grew fastest, with strong increases since the mid 1980's. Finally, the most recent rise in overall debt since 2008 is mainly due to an increase in government debt in response to the deep recession, while the private sector is deleveraging particularly in the United States. As noted by Reinhart and Rogoff (2008), the increase in sovereign debt levels is typical following a financial crisis and is not primarily caused by the implicit or explicit bail-out costs, including guarantees to the private sector, but instead it is the consequence of a period of increased use of automatic stabilisers and government spending to offset the recession.

Overall, the period since 1995 has been characterised by booms and busts in asset prices and the build-up of financial imbalances against the background of stable prices and economic activity. The current financial crisis since August 2007 was triggered by a European bank declaring it could not value the underlying assets in three of its funds that were invested in U.S. sub-prime mortgages. Its ultimate source derived, however, from the excessive build-up of debt and leverage in the great moderation period.

\section{The economy and the strategy}

Macroeconomically speaking, and despite growing financial imbalances, the period between 1999 and 2007 was successful for the euro area. Defying the odds, monetary union built a solid constituency for low inflation in Europe. The ECB acceded to the people's demand for economic security by delivering stable prices, in a context of steady income progression and moderate real fluctuations. The financial crisis that started in 2007 and deflagrated in 2008 sharply changed that economic landscape. This is where Section 2 leaves us.

In the jargon of Great Moderation analysts, the first 9 years of monetary union pose an identification issue. What provided the underpinnings for good macroeconomic performance? Is it just that the euro area - not unlike other advanced economies globally - benefited from a very benign constellation of economic shocks and structural economic conditions that promoted economic welfare and thus facilitated the conduct of policy? In other words: "Did the economy cooperate?" Or, did monetary policy have a more active role in steering the economy along a steady path, which would not have been steady otherwise? In other words, "Did the Monetary Policy Strategy Lead the Economy?" If it did, what core principles of the strategy were the main ingredients of success? And what would have happened if those principles had not been adhered to? In this Section we seek an answer to these questions.

18 See in this respect also Trichet (2008). 


\section{I Questions and methodology}

Our first question, "Did the economy cooperate?", requires structural inference. We generate structural inference using historical shock decomposition analysis. Shock decomposition is a natural by-product which one obtains when estimating a dynamic stochastic general equilibrium macroeconomic model of the sort proposed by Smets and Wouters $(2003,2007)$. Shock decomposition analysis serves two purposes, both of which are instrumental in answering our first question.

- First, it helps to dissect the underlying state that faced monetary policymakers at each point in time. We are particularly interested in the sources of fluctuations: whether the driving forces that moved the state of the economy originated predominantly in demand or supply. ${ }^{19}$ As we shall argue below, the composition of fluctuations is as critical to the success of policy as their frequency and amplitude.

- Second, given the underlying state, we want to be able to measure the difficulty for the central bank to control the state. In other words, we look for ways to assess the viability and efficiency of the transmission mechanism at each point in time over the recent past. One might legitimately wonder how a central bank can pursue price stability in a seriously unstable financial environment. So, in order to answer our questions, it is important to identify financial shocks and their impact on those asset returns that are most critical in determining the cost of borrowing in the broad economy.

Given the booms and busts phases which characterised asset and credit markets over the period since monetary union we need a DSGE model that combines the real, nominal and monetary policy variables that are conventional in New Keynesian analysis with variables that pertain to the markets for liquidity, credit and equity. This requirement determines the choice of our tool. Specifically, we use a version of the model described in Christiano, Motto and Rostagno (CMR, 2003, 2010), a DSGE model of the monetary business cycle with a banking and a financial sector. The very broad contours of the model and the methodology that we utilise to extract structural inference from it are described in the Annex.

For answering our second question - "Did the strategy lead the economy?" - shock decomposition alone is not rich enough. The strategy has to do with the systematic pattern of monetary policy conduct. In the jargon of modern quantitative macroeconomics, a strategy is identified by the 'policy rule'. Analysts know that if the systematic behaviour - the coefficients and the reaction variables - of the central bank had been different, history would have looked different. So, we try to answer our second question by conducting policy counterfactuals. These are exercises that presuppose and are predicated on the findings of our shock analysis. We start from that analysis. We hold fixed the history of the economic non-policy shocks that the CMR model identifies over our sample period. And we re-simulate the model using a different 'policy rule'.

But which 'policy rule' is our baseline? And in which directions do we twist its specification in counterfactuals in order to test the performance of the strategy? Arguably, there is a big hiatus between our ambition to assess selective elements of the ECB's monetary policy strategy, and the limitations of the tool at our disposal. The gap is measurable by considering the list below, which enumerates the main elements of the ECB's monetary policy strategy.

- First, the Treaty that has laid the institutional foundations of economic and monetary union has instructed the ECB - and the whole European System of Central Banks - to pursue price stability as its overriding objective, to which any other policy consideration is to be subordinated. The ranking of priorities is clearly lexicographic.

19 Financial shocks and shocks associated with banks' liquidity funding could be assigned to demand, but in the analysis that follows we single them out as a stand-alone category. The reason for this is explained in the second bullet point which follows. 
- Second, as mentioned in Section 2, the Governing Council of the ECB has quantified its overriding objective with a range of values for inflation - positive inflation rates of below $2 \%$ - which, if realised over the horizon that is relevant for policy (see below), would be consistent with the attainment of price stability. Here, it is critical to note that a quantitative definition of price stability is not a point target for inflation.

- Third, the Governing Council has enunciated that, in pursuing its objective, it will aim at maintaining inflation around values not too far below $2 \%$ in the medium term. The notion of the medium term horizon is critical. It is not pre-set or quantified, but it is meant to depend on the nature and source of the shocks that hit the economy from time to time. Even more importantly, it is associated with a steady handed response to the evolution of the economic state - realised or expected - and a rejection of day-to-day fine tuning. ${ }^{20}$

- Fourth, in assessing the risks to price stability, the Governing Council gives great prominence to monetary factors, which - if left unattended - can pose threats to price stability over longer horizons. Analysis of monetary trends and imbalances - for example, money and credit growing consistently out of line with sustainable trajectories - is a cornerstone of the strategy. It provides a perspective from which the Governing Council cross-checks the robustness of the policy implications that emanate from standard conjunctural analysis and macroeconomic projections. It is an insurance against policy myopia.

The distance between these strategic principles and the measurement tool at our disposal is evident. Price stability is a pre-ordered policy priority in the ECB's statutes, but it is only a weighted objective among others in the policy rule that we estimate and simulate. Put differently, our rule is non-lexicographic. A price-stability quantification is not an inflation point target. Yet, specifying a policy rule requires postulating a reaction to inflation in deviation from a single numerical value. The medium term horizon is not a fixed time window in the ECB's strategy, but it necessarily has a mechanical element in the policy feed-back in our simulations. Finally, a two-pillar strategy where the Governing Council systematically cross-checks inferences and policy implications across different ways to describe the monetary transmission mechanism is, by construction, impossible to render if one - like us - is to use a single model.

These are the terms of our heuristic compromise. Our analysis in this Section will fall short of the task also on another dimension: it will be selective. We will mainly concentrate on two elements of the strategy: the medium term orientation and the role of monetary analysis. We justify this choice by two observations. For sure, both the medium-term orientated, steady-hand approach and the prominent role of monetary analysis are critical to the entire structure of the strategy. In fact, we will try to demonstrate that they have inspired a policy attitude which could have been instrumental in avoiding major policy mistakes over the recent past. Those mistakes, if incurred, would have worsened the starting conditions in which the ECB would have found itself when the crisis hit its climax in the autumn of 2008. Second, both strategic elements have been contentious, although to a degree that has varied in intensity over time.

\subsection{First answer: The economy did not cooperate}

We devote this sub-section to shock analysis. But we soon encounter a technical complication. The model cannot deliver a shock decomposition of the variables included in the estimation unless it is run under a feedback relationship that connects the short-term interest rate to the economic state. This feed-back depends critically on the 'policy rule' governing monetary policy - the strategy - and the way monetary policy is

20 For a different view on the role that fine-tuning should receive in the monetary policy strategy, see Blinder and Reis (2005) who suggested that the Fed under Chairman Greenspan brought "a new life" into the idea that the central bank should pursue fine tuning. 
implemented. While the former has not changed since monetary union, the latter has changed in important directions over the last two years, because of the crisis.

We devote Section 4 to the ECB's non-standard measures. Here, however, we need to anticipate one element of the emergency package that was adopted in October 2008, because this element has implications for the functioning of the money market. This is the decision to move from variable rate tender procedures in liquidity providing operations to so-called fixed-rate-full-allotment tenders. Technically, it meant that, in its regular executions of liquidity operations, the ECB was ready to accommodate any demand for liquidity its bank counterparties might express at the policy rate - against eligible collateral - in unlimited amounts. As we document in Section 4, this was a relevant shift. In conjunction with the ample - and expanded - array of maturities at which liquidity was being offered to the market, the measure generated a steady excess of liquidity balances in the overnight market, as banks began supplying in the interbank market the precautionary cash buffers that they were securing at the ECB weekly and longer-term liquidity operations. An excess supply of liquidity in overnight trades put downward pressure on the overnight interest rate, which drifted toward the lower limit of the monetary policy corridor. ${ }^{21}$ Viewed from our modelling perspective, excess liquidity changes the feed-back relationship that in our exercises links the overnight money market interest rate and the economic state.

We tackle this break by a two stage procedure. In a first stage, we estimate the CMR model over the pre-crisis sample period which stops in 2008Q3. For this estimation, we use the following specification of the money market feed-back relationship:

$$
R_{t}=\left(\rho R_{t-1}+(1-\rho)\left[\alpha\left(E_{t} \pi_{t+1}-\pi^{*}\right)+\beta \Delta y_{t}+\gamma \Delta M_{t}\right]+\varepsilon_{t}\right)+\theta \xi_{t}
$$

In (I) the very short-term money market interest rate on the left side, which we identify with the euro overnight index average (EONIA), is determined by two components. The first component corresponds to the first term in round brackets on the right-side of $(\mathrm{I})$ and reflects policy intentions: the 'policy rule' proper. Conventionally, this includes the lagged interest rate, the expected gap between GDP inflation and a numerical value consistent with price stability, GDP growth in deviation from its trend, and a white noise policy error, $\varepsilon_{\mathrm{r}}$. Unconventionally, and in order to capture monetary analysis considerations, we add an extra regressor to this term: excess growth of a monetary indicator, $\Delta \mathrm{M}_{\mathrm{t}{ }^{22}}$ The second component of $(\mathrm{I})$ is the last term on the righthand side, $\theta \xi_{\mathrm{t}}$. This includes a latent shock, $\xi_{\mathrm{t}}$, which in the model calibrates banks' demand for central bank credit. $^{23}$ In estimation, this shock is identified with the total outstanding stock of Eurosystem refinancing operations, which is included in the set of observables. The coefficient, $\theta$, attached to the shock thus measures the sensitivity of the overnight interbank rate on the left of the equal sign in (I) to money market liquidity conditions. Indeed, we find that this estimated elasticity is positive, large and highly significant in the pre-crisis period. This provides evidence that, under the variable rate tender regime that was in place before October 2008, shifts in the demand for liquidity in the money market were statistically significant - though

21 As explained in Section 4, the Eurosystem's channel framework of monetary policy implementation consists of a symmetric corridor bracketing the interest rate at which liquidity is supplied in the regular weekly monetary policy operations, the main refinancing rate. The lower bound of the corridor is determined by the rate at which counterparties can deposit cash overnight with the Eurosystem (the rate on the deposit facility). The upper bound is the marginal lending rate, at which counterparties can borrow funds overnight from the Eurosystem.

22 Later on in this Section we shall discuss the reasons behind our choice of credit - rather than headline money - as a proxy for the monetary variable to be included in (I).

23 The Annex gives an intuition for this and other latent shocks. 
observationally unimportant because of offsetting policy adjustments - explanatory factors for the observed behaviour of the overnight rate. ${ }^{24}$

In a second stage, we fix all structural non-policy parameters at the values of their posterior modes as estimated in the first stage, and we re-estimate $(\mathrm{I})$ - and only $(\mathrm{I})$ - over the crisis data sample comprising the quarters 2008Q4 through 2010Q2. Interestingly, we find that $\theta$ switches signs - an excess demand for liquidity now being associated with a decline in the money market rate - drops in value toward zero, and becomes insignificant. So, we set $\theta$ equal to zero in all exercises done using post-crisis data. ${ }^{25}$

\subsection{Supply side headwinds}

We place the underlying fundamental shocks as backed out by our model in three categories: demand, supply and monetary-financial factors. The first group includes shocks that move output and inflation in the same direction. We include here a shock to households' intertemporal preferences for consumption and a shock to the government's and the foreign sector's absorption. ${ }^{26}$ Supply shocks move output and inflation in opposite directions. In the CMR model, a temporary TFP shock hitting intermediate-goods production, an oil price shock and the shock to price mark-ups share this property. The last group comprises shocks to the funding conditions faced by financial intermediaries and - importantly - a shock that captures changes in the appreciation of market risk. ${ }^{27}$ This risk is identified primarily by stock market and credit market information, notably the credit risk premium and the growth rate of credit to the private sector. Due to its powerful propagation properties, the evolution of the risk shock causes shifts in the riskiness of the overall macroeconomic environment in the model, and it is interpretable as a systemic risk shock.

Charts 3.1 and 3.2 show historical decompositions for GDP growth and GDP-defined inflation, respectively, using the posterior modes of the distributions of the coefficient estimates. We display our three composite factors with bars of different colours: the algebraic sum of the bars assigned to each point in time corresponds to the observation on the solid line, which represents the value of the observable at the same point in time. The break in the continuity of the chart marks the switch in the estimation from the baseline money market interest rate feed-back rule to the new fixed-rate-full-allotment regime whereby liquidity demand shocks are offset by construction. We make three observations.

24 Note that the application in normal times of a 'separation principle' (see Section 4) whereby the monetary policy decisions over the appropriate stance are kept distinct from - and, as much as possible, unaffected by - the liquidity conditions prevailing in the money market is captured by the first component of (I). This term, and notably the monetary policy surprise, $\varepsilon_{t}$, is adjusted in such a way as to align the overnight rate with the central bank's policy intentions.

25 In fact, we make sure that the initial conditions for estimating the model over the restricted post-crisis period coincide with the state of the model at the end of the pre-crisis period. Note that in re-estimating (I) over the post-crisis period we assume that the monetary policy shock had a more complex representation than over the pre-crisis sample, involving some signalling shocks at a 4-quarter horizon.

26 Christiano et al (2010) is a closed-economy model. As GDP growth is matched precisely, the net foreign demand component of output has to be treated as an exogenous disturbance. Government consumption is also treated as an exogenous shock.

27 It is mainly the appreciation of market risk, rather than its realisation, that matters most in our analysis. This is because, as in Christiano et al (2010), shocks to the riskiness of the financial contract come both in the form of contemporaneous unexpected innovations to the risk process itself, and as innovations to the anticipations of the future evolution of the shock. The latter components of the shock process - which are referred to as 'signals' - account for a large portion of the contribution of this shock to the cycle. Among 'monetary and financial factors' we also include the contributions of the $\xi_{\mathrm{t}}$ and the $\varepsilon_{\mathrm{t}}$ shocks discussed above. 
- $\quad$ First, as a matter of regularity, shocks related to aggregate demand (the green bars) follow with a lag the turning points in growth, but rarely coincide with or lead a change in direction in the conjunctural state. This is certainly the case throughout monetary union - since $1999 .^{28}$

- Second, monetary and financial factors (the red bars) lead or coincide with the peaks and troughs in the chart for growth. Except over the dot.com recession and the recent crisis, they tend to dissipate quickly as a determinant of growth, while they introduce long-lasting trends in inflation.

- Third, supply shocks (the yellow bars) are usually timely indicators and certainly extraordinarily persistent pro-cyclical determinants of growth and inflation, at least since the start of monetary union.

Eye-balling the boom-bust episode of the early years of monetary union offers an instructive story. While financial markets were providing a robust spurt to growth during 1999 and much of 2000 - after the shortlived Asian-crisis-related deceleration of 1998 - a pro-cyclical adjustment in productivity and mark-ups intervened to amplify the cycle. This appears to have damped the influences that the cyclical exuberance would have had on inflation otherwise. The bust phase that ensued and lasted until 2005 is the mirror image of the same pattern. As Section 2 has demonstrated, pro-cyclical adjustments in productivity aggravated the slump and kept inflation from falling.

Note that a pro-cyclical supply side complicates the economic environment for monetary policy, ${ }^{29}$ It does so for two reasons:

- First, it de-synchronises inflation and the economy. Provided inflation expectations are well-anchored, pro-cyclical changes in inflation can work as an automatic stabilisers and ease the task of monetary policy management. In booms, higher-than-normal inflation reinforces the signals that are released by the economy and thus encourages the tighter stance that can counter over-heating in the markets and in the broad economy. A counter-cyclical monetary policy restriction in those conditions is wellunderstood and easy to communicate. In busts, a decline in actual inflation - relative to steady inflation expectations - can partly offset the cyclical fall in real incomes, and thus sustain demand at a critical juncture. Our analysis indicates that neither of these equilibrating mechanisms seems to be available in the euro area.

- Second, it makes the economic environment more difficult to interpret. A typical demand shock poses little puzzle to a stability-orientated central bank. A timely and determined response to such a shock both protects against the risk to price stability and minimises the economic volatility that the shock would introduce in the absence of policy action. A supply shock, instead, needs to be interpreted. It is not so much the supply shock per se which requires a monetary policy reaction, particularly if the shock is expected to be temporary and reverse itself before long. Rather, it is the implications that the shock is expected to have for inflation expectations and for the self-sustaining momentum that expectations - once unsettled - can add to the inflation process going forward. If inflation expectations are sufficiently impervious to a supply shock, then monetary policy can afford lengthening its policy horizon and look through the disturbance. Otherwise, it needs to intervene to stem the transmission of the shock via expectations. In a way, central banks need to be vigilant to the fact that a supply shock might morph into a demand shock, if and when it is allowed to influence inflation

28 Note, however, that virtually all shocks included in the "Monetary and Financial" group display typical demand-side propagation. Therefore, in order to assess the incidence of shocks which produce positive correlation between inflation and growth, one needs to look at the green and red bars combined.

29 From an optimal monetary policy perspective, the productivity shocks included in the yellow bar group do not present monetary policy with a trade-off. Strictly speaking, this is only true for mark-up shocks in the group. See Woodford (2003). Nevertheless, the whole yellow-bar category is responsible for a countercyclical pattern in inflation. It is the latter feature that poses a communication and a signal-extraction problem to monetary policymakers. And this is the aspect that we address in the text. 
expectations. It is this mutation that is most relevant for policy. But, of course, judging whether the mutation will happen or is likely to happen is fraught with hazards in real time.

This sub-section ends with this conclusion: the supply side did not cooperate, and in fact blew headwinds which monetary policy had to resist. This was most evident when the energy prices surged and labour productivity contracted in the midst of a sharp deceleration of output. But the statement applies to the case of a favourable technology shock as well, which is expansionary and disinflationary at the same time. Of course, as Blinder and Reis (2005) argue: "[A]n acceleration of productivity gives a central bank a pleasant choice: It can have some combination of lower inflation and lower unemployment than previously planned." But that apparent blessing can turn into a curse down the road, if - short-sightedly - it induces excessive policy forbearance. This is why the central bank needs insurance against myopia and short-termism, a theme to which we return in sub-section 3.3.

\subsubsection{Financial shocks and the transmission mechanism}

The efficacy of monetary policy notoriously depends on monetary policy deliberations setting in motion a long, but predictable, chain of adjustments in a whole spectrum of asset prices. Spending decisions and price setting behaviours stand at the end of this chain and are influenced by these adjustments. Policy itself is calibrated on reaction patterns and cross-elasticities between the policy instrument and key asset returns that have been observed in the past. But then, any shock or special factor which might disturb or distort those crosselasticities in directions that are atypical and difficult to quantify ex ante can seriously interfere with the policy process. Two examples come to mind. First, a monetary policy tightening cycle is less effective in restraining spending if it is offset by an autonomous decline in long-term interest rates or in corporate credit spreads. The latter provides the financial stimulus that the former is meant to withdraw. Second, a sharp widening of financial spreads in the early phase of a recession can make credit conditions tighter than a central bank would deem appropriate given the economic state and its likely evolution.

Section 2 and Charts 3.3 and 3.4 show that the euro area saw a bit of both examples during its brief life. While monetary policy was being restricted after 2005 to respond to a resurgence in inflation (see Figure 3.2) and an excess of exuberance in credit markets (see below), the same financial factors that were moving inflation and real activity were causing countervailing adjustments in asset prices. These uncontrolled adjustments worked against the inclinations of the Governing Council. Figure 3.3 shows the response of the spread between the long-term risk-free rate and the overnight rate. While a decline in the spread is typical in tightening phases - as the short-end of the term structure rises relative to the long-end, which remains well-anchored by the price stability objective of policy - the pace of the decline was atypical. Long-term rates were easing the terms of borrowing long-term at a time in which the price of borrowing short-term was being raised. Developments in private credit markets were adding further stimulus. Figure 3.4 shows that the credit risk premia which corporate borrowers were required to pay over and above the interest rate charged on risk-free loans fell steeply too. Market rates were falling rather than increasing in response to the monetary policy tightening. According to the Figure, the red bars caused the fall. Looking inside this group of shocks, one sees that the main explanatory force was a sharp revision in the appreciation of market and macroeconomic risk. ${ }^{30}$

The second, dramatic example of swings in financial prices interfering with monetary policy is more recent. In the immediate aftermath of the inter-bank money market turmoil of the summer 2007, the CMR model interprets the sharp contraction in MI (not shown) as indicative of severe impairments in bank intermediation. Starting in the second half of 2008 , and despite a recovery of MI, the euro area banks faced fresh difficulties in accessing the market for short-term securities - and M3-MI began contracting in the third quarter of the year.

30 See Christiano et al (2010) for a detailed econometric analysis of the financial forces behind the spread and the credit risk premium and a discussion of the dominant role of the risk shock. 
Coincidentally, and despite a series of aggressive reductions in the overnight rate, credit premia whipsawed sharply up and stayed at historically elevated levels for another two quarters. ${ }^{31}$

Clearly, in the first instance, loosening standards in the credit market made the effective stance more permissive than was intended by the ECB. ${ }^{32}$ In the latter instance, a poorly functioning financial system impinged on the cost and availability of credit to businesses and households and obstructed the transmission of monetary policy stimulus to the economy.

\subsection{Second answer: The strategy did steer the economy}

In this sub-section we stress-test the ECB's monetary policy strategy along two dimensions: its medium-term orientation and its emphasis on money. Although the two dimensions are strictly complementary, as the latter element reinforces the former, we treat them separately.

\subsection{Medium term orientation}

Observing monetary policies over the mild 200I-2003 slump, some commentators remarked about the ECB's more cautious approach to monetary policymaking, if compared with the more active management of the Federal Reserve. At the time, the ECB's approach was chastised as one that did "too little, too late." ${ }^{33}$ The ECB justified its paradigm on the notion that each central bank should design its policy conduct having in mind the structural and stochastic characteristics of its economy. And the structural economic landscape facing the ECB would be destabilised by a less predictable, more judgemental policy conduct. As ECB (2006) put it:

The appropriate degree of central bank "activism" depends on the adjustment to outside disturbances required by the central bank's objective. The associated monetary policy pattern hinges upon the structural characteristics of the economy and the sequence, nature and size of the shocks to which the central bank has to respond. The pattern of policy rates observable in the euro area in comparison with those of other central banks, rather than reflecting an inappropriate lack of commitment on the part of the ECB in the pursuit of its objective, has to be understood against a background of stable long-term inflation expectations, which in turn reflect and interact with the credibility of monetary policy, an unfavourable mix of shocks that have hit the euro area, notably disappointing supply-side developments, and the high degree of nominal rigidity displayed by the economy (page $8 \mathrm{I}$ ).

The notion that policy should be tailored to the deep structure of the economy is intuitive and has been well researched in recent years. For example, Altissimo, Ehrmann and Smets (2006) and Christiano et al (2007), ECB (2006) and Trichet (2007) all have drawn attention to the fact that comparatively high price and wage inertia combined with well-anchored inflation expectations in the euro area call for a steadier course of

31 The long-term spread, instead, was kept relatively compressed relative to the overnight interest rate by the ECB's decision to extend the tenors of its loans to banks. We shall return to this impact in Section 4.

32 Trichet (2008) elaborates on the puzzles that an uncooperative financial system - and notably an under-appreciation of financial risk - can pose to monetary policy.

33 See, for example, the article "Better Late than Never" published in The Economist on 5 June 2003. Later, as Chairman Greenspan defined the Fed's standard when confronted by tail events with potentially highly adverse consequences (Greenspan, 2004), the debate evolved into one balancing off the advantages and the risks of a 'steady hand versus risk management'. 
policy. ${ }^{34}$ We will not concentrate on this aspect here. Instead, we will focus on how the stochastic properties of the euro area may have a bearing on its monetary policy. This will lead us to draw broader conclusions on the desirability for a central bank to mechanically react to inflation forecasts - irrespective of the shocks - and to the forecast dispersion.

To this end, we artificially re-create the decision-making environment facing the ECB at some critical juncture in the past. We ideally endow the ECB decision-making body with an analytical instrument that is now standard in central banks for monetary policy evaluation exercises: stochastic simulations. And we ask the following two questions. First, what would have been the correct implications that policymakers could have extracted from stochastic simulations at the time concerning the risks to the macroeconomic outlook, given the nature and source of the shocks hitting the euro area economy on average? More importantly, would the ECB have done a better job of stabilising the economy if it had assigned deflation risks a more prominent role in its policy design $?^{35}$

The critical juncture at which we position ourselves to run the counterfactual is the first quarter of 1999. According to Figure 3.2, at the time the euro area was being hit by a string of supply-side shocks which were producing rapid disinflation. Figure 3.5 shows the predictive distribution of inflation that the policymakers would have found if they had run stochastic simulations on the basis of the CMR model estimated up until early 1999. The overall band covers 90 percent of all possible realisations, and the different colours mark the percentiles of the distribution in steps of 5 percentage points. We have accounted for the fact that particularly extreme inflation realisations would induce the central bank - following its estimated policy rule implicit in (I) to lower its policy rate aggressively, and that some of those policy paths would have violated the zero lower bound. So, we constrain the policy rate to never become negative in the projections. This visibly tilts the distribution asymmetrically to the downside. As is customary in this type of analysis, on the left side of the figure we show the distribution that modellers would have obtained drawing from all the shocks estimated in the model - including those hitting the supply side. The right-hand figure, instead, excludes supply-side shocks from the simulations.

We note two aspects of these pictures. First, the portion of the distribution in the left panel falling below zero is sizeable and the skewness to the downside increases the probabilities of more negative inflation rates. If the ECB had measured the macroeconomic risks surrounding the outlook by the negative-inflation portion of that distribution, it would have concluded that there was a 15 percent chance of deflation looking two years into the future. Second, the range of possible inflation realisations obtained by ignoring supply shocks would have looked more firmly centred around values consistent with the ECB's definition of price stability. ${ }^{3637}$

34 Quoting from ECB (2006): “[l]n an economy characterised by significant nominal frictions, inflation would tend to be less reactive to a shock as price-setters would be slower in bringing economic news to bear on their decision-making. Furthermore, high central bank credibility implies that price setters would anticipate that the central bank will ultimately drive inflation back to its pre-shock level. So, in spite of the presence of significant frictions, which would tend to slow down the process by which shocks drive inflation over time, inflation may tend overall to be less persistent and the shocks themselves may dissipate more quickly" (page 75).

35 In reproducing the policy environment facing the ECB at the time, we do not use real time data. However, data revisions have not changed that environment to a degree relevant for our conclusions.

36 Note that, by disregarding some sources of uncertainty, the predictive distribution mechanically becomes tighter. But the point we want to make is not related to the best forecast of inflation unconditionally, or the best way to describe the uncertainty surrounding the point forecast. We are interested in the monetary policy implications of a given expected path of inflation. And we claim that this requires to understand the underlying shocks driving a given inflation path. It should also be noted that the central bank can afford to discriminate across different sources of shocks to the extent that long-term inflation expectations are well anchored. Otherwise, as explained above, supply-side shocks may 'morph' into demand shocks. 
A 15 percent risk of deflation is non-negligible. ${ }^{38}$ What if the Governing Council had decided to take out insurance against that risk by reducing its policy rate more aggressively than it did in April of that year? ${ }^{39} \mathrm{We}$ simulate a policy action which reflects a conventional interpretation of a risk management strategy in the face of deflation risks:

- reduce the policy rate pre-emptively to forestall the risk;

- give forward guidance about the policy path in the near future so that the stimulative impact of the decision on expectations is amplified.

Note that the latter element of this alternative strategy, as reproduced artificially in our model, requires that the central bank release 'signals' about its future policy course. So, we implement the exercise by postulating that the surprise reduction in the policy rate to 2 percent in 1999Q2 comes together with a string of expectational shocks concerning the future value of the error terms $\varepsilon_{\mathrm{t}}$ in (I). These 'signals' induce all agents in the model economy to anticipate a 2 percent level for the overnight interest rate over a 1.5 year horizon. ${ }^{40} \mathrm{As}$ the future rolls on, the signals about future policy remain in place and expectations are systematically confirmed by the actual policy settings. The central bank in this counterfactual is therefore fully credible in its forward guidance. We show the results of the counterfactual exercise in Figure 3.6. The solid line represents history. The dotted line is the outcome of the alternative strategy.

Note two things. First, as the structural determinants of disinflation were a sequence of favourable supply shocks, both the financial markets (stock market panel) and the economy at large were on a rise, even under baseline policies. Second, introducing extra policy accommodation in those conditions would have provided a

37 There are two important caveats to this analysis. The first one is that the ECB's objective is defined in terms of a harmonised index of consumer prices (HICP), whereas the exercise that we conduct is based on simulating the GDPdefined inflation rate. The second caveat is that the distribution is re-centred on the realised path of inflation. This is motivated by the fact that central banks construct forecasts by and large following a judgemental process. Models intervene at a later stage in the process, to replicate the baseline forecasts and to create confidence bands around them. Furthermore, our focus is on risks rather than point forecasts.

38 A 15 per cent probability of negative inflation realisations can be judged catastrophic if it is weighted by a very large welfare loss in policymakers' reaction function. This is more likely to be the case if there is a sufficiently strong presumption that negative inflation would be fed into inflation expectations and thus would soon induce a self-fulfilling downward spiral of prices and the macroeconomy. By contrast, evidence that inflation expectations are well-anchored even in the face of negative inflation realisations - can inspire a less reactive stance.

39 Many central banks use this type of analysis to compute the probability of deflation and inform the policy process. At the Fed, for example, stochastic simulations of this sort conducted in the summer of 2003 triggered a policy debate over the precise interpretation to be given to the results. The FOMC Transcripts suggest that the prevailing view was that it was appropriate to look at the entire distribution (as in the left panel). Arguably, this interpretation contributed to substantiating the language adopted in official communications about the non-negligible probability of deflation. However, it was also argued that one should discriminate between shocks. The complete-shock distribution was suggesting a 28 percent probability of deflation looking forward, whereas the simulations done by removing the supply side shocks were consistent with a much smaller probability, in the order of 8 percent. Note that, at the time of the Fed debate, productivity was increasing at a very robust rate, which in one quarter reached almost $9 \%$ annualised. FOMC member Mr Parry remarked: 'This [referring to deflation generated by favourable productivity] may be more like a China version of deflation, where the deflation probably reflects what is happening to productivity'. The immediate reply by staff to this remark was given by Mr Stockton: 'That's right. Certainly, if we created 5,000 stochastic runs of the model to calculate the probabilities, within the 28 percent of cases with deflation there would be many instances in which the deflation was relatively benign. Those would be instances where the deflation was caused by faster productivity growth or beneficial shocks to wage and price setting, with what I would perceive to be less serious consequences for monetary policy.' (FOMC Transcript, 10 December 2002, p 23). 
further boost to asset prices and lending, which in turn would have introduced further inflation and output volatility. ${ }^{41}$

In retrospect, looking through the supply-side disturbances was a superior policy approach and helped stabilise the economy. The ECB (2004) rationalised this approach as follows:

[T] he optimal monetary policy response to ensure price stability always depends on the specific nature and size of the shocks affecting the economy. For a wide variety of shocks (e.g. demand shocks, that move output and prices in the same direction) a prompt reaction by monetary policy is often adequate and will not only preserve price stability but also help to stabilise the economy. However, there are other types of economic shock (e.g. of a cost-push nature, like oil price hikes) that move output and prices in opposite directions. An excessively aggressive policy response to restore price stability in a very short span of time may, in these circumstances, risk imparting a significant cost in terms of output and employment volatility which, over a longer horizon, could also affect price developments. In these cases, it is widely recognised that a gradual response of monetary policy is appropriate both to avoid unnecessarily high volatility in real activity and to maintain price stability over a longer horizon (page 54).

The results of our counterfactual tend to confirm this assessment. In the event, a forward-looking, pre-emptive strategy needs to be balanced by safeguards which insure policymakers against an excess of 'risk anxiety'. Good policy can only be the outcome of a difficult balancing act, by which a central bank weighs the need to be ahead of the events against the costs of policy myopia. Of course, time inconsistency will always tilt this act of good judgement toward short-termism in real time. ${ }^{42}$ This is why a robust strategy needs built-in commitment mechanisms which can enforce a steady hand when the time comes.

\subsubsection{Monetary analysis}

Monetary analysis can provide such a commitment. In this sub-section we explore one avenue through which it does so.

The controversy over the usefulness of monetary analysis has subsided somewhat more recently. Many academic critics who had long advised the ECB to de-emphasise the role of money in its strategy have qualified or recanted their earlier positions. At the same time, the related question whether a central bank should concentrate on targeting inflation or should also "lean against the wind" blown by rising monetary and financial imbalances has been put back on the agenda of discussions over the theory and practice of central banking. Inflation targeting was the almost-undisputed view of the majority of participants in that debate before the crisis. After the crisis, the median view arguably has shifted.

It is this latter aspect of monetary analysis that we want to address. ${ }^{43}$ As the ECB - like all other central banks - have presided over a period of heightened volatility in financial markets, it is interesting to ask whether the macroeconomic history would have looked materially different in the euro area, if the ECB had not relied on its monetary pillar. This requires a counterfactual. But, as we mentioned before, this counterfactual exercise is

41 Christiano, llut, Motto and Rostagno (20l0b) show how over-expansionary monetary policies in the face of (expected) productivity shocks can trigger unsustainable trends in asset prices.

42 Time consistency is, of course, not an element which interferes with policy design in our exercise. In our simulations policy is determined once and for all on the basis of a policy rule. However, note that - ex post - the model estimation needs to account for any deviations from a central bank systematic policy behaviour which might have occurred in history through a policy shock. These shocks might well capture a time-inconsistent preponderance of risk considerations in real time.

43 The fact that trends in money are highly coherent with trends in consumer prices provides the main foundation for the role of money in the strategy of the ECB. This role is sufficiently well-established in theory and econometrics (for example, see Lucas, 1995, and Benati, 2009). So, we concentrate on the leaning against the wind component of the monetary pillar. 
not an easy one, for essentially two reasons. First, using one single model, we obviously forfeit one critical side of the monetary pillar approach: that it can induce robust policy, namely a policy that has a better chance of delivering good results across different specifications of the inflation process. It is the cross-checking aspect of the two pillar strategy that we are sure to miss. Quoting from ECB (2003):

In order to assess the indications about the appropriate stance of monetary policy, the two-pillar approach provides a cross-check of the information that stems from the shorter-term economic analysis with that from the monetary analysis, which mainly provides information about the medium to long-term determinants of inflation (page 92).

Second, the policy rule should include the underlying money trend as an indicator of the underlying trend in prices. Indeed, it is this connection that lies at the centre of the ECB's mandate (see Stark, 20I0). ${ }^{44}$ Avoiding excess volatility in asset markets is a by-product of the strategic role of money, and is justified only to the extent that it can contribute to price stability over a medium to long term horizon. However, due to the technical complications implicit in estimating and simulating a policy reaction function which feeds back on the underlying trend - as opposed to headline growth rates - of money, in our quantitative exercises we need to use a proxy. Our proxy is the growth rate of bank credit to the non-financial sector in deviation from its longrun trend. This is the reaction variable $\Delta \mathrm{Mt}$ which we include in the money market interest rate feed-back equation (I).$^{45}$ Figure 3.7 below gives some grounds to believe that such a proxy might indeed be acceptable. It shows that the correlation - at least since monetary union - between credit and underlying money growth based on the CMR model (the red bars) is large. ${ }^{46}$

Subject to these limitations, we run the following counterfactual exercise, and we display the results in Figure 3.8. We set the reaction coefficient $\gamma$ which in $(I)$ is attached to excess credit growth equal to zero. ${ }^{47}$ We then re-simulate the model in response to the estimated sequence of all non-policy shocks. The difference between history and the artificial path is a rough representation of the contribution of the monetary pillar. Figure 3.8 is consistent with the following two conclusions. First, inflation would have been distinctly higher at times of financial exuberance and would have fallen precipitously into negative territory in the wake of the financial market collapse, starting in the autumn of 2008. In other words, inflation would have been more reactive to the state of financial sentiment. Second, the economy as a whole would have been more volatile. Monetary policy would have added fuel to credit market euphoria - visibly in the early years of monetary union - which would have made the subsequent reversal even more spectacular and destabilising than it was in retrospect.

We generalise these results to test their robustness to all possible realisations of shocks. Figure 3.9 shows the inflation-output variability frontier - the Taylor frontier - that can be traced out in our model given the profile of the whole spectrum of shocks that hit the euro area economy on average. ${ }^{48}$ The black line with diamonds on the right side of the figure shows the frontier that is attainable if the feed-back rule does not feature a reaction

44 Quoting from Stark (2010): "[Monetary analysis] compels policy-makers to consider trends in money and credit growth, which may exert an influence on price developments beyond that identified by a purely conjunctural or output-gap view of the world."

45 Due to the prevalence of shifts in the demand for money over the relevant sample period, estimating $(I)$ with a feedback on headline - as opposed to trend - money growth does not yield a significant reaction coefficient.

46 In the CMR model, underlying M3 growth is derived by generating the M3 growth path in response to all shocks identified in sample by the model estimation, except those that pertain to the demand for money by households and firms. For a thorough discussion of the measures of underling money computed by the ECB, see Papademos and Stark (2010).

47 The mode of the estimated posterior distribution for $\gamma$ is 0.54 .

48 When comparing the standard deviation of inflation and the standard deviation of GDP depicted in Figure 3.9 with the ones shown in Figures 2.7 and 2.9, it should be noted that the model, as most DSGE models, has a tendency to underpredict or overpredict the unconditional variance of some variables. However, this does not affect the evidence shown in Figure 3.9, which makes a relative assessment across policy rules. 
to excess credit growth (the $\gamma$ coefficient in (I) is zero). Diamonds of a bigger size correspond to higher coefficients -with step size of 0.2 - of reaction to inflation (the $\alpha$ coefficient). It is apparent that starting from very low values of $\alpha$ and shifting along the upper portion of the black line, which is positively bent, a central bank would be able to improve on both dimensions of policy by just making its response to inflation more aggressive. Note, however, that adding a response to excess credit growth would be even more effective: it would systematically curtail output volatility at no cost in terms of inflation volatility. ${ }^{49}$ This is shown by the blue lines that depart from the black Taylor frontier on the right side of the figure and point left. The blue diamonds along these lines indicate different degrees of response (step size of 0.05 ) to excess credit growth. Among them, the red diamonds mark the maximal response to credit - in association with the corresponding inflation coefficient on the black frontier - that would be possible without incurring a trade-off. Connecting the red diamonds with a line, one could trace out a curve. This curve would represent a shift of the black curve toward the origin. In other words, reaction to credit brings with it a Pareto improvement in policy design which would be unattainable otherwise.

Notice the difference between a monetary pillar and a genuine 'lean against the wind' approach. The ECB has long recognised that it is not asset prices per se that a central bank should incorporate in its policy framework. After all, the equilibrium value of assets - particularly real assets, such as claims on companies and houses - is difficult to compute and is certainly state contingent. So, there is little merit in an unconditional monetary policy response to asset price changes, as was advocated by the early proponents of a "leaning against the wind" strategy. ${ }^{50}$ The policy response should be conditional. And the critical condition that a central bank should ascertain before judging if an asset price trend is policy-relevant is whether the market trend is causing and/or is being fed by - a concomitant monetary imbalance. Quoting from ECB (2005):

Monetary analysis can contribute to assessing the extent to which generously valued assets can be traced to - and at the same time become a source of - excess creation of liquidity and overextension of credit. Detecting and understanding this link helps the ECB form an opinion on whether an observed movement in asset prices might already reflect the inflating of an unsustainable bubble (page 59).

A market bubble that progresses in symbiosis with a credit bubble, and which then spills over into excess money creation, is certainly a policy-relevant event. Being vigilant to the monetary imbalance means for a central bank being better able to discriminate between benign and less-benign phenomena in financial markets.

In conclusion, the mechanism by which a monetary pillar can improve over policy outcomes achievable under different policy strategies is simple. The monetary pillar alerts policy to rising imbalances in the monetary sector. Monetary imbalances are well-correlated with financial imbalances. In turn, financial imbalances are typically a distinct feature of the macro-economy at those critical time junctures, when the central bank is called upon to draw its balancing line between short-term risks and its long-term stability objective. In the formulation of those difficult balancing acts, monetary analysis can promote a longer-term perspective. It can act as the commitment mechanism which a central bank needs to have in place to overcome policy myopia.

\section{The financial crisis}

The initial turmoil and subsequent crisis that swept through financial markets over the past three years have posed unprecedented challenges for central banks. Their policy responses have been equally unprecedented and have involved non-standard measures - that is actions that go beyond the usual changes in a "policy"

49 Note that there is larger gain in output volatility than in inflation volatility. This is due to the fact that inflation is measured in terms of quarter-on-quarter growth rate and responding to monetary indicators seems to introduce some short run volatility. We plan to drop such higher frequencies, or alternatively, to smooth out the monetary indicator.

50 An early manifesto of "leaning against the wind" is Cecchetti, Genberg, Lipsky and Wadhwani (2000). Bernanke and Gertler (200I) provide a critique to that approach. 
interest rate. In this section, we turn our attention to this period and attempt to provide a first assessment of the macroeconomic effectiveness of non-standard measures in the euro area. ${ }^{51}$

Inevitably, the exceptional nature of the financial crisis which led to the deep recession of 2008-2009 - often referred to as the "Great Recession" in the academic literature - implies that a full assessment of the effectiveness of non-standard policies deployed by monetary and fiscal authorities will have to wait until the world major economies have completely recovered. The exceptional nature of these policies also implies that their effectiveness cannot be entirely understood using traditional frameworks and models. From this perspective, new benchmarks for "appropriate policy" and new interpretative tools have to be developed before alternative policy responses can be studied - with the considerable benefit of hindsight.

Our analysis in this section, therefore, does not pretend to provide a final judgement on monetary policy in the euro area during the crisis. It is however an attempt to measure quantitatively, using readily available tools, the effectiveness of monetary policy actions in helping the banking sector to absorb the financial shock and in providing the appropriate economic stimulus when needed.

More specifically, we proceed along two separate routes. We first provide an empirical assessment of the transmission of non-standard policy decisions to the economy at large. In so doing, we attempt to impose the minimum possible amount of theoretical structure, so as to "let the data speak". We therefore adopt a standard identified VAR approach, where the identification assumptions are designed to capture the specificities of euro area liquidity policy. More precisely, we identify standard and non-standard policy impulses and analyse their dynamic impact on inflation, output, loans to the non-financial sector and measures of credit and term spreads. The VAR can therefore help us to judge whether certain policy actions had the intended expansionary effect on the economy. This approach has the advantage of being relatively robust, i.e. not dependent on a particular view of the world reflected in a fully specified structural model. For the same reasons, however, it also has the drawback of not permitting a full counterfactual analysis, i.e. the assessment of what could have happened if monetary policy in the euro area had reacted differently.

A counterfactual exercise must, however, be performed to appreciate the effectiveness of the most urgent and fundamental aim of non-standard measures: to prevent a melt-down of the entire financial system. The primary aim of monetary policy actions was arguably to avoid the even deeper recession which would have occurred, had they not been implemented. Unfortunately, a fully satisfactory modelling framework allowing us to conduct such a counterfactual exercise is not yet available. The model used in section 3 , however, can be used to provide a tentative assessment. The second exercise that we perform in this section, therefore, is a counterfactual analysis based on the CMR model.

The rest of the section is organised as follows. We first provide a summary description of economic and financial developments in the euro area starting from August 2007 and until mid-2010. The main objective of this review is to highlight the main standard and non-standard measures enacted by the ECB and to clarify their stated intent. In so doing, we attempt to relate non-standard measures to the academic literature, including both papers which were already available at the time of the crisis - and therefore provided a possible framework to help interpret unfolding events - and papers which were written after the crisis - and therefore are tools to understand ex post policy decisions already taken. After this historical overview, we move on to study the effectiveness of some non-standard measures using, in turn, the VAR and the structural model.

\section{I From the financial turmoil to the Great Recession}

Before the inception of the financial turmoil, euro area developments in 2007 were characterised by an environment of sound economic growth and vigorous money and credit expansion. Throughout the year,

51 See also Baumeister and Benati (2010) and Lenza et al (2010) for a description and analysis of non-standard monetary policy measures in the euro area and other countries. 
medium-term risks to price stability remained clearly on the upside. Average annual HICP inflation stood at $2.1 \%$ in 2007 , raising sharply towards the end of the year, mainly due to substantial increases in international oil and food prices. Economic activity expanded at solid rates throughout the year, with contributions from all GDP components, thanks to favourable financing conditions (especially in the first half), and positive developments in real disposable income, as labour market conditions improved. Monetary analysis confirmed the existence of upside risks to price stability at medium to longer horizons, due to the strength of the underlying rate of money and credit expansion, as underlined, in particular, by the sustained growth of loans to the private sector. To contain these risks, the Governing Council adjusted the monetary policy stance, raising the key ECB rates twice in the first half of the year. As a result, the minimum bid rate in the main refinancing operations of the Eurosystem stood at $4.00 \%$ in June 2007 (see Figure 4.2).

At the same time, longer term risks for economic growth remained on the downside, mainly due to external factors, such as the possibility of further rises in oil and other commodity prices. Following the onset of the turmoil and increased volatility in financial markets in early August 2007, the outlook for economic activity in the euro area was characterised by unusually high uncertainty. ECB interest rates remained unchanged in the second half of the year.

\section{I.I The period before September 2008}

When the first signs of turmoil erupted on 9 August 2007, the ECB was amongst the first central banks to react to the shock and to inject abundant liquidity into the money market. Due to the adverse developments in the US sub-prime mortgage market, euro area banks became increasingly concerned with the risk of having to provide funding to structure investment vehicles that had invested in mortgage backed securities. At the same time, banks became increasingly unwilling to provide funds to counterparties in the interbank market due to concerns about their creditworthiness. These two phenomena led to hoarding of liquidity and weak activity in the interbank market. An indicator of these difficulties is the spread between the interbank rate, which is unsecured, and the overnight swap rate, which is only subject to a minimum amount of counterparty risk. After remaining very close to zero for years, these spreads rose to around 60 basis points for 12-month rates in the euro area, the US and the UK (see Figure 4.I).

The first consequence of the turmoil was that banks, that had lost access to liquidity from the interbank market, started increasingly to rely on liquidity from the Eurosystem and notably to front load the fulfilment of the reserve requirement at the beginning of the maintenance period. The Eurosystem's reaction over the rest of the year and until the collapse of Lehman Bros was to satisfy the increase in demand for liquidity, while keeping the overall policy stance unchanged. Significant changes were therefore decided in the timing and maturity of open market operations, so as to continue steering aggregate liquidity conditions in a way which supported banks' liquidity management process.

The distinction between monetary policy decisions and liquidity operations has been characterised by the ECB as a "separation principle" - see e.g. ECB (2008). The separation principle can be understood in the context of the traditional analysis of Poole (1970), according to which stabilising the short-term interest rate in the face of purely financial shocks is the best way to insulate the real economy from the effects of those shocks. Poole's analysis is obviously merely illustrative, since it is based on a backward-looking model and also abstracts from the inflationary consequences of any shock. At the same time, the intuition for why the central bank should stabilise the short-term interest rate, rather than the supply of liquidity, in the face of high-frequency financial shocks appears relevant also in relation to the late 2007-early 2008 period of financial turmoil. If the ECB had not accommodated banks' desire to front load their reserve requirements, excess demand for central bank money would have driven the EONIA rate upwards at the beginning of the maintenance period, and downwards at the end. These fluctuations could have led to a change of the policy stance de facto - in spite of the Governing Council's decision not to move the ECB interest rates - and thus induced undesired consequences on the economy. 
The separation principle could also be understood under the more recent conceptual framework provided by Woodford (2003) and, with specific reference to the financial crisis, Cúrdia and Woodford (2010). These analyses suggest that the central bank should operate a corridor system and remunerate reserves at market interest rates - like the ECB does for required reserves - or at least at a constant spread below market rates which is again consistent with the ECB approach for excess reserves. The remuneration of reserves has the advantage of eliminating (if the remuneration is at market rates), or making constant (if the remuneration is a constant spread below market rates) banks' opportunity cost of holding reserves. Fluctuations due to exogenous factors in banks' needs for reserves can then be accommodated through corresponding changes in the demand for central bank liquidity without any additional burden for banks. Hence, liquidity policy can be implemented independently from monetary policy proper, i.e. without involving changes in the stance of monetary policy.

From the perspective of both Poole's and Cúrdia and Woodford's analyses, the changes in the ECB's liquidity policy in the second half of 2007 can be understood as shock absorbers, rather than as the desire to stimulate the economy in the face of an adverse shock. While certainly increasing the uncertainty of the economic outlook, the financial turmoil of the late 2007 and early 2008 period did not pose direct threats to the economy, provided that the risk of a "bank run"-type collapse of the banking sector due to the drying up of interbank liquidity could be avoided.

In this paper, we do not venture into a detailed discussion of money market developments (see Cassola et al for an in-depth analysis of the latter). Nevertheless, recent analyses have supported the view that spreads in the interbank markets were initial signals of a type of bank run (see Gorton, 2009). At the ECB, Heider et al (2009) provides a model of how varying levels of counterparty risk, together with asymmetric information, can lead to the evaporation of liquidity in the unsecured interbank market. At high levels of risk, safer banks leave the unsecured market and trading occurs at a higher interest rate amongst riskier banks. When the dispersion of risk is particularly high, the interbank market may break down altogether, leading to multiple equilibria driven by self-fulfilling expectations. In these circumstances, the central bank can be thought of as acting as a "market maker of last resort". It can offer to take on the excess liquidity and act as a counterparty for all liquidity transactions. In the limit, the central bank could entirely replace the interbank market.

\section{I.2 Developments after September 2008}

With the financial turmoil still ongoing, inflationary pressures in the euro area increased in the first half of 2008 leading to a climb in annual HICP inflation from $3.2 \%$ in January to $4 \%$ in June and July. While the US slowdown and the financial market turbulence kept the outlook particularly uncertain, there were clear risks that levels of inflation well above the ECB definition of price stability could begin affecting expectations of future wage and price levels. To ensure that long-term inflation expectations remained anchored, the Governing Council raised the ECB rates by 25 basis points in July.

As of 15 September, however, the financial turbulence intensified after the bankruptcy of Lehman Brothers, leading to a renewed and unprecedented increase in interbank spreads (see Figure 4.I). The high levels, around 60 basis points, reached by the EURIBOR-OIS spreads at the end of 2007 were dwarfed by the new values, of over 200 basis points, touched by the same spreads in September 2008. The overall level of macroeconomic uncertainty -- as measured, for example, by stochastic volatility in the stock market -- also increased to unprecedented levels. In a few weeks, the outlook changed dramatically. Euro area GDP contracted by $0.2 \%$ in the third quarter of 2008 (quarter on quarter) and by a further 1.5\% in the fourth quarter. Annual HICP inflation fell to $1.6 \%$ in December. By the turn of the year, a clear decline was also observed in the growth rate of loans to non-financial corporations. Overall, monetary trends supported the view that inflationary pressures were weakening further.

Against the background of this worsening outlook, the Governing Council decided on a fast sequence of reductions in ECB interest rates, starting with a coordinated move with the Bank of Canada, the Bank of 
England, the Federal Reserve System, the Sveriges Riksbank and the Swiss National Bank on 8 October. In 8 months, ECB rates fell by 325 basis points, so that the MRO rate stood at I\% in May 2009.

\section{I.3 The expansion of the ECB balance sheet}

At the same time, the worsening of the macroeconomic situation was accompanied by signals of increasing impairments in credit markets. Evidence from the ECB's Bank Lending Survey suggested that part of the reduction of credit to the non-financial sector may be due to supply constraints (see e.g. Ciccarelli et al, 2010). While reducing interest rates, the Governing Council adopted non-standard measures to deal with the dysfunctional money market, relax banks' balance sheet constraints and facilitate the transmission of key ECB interest rates to bank lending rates. First, it decided a temporary narrowing of the corridor formed by the rates on the standing facilities, thereby increasing the ECB's role of market maker in the interbank market. Second, the Governing Council introduced additional open-market operations at one, three and six months horizons to cover a longer maturity spectrum for liquidity provision. Third it announced full allotment at fixed rates in its tender operations. This led to a surge in central bank liquidity demanded by banks and, as a result, to a large increase in the ECB balance sheet (see Figure 4.3).

Additional non-standard measures were adopted in May 2009 -- when the MRO rate reached the $1 \%$ level -- to support the flow of credit to households and corporations. These included: the lengthening of the maximum maturity of refinancing operations to one year; the extension of the list of assets accepted as collateral; the provision of liquidity in foreign currency; and outright purchases in the covered bond market. These decisions, together with those adopted in October 2008, configured the ECB's policy of "Enhanced credit support" in response to the financial crisis.

The measures taken under the enhanced credit support umbrella aimed to overcome the financial market impairments which were constraining the process of credit creation in spite of the reduction in policy interest rates. As a result, the ECB succeeded in lowering the cost of financing in specific financial market segments. For example, the covered bond programme led to a fall in yields in this market, which is important for banks' financing needs. A more direct impact of the vast expansion of ECB liquidity which went along with the full allotment policy, especially after the lengthening to one year of the maturity of longer term refinancing operations, was to lead to a persistent fall in the EONIA below the levels of the MRO rate. This fall was also facilitated by the decision to widen again to $2 \%$, in January 2009 , the corridor formed by the rates on the standing facilities: the corresponding $0.5 \%$ reduction in in the rate on the deposit facility allowed for a further decrease in the EONIA rate.

Allowing for a persistent spread to open between the EONIA and the MRO rate -- something unprecedented in the ECB history -- was the approach followed by ECB to deal with the segmentation which had in the meantime materialised in the banking sector. Only some of the banks with liquidity needs could borrow funds from their counterparties at the EONIA rate; other banks were considered too risky and therefore forced to obtain refinancing directly from the ECB at the higher MRO rate. The spread between the EONIA and the MRO rate had two effects. On the one hand, the lower refinancing rate (the EONIA) faced by banks with access to the overnight market could be expected to influence other money market segments and ultimately the rates on loans to the non-financial sector. On the other hand, the MRO refinancing available for banks with larger perceived exposures to illiquid assets -- together with the extension of the list of assets accepted as collateral -- could be interpreted as a standard application of the Bagehot principle according to which, at times of crisis, the central bank should provide unlimited liquidity at a penalty rate. The unlimited provision of liquidity allowed solvent banks to overcome their liquidity problems, while the penalty at which they obtained central bank funds maintained their incentives to restructure their balance sheets. This policy also aimed to keep low the risk of "zombie banks" (see Caballero et al, 2005) operating in the euro area.

Overall, the ECB's enhanced credit support policy has a distinct character from the "quantitative easing" policy introduced in Japan between $200 \mathrm{I}$ and 2006. One key feature of the latter approach was to target the amount 
of excess reserves of commercial banks, primarily by buying government securities. In contrast, the ECB's objective was to improve liquidity in market segments especially impaired. The increase in excess reserves was therefore only a by-product, rather than the primary target, of the ECB's enhanced credit support. This also explains why government bonds purchases were not part of the programme.

A second key feature of quantitative easing is that it was only introduced after policy rates had reached levels very close to zero. Quantitative easing can therefore be seen as a substitute for conventional policy easing, to be exploited only once there is no more room for manoeuvre of policy interest rates. In contrast, the ECB programme was rather a complement of the standard policy easing. Standard and non-standard measures were in fact adopted in parallel, as of October 2008. Non-standard measures aimed to reinforce, rather than replace, the impact of the reductions of policy interest rates, whose effectiveness had been reduced by impairments in the financial market.

The enhanced credit support programme was therefore independent of the level of the MRO rate: it could have been adopted, thus generating a large expansion of the ECB balance sheet, at any interest rate level. The possibility of creating large amounts of excess reserves at any level of the policy rates, and not only when they are zero, is an implication of the ECB corridor system. This system makes the opportunity cost of excess reserves independent of the level of the MRO rate and only a function of the spread between the MRO rate and the rate on the deposit facility. As a result, lowering policy interest rates to zero is not a prerequisite for an expansion of the ECB balance sheet.

Some elements of the ECB's enhanced credit support make it akin to the credit easing of the Federal Reserve System. Both policies, for example, share the objective of targeting specific segments of the financial market. At the same time, there are differences in the specific implementation of this objective. While the Federal Reserve intervened through direct lending to the non-financial sector, the ECB approach was by and large limited to improving liquidity in the banking sector. These differences reflect simply the different financial structure of the euro area and the US. The ECB focused on banks because in the euro area banks are the primary source of financing for the real economy. The bulk of external financing of non-financial corporations comes from the banking sector, which is especially important for small and medium-sized enterprises.

Another distinguishing feature of the Enhanced credit support programme, compared to the Federal Reserve's credit easing, is that most operations carried out in the context of the ECB programme have been conducted as repurchase transactions. These operations facilitate the "phasing out" of non-standard measures, because they can easily be terminated if they are not renewed upon maturity.

After the crisis, new frameworks to understand developments during 2008 and 2009 and to help devise the best policy response have been devised in the literature (see Gertler and Kiyotaki, 2010, Curdia and Woodford, 2010). By and large, these analyses conclude that non-standard monetary policy measures were warranted, since they addressed the inefficient intensification of credit market frictions.

For example, in the Gertler and Kiyotaki (2010) framework, the ECB expansion of liquidity can be understood as a means to support the provision of credit to the economy through the relaxation of a liquidity constraint for some banks. In that framework, banks willing to provide lending may be unable to do so due both to the deterioration of their own balance sheet, and to the segmentation of the interbank market. Central bank intervention through the provision of liquidity is then warranted, provided that the central bank has an advantage, with respect to other commercial banks, in ensuring that the funds will be used for productive purposes. Then banks that have good investment opportunities, but are otherwise constrained, can benefit from the provision of central bank liquidity, even at a penalty rate. Gertler and Kiyotaki (2010) report that, in their simple model, this policy has equivalent effects to the central bank's direct lending to the private sector. 


\section{I.4 The Securities Market Programme}

Over the course of 2009 spreads in the money market began to gradually decline and overall financial markets conditions started showing signs of stabilisation. The ECB therefore announced in December 2009 that nonstandard measures would begin to be gradually phased out, alongside with the normalisation of financial markets. The phasing out began with the discontinuation of I-year longer term operations. In March 20I0, the return to a variable rate tender procedure in the 3-month operations was also decided.

In early 2010, however, new tensions emerged in euro area government bond markets. Market concerns about the sustainability of public finances in some euro area countries led to the increase in spreads between ten-year government bonds of those countries relative to German bonds. Once again, some secondary markets dried up. The tensions increased in April and early May 2010 and, on 9 and 10 May, area governments announced a comprehensive package of measures, including the European Financial Stability Facility, to react to the new financial market tensions.

On 10 May the ECB announced the launch of the Securities Markets Programme. Under the programme, targeted to overcome the new market impairments, the Eurosystem can intervene in the euro area public and private debt securities markets to ensure depth and liquidity in dysfunctional market segments and to restore the proper functioning of the monetary policy transmission mechanism. All purchases are fully sterilised by conducting liquidity-absorbing operations. In addition, in order to avoid spillovers from domestic sovereign bond markets to other financial markets, the ECB reintroduced the fixed rate tender procedure with full allotment for the 3-month operations and conducted a new 6-month refinancing operation with full allotment. The temporary liquidity swap lines with the Federal Reserve System were also resumed.

The Securities Markets Programme appears to have been temporarily effective in reducing the risks of contagion across euro area Government bond markets. It is however too early to draw conclusions on the effectiveness of the programme based on an econometric analysis. We therefore ignore this programme in the rest of this section.

\subsection{A VAR analysis}

We start our assessment of the non-standard measures undertaken by the ECB with an analysis based on a structural VAR. Advantages and drawbacks of this approach are well-known. The main advantage is that it imposes very mild theoretical description: VAR results are therefore data-driven and not model-dependent. The main drawback is that a VAR is a reduced-form model: as such it cannot be used to perform a counterfactual analysis. Our VAR results should therefore be interpreted as simply shedding some light on the way in which non-standard policies have been transmitted to the rest of the economy.

A general problem in assessing the effectiveness of non-standard measures in the euro area is that these measures are unprecedented and related to exceptionally large fluctuations in economic variables - from interbank spreads to investment and GDP. This has two implications. First, historical data do not provide information useful to understand recent developments. Using pre-EMU data would therefore not be beneficial to our analysis. To rely on consistent series of central bank liquidity, we only use euro area data - from January 1999 until June 2010. The second implication is that the data show signs of time-variation in variance parameters. This is a problem for our standard VAR, which assumes homoskedastic shocks. As a robustness check, we also estimated the model on the January 2007-June 2010 sample. The impulse response results were broadly in line with those over the full sample, but uncertainty bands were considerably larger.

We estimate the VAR at the monthly frequency. The VAR includes standard macroeconomic variables, such as HICP inflation, de-trended industrial production, the Purchasing Managers Index and the rate of growth of loans to the private non-financial sector. In addition, to study the effects of non-standard measures on the macro economy, we include in the VAR indicators of financial distress: (a) the 3-month EURIBOR-OIS spread (which we label "interbank spread" in the figures); (b) the spread between short-term loans to non-financial 
corporations and the 3-month EURIBOR (which we label "Loan spread"); and (c) a measure of implied volatility in the euro area stock market. For policy, we include the MRO rate, the spread between the MRO and the rate on the deposit facility (labelled "MRODEP"), and a measure of the total amount of central bank money allotted in liquidity providing operations (labelled "LiqTot"). Finally, we use market-based measures of expected future interest rates and inflation: the I-year forward spread and the 10-year break-even inflation rate. ${ }^{52}$ Overall, our VAR includes 12 variables. Given the relatively short available sample period, we estimate it using Bayesian methods and a Minnesota prior. ${ }^{53}$ We include 10 lags in the specification.

A key step in our analysis is the identification of the shocks, where we proceed adopting the approach of Bernanke and Mihov (1998). More specifically, from the block of policy variables -- the MRO rate, the spread between the MRO rate and the rate on the deposit facility, and the total amount of liquidity -- we attempt to identify a standard policy shock and a non-standard policy shock. The policy block is ordered after all standard macroeconomic variables and also after our indicators of financial distress. This is consistent with the frequently used assumption that monetary policy can react to all these variables and indicators contemporaneously, but they are only affected by policy with at least a lag of I month. After the policy block, we include our measures of expected future interest rates and inflation. This choice allows these variables to react to policy shocks contemporaneously.

In the identification of our "non-standard policy shock", we need to be precise about the feature of the Enhanced credit support programme that we wish to capture. From this perspective, we again take the limitations of the VAR approach into account. For example, we must abstract from the extension of the list of assets accepted for refinancing, because of the problems in incorporating this type of qualitative information in a VAR. We also abstract from the outright purchases in the covered bond market, because of the difficulty to identify the separate benefits of this programme, which was relatively small in quantitative terms compared to the overall expansion of liquidity. Finally, we abstract from the provision of liquidity in foreign currency, which would require expanding further, to take open economy effects into account, our already large VAR.

We are therefore left with three main non-standard measures: the decision to adopt fixed rate, full allotment liquidity operations; the changes in the size of the corridor identified by the ECB standing facilities; and the decision to extend the maximum maturity of longer term operations. In this paper, we mainly focus on the full allotment policy and the changes in the size of the corridor. We also analysed a second VAR model to check whether additional effects could be identified from the extension of the maturity of longer term operations. The economic literature has emphasised how the monetary policy stance can be altered, for given current policy rate, by steering expectations of future interest rates. This type of policy actions can be particularly useful when policy rates have reached their lower bound (see Eggertsson and Woodford, 2003). From this perspective, the lengthening of refinancing operations to I-year could be given the interpretation of an implicit signal of the persistence of the ECB's low interest rate policy. We therefore tested for an impact of the

52 More precisely, the following variables are included in the VAR: I. inflation, measured as the year-on-year log-difference of the HICP for the euro area; 2. industrial production, measured in log-deviation from a quadratic trend; 3 . the

Purchasing Managers Index (also in logs); 4. the annual growth rate of bank loans to the private sector, adjusted for sales and securitisation (index of notional stocks); 5. the implied volatility on the Dow Jones Euro Stoxx 50 Price Index (in logs); 6. the 3-month spread between the EURIBOR and the Overnight Index Swap rate (for 1999, when OIS rates are not available, the 3-month yield on German government bonds is used instead); 7. the spread between the rate on bank loans (with maturity of up to I year) to non-financial corporations and the 3-month EURIBOR; 8. the MRO rate; 9. the spread between the MRO rate and the rate on the deposit facility; 10. the outstanding amount of ECB liquidityproviding operations (in logs); II. the I-year forward spread, namely the spread between the I-year ahead overnight rate (implicit in the term structure of German government bonds) and the MRO rate; 12. the 10-year break-even inflation rate (extended backwards to the pre-2004 period in which index-linked bonds were either unavailable or very illiquid using fitted data from Hördahl and Tristani (2010)).

53 The tightness hyper-parameter is set to 0.1 ; the weight parameter is set to 0.5 . 
lengthening of the operations on expected future interest rates, as proxied by forward premia. These results were however statistically insignificant and are therefore not reported.

\subsection{The short-term model}

In our VAR, we attempt to capture two facts. First, the fact that the expansion of the ECB balance sheet was purely demand-induced at the given rate on refinancing operations -- though the full allotment policy was in itself a policy decision. Second, the fact that changes in the rate on the deposit facility, for given MRO rate, can have macroeconomic impact through two channels. The first channel operates through changes in banks' opportunity cost of holding excess reserves: ceteris paribus, a reduction of the deposit rate would thus entail a higher cost of excess reserves. The second channel works in conjunction with the full allotment policy and the availability of vast amounts of reserves. In these circumstances, lowering the deposit rate permits a larger fall in the EONIA rate, compared to the level of the MRO rate.

The identification of the policy block is based on the following simple model of the market for central bank money.

First, we assume that the MRO rate is set independently of banks' liquidity needs. This reflects the fact that the $M R O$ is, under normal circumstances, the main indicator of the ECB policy stance. Any shock to banks' demand for $E C B$ reserves is therefore implicitly accommodated without triggering changes in the intended policy rate. If we use $u$ to denote the portion of our VAR residuals which is orthogonal to the VAR residuals in the nonpolicy block and $\varepsilon$ to denote the structural shocks of the policy block, we can therefore identify the standard policy shock $\varepsilon_{\mathrm{p}}$ as

$$
u_{M R O}=\varepsilon_{P}
$$

Our second identification assumption exploits the fact that excess reserves are only remunerated at the rate on the deposit facility. They therefore carry an opportunity cost equal to the spread between the MRO rate and the rate on the deposit facility. Total reserves include required reserves and excess reserves. For simplicity, we abstract from this distinction and simply allow for total reserves to be sensitive to the MROdeposit rate spread. The residual component is a liquidity demand shock $\varepsilon_{d}$ due to factors not explained by our VAR. We therefore write

$$
u_{\text {LiqTot }}=-\beta u_{\text {MRODep }}+\varepsilon_{d}
$$

where $\beta$ is an elasticity to be estimated.

Finally, we acknowledge that the central bank has the additional policy tool of modifying the spread between MRO and deposit rates. We postulate a generic "reaction function" which depends on the state of the economy, but assume that this is independent of other liquidity market shocks. The reaction function residual can then be interpreted as a second, "non-standard" policy shock $\varepsilon_{s}$ :

$$
u_{\text {MRODep }}=\varepsilon_{\mathrm{s}}
$$

Note that the model implies that total liquidity is related to structural shocks in the following manner

$$
u_{\text {LiqTot }}=\varepsilon_{\mathrm{d}}-\beta \varepsilon_{\mathrm{s}}
$$

so that an increase in liquidity can result from a reduction of the spread between MRO rate and deposit rate or from an increase in liquidity demand. By assumption, liquidity demand shocks are perfectly accommodated at an unchanged opportunity cost.

In our estimates, we find that $\beta=0.08$. This suggests that an increase in the spread between the MRO rate and the rate on the deposit facility has only a small negative impact on the demand for liquidity.

As a robustness check, we re-estimated the model allowing for the distinction between excess reserves and total reserves. In this case, only excess reserves (labelled "Xcess") are assumed to be sensitive to the spread 
between the MRO rate and the rate on the deposit facility. Excess reserves are defined as the total recourse to the deposit facility and are modelled as

$$
u_{\text {Xcess }}=-\beta u_{\text {MRODep }}+\varepsilon_{d}
$$

The remaining amount of "net liquidity", which is defined as total central bank liquidity minus excess reserves, does not bear an opportunity cost. The innovation is therefore directly interpreted as a liquidity demand shock due to factors not explained by our VAR

$$
u_{\text {LiqNet }}=\varepsilon_{b}
$$

The policy reaction function for the spread between MRO and deposit rates is now also allowed to depend on (net) liquidity demand shocks. As above, reaction function residual can be interpreted as a "non-standard" policy shock $\varepsilon_{s}$ :

$$
u_{\text {MRODep }}=\phi_{b} \varepsilon_{b}+\varepsilon_{s}
$$

The remaining equation for the MRO rate remains unchanged. We use this short-run model mainly to conduct a robustness check, because it is identified less well. The mean estimate of $\beta$ becomes much larger, but it is very imprecisely estimated. We also find $\phi_{b}=-0.14$.

\subsubsection{Impulse response analysis}

We mainly focus on the results of our benchmark VAR which abstracts from the distinction between excess reserves and total liquidity. To gauge the overall performance of the VAR, we first look at its implications in terms of two benchmark shocks: an increase in the spread between 3-month EURIBOR and overnight swap rates, which we interpret as indicative of the financial crisis; and a standard policy tightening, which is comparable to existing results. The first shock is identified recursively, under the assumption that any innovation in the spread which is not correlated with innovations in macroeconomic variables is a structural "spread shock". All impulse response graphs report the mean response over 5,000 draws from the posterior parameter distribution, together with the 16th and 84th percentile of the distribution.

A $1 \%$ increase in the spread between the 3-month EURIBOR and the overnight swap rates (the BnkSpr variable in the graph) is displayed in Figure 4.4. Consistently with the developments over the past 3 years, the shock is very persistent: the spread falls by two thirds after 6 months, but remains at these higher levels for the following 6 months. The pass-through of the shock to lending rates to non-financial firms takes a few months, but is then completed with a mark-up, since loan rates increase more than one-to-one with EURIBOR rates -hence the positive response of the spread between loan rates and the EURIBOR rate displayed by the LoanSpr variable. As a result, there is a persistent increase in the demand for central bank liquidity after the shock. Consistently with the developments in October 2008, the increase in liquidity is also smoothed by a temporary reduction in the spread between the MRO rate and the rate on the deposit facility. Monetary policy also reacts through standard means, with a reduction of the MRO rate by 40 basis points after 6 months. Nevertheless, loans fall by $2 \%$ after one year, and industrial production goes down by up to $4 \%$. This shock is therefore quite consistent with the assumption that the shock to the EURIBOR-overnight swap rates played a significant role in the recession of 2008-2009.

Figure 4.5 reports impulse responses to a standard expansionary policy shock, i.e. a 25 basis points cut of the MRO rate. The shock is transmitted to the economy very slowly - we therefore show impulse responses over 2 years. With the exception of a fast rise in the Purchasing Managers Index, the amount of loans, industrial production and inflation increase only over one year after the policy tightening. Inflation actually falls initially -a manifestation of the "price puzzle" phenomenon. The price puzzle could be a symptom of firms' need to resort to external finance to fund their production costs: the fall in the MRO rate would be translated into lower loan rates, hence lower firms external financing costs. Under this interpretation, the price puzzle reflects firms' attempts to pass-through to final prices this change in their funding costs. 
We now turn to the analysis of non-standard shocks.

Figure 4.6 illustrates the response of the economy to an increase in the spread between the MRO rate and the rate on the deposit facility - the MRODEP variable in the lower right portion of the figure. For given MRO rate, this shock represents a fall in the rate on the deposit facility which is not correlated with contemporaneous increases in the amount of central bank liquidity. It is therefore most closely related to the widening of the ECB corridor that occurred in January 2009.

The shock has two effects. On the one hand, it tends to increase the opportunity cost of borrowing at the MRO rate. Ceteris paribus, this tends to reduce the demand for liquidity, as shown by the graph in the southwest corner. The tighter liquidity conditions also lead to a marginally higher EURIBOR-overnight index swap spread - (see the response of the BnkSpr variable). This consequence of the shock tends to be contractionary for banks which need to rely on ECB liquidity. On the other hand, the shock permits a fall in the EONIA which reduces refinancing costs on the overnight market. This consequence of the shock is expansionary for banks which can obtain liquidity from the market and are not forced to rely on central bank funding.

The impulse responses show that the net effect of the shock is expansionary, i.e. that the easing effect of the fall in the EONIA rate dominates. Loans and industrial production increase significantly for a few months.

Figure 4.7 illustrates the response of the economy to a liquidity demand shock, i.e. a signal of stress in the banking sector, which is fully accommodated by policy. The shock is standardised to the increase in total ECB liquidity that occurred in October 2008. Total liquidity is measured, in natural logarithms, by the LiqTot variable in the south west corner of the figure. Figure 4.7 suggests that the ECB's full-allotment policy was an effective shock-absorber. The shock is accompanied by a slowdown in industrial production, but produces no adverse effects on interbank spreads. The effects on the other variables are economically small or statistically insignificant - only break-even inflation rates fall slightly for a few months.

As a robustness check, figures $4.6 \mathrm{~b}$ and $4.7 \mathrm{~b}$ show impulse responses from the extended VAR which discriminates between excess reserves and total reserves.

The impulse responses to an increase in the spread between the MRO rate and the rate on the deposit facility, reported in figure 4.6b are in line with the results of our benchmark VAR shown in figure 4.6. In both figures, the net effect of the shock is expansionary in terms of the industrial production.

Figure 4.7b confirms and strengthens the result that the ECB's full-allotment policy worked as a shock absorber. The shock, whose size is calibrated to match the increase in the recourse to the deposit facility in October 2008, is contained to the market for central bank liqudity. The impulse responses of all other variables in the VAR are statistically insignificant. More specifically, the shock is not accompanied by a reduction of credit flows to the euro area economy

All in all, the VAR results assign an important role to financial shock -- namely shocks that affect the spread between EURIBOR and overnight index swap rates -- in explaining the 2008-2009 recession. They are also roughly consistent with existing results on the effects of a standard policy shock.

Concerning non-standard policy, the VAR results are consistent with the hypothesis that the ECB's enhanced credit support programme played a non-negligible role in helping the banking sector to absorb the financial shock and in supporting the expansionary impact of the interest rate reductions.

\subsubsection{Three counterfactuals}

The effectiveness of the strategy over the most severe phase of the financial crisis can be measured by the distance between history and the hypothetical macroeconomic outcome that could have occurred had the ECB not adopted the non-standard policy measures which have been described in this Section. In order to measure this distance, we resort to the same sort of counterfactual analysis that we used in Section 3. Again, we are 
forced to be model-specific: we rely on the CMR model only. And we need to be selective: we concentrate on three aspects of the October 2008-May 2009 policy package:

I. The switch to fixed-rate-full-allotment tender procedures in regular liquidity operations.

2. The expanded spectrum of maturities (from 3 months to 6 months and, as from June 2009, 12 months) at which liquidity has been offered in unlimited amounts.

3. The deliberate avoidance to enter commitments regarding the future path of policy interest rates.

We first simulate the impact of the liquidity measures, I and 2. Then, we move to the counterfactual scenario which could have materialised if the ECB had given systematic forward guidance in its communication about the future path of policy rates.

In designing the liquidity counterfactuals we face, however, the problem of discriminating the genuine impact of the switch to the unlimited provision of liquidity (point I) from the concomitant expansion of the spectrum of maturities at which liquidity was provided in unlimited volumes (point 2). In order to discriminate 2 from I, we proceed as follows. First, we quantify the elasticity of the 10-year risk-free interest rate to the overnight interest rate under normal conditions. We reckon that the spread between the 10-year average government bond interest rate and the overnight interest rate would have increased by more than it actually did during the crisis, and we attribute the reduced response to the expansion of the spectrum of maturities. ${ }^{54}$

The first counterfactual scenario thus allows quantifying the measure under point 2 in isolation. Specifically, the implementation of the first counterfactual requires the following modelling steps: (a) we assume that the structural non-policy shocks in the counterfactual would have been the same as those identified in the estimation under the new policies during the post-crisis period (as in Charts 3.I-3.4 in Section 3); (b) the overnight rate would have evolved according to the feedback relationship described in equation (I), Section 3 , using the coefficients estimated over the post-crisis and with a zero elasticity, $\theta$, of the overnight rate to bank liquidity demand shocks. If a zero value of $\theta$ can be thought of as the distinct implication of the unlimited provision of liquidity - whether in weekly or in longer-term operations - then our choice of conducting this counterfactual scenario under a zero value for $\theta$ is meant to simulate a situation in which the ECB does provide liquidity in unlimited amount in its weekly main refinancing operations but does not provide unlimited liquidity in the 3-month or longer-maturity operations; (c) we manipulate the policy shock process, $\varepsilon_{\mathrm{t}}$, to generate the same path for the overnight interest rate, but force the 10-year spread to follow past regularities of long-term interest rate adjustments following policy action. ${ }^{55}$ For example, in a term-structure model estimated on German, pre-EMU data, Hördahl, Tristani and Vestin (2006) show that the response of long-term yields to a monetary policy shock is insignificantly different from zero. Hence, movements in policy rates caused by policy shocks induce, as a matter of regularity, a one-to-one change in the term premium of the opposite sign. These results are also consistent with our VAR evidence in Figure 4.5 where, in reaction to an increase in the MRO rate by 25 basis points, the I-year forward premium falls by approximately the same amount.

The second counterfactual exercise tries to answer the question: what would have happened if the demand for liquidity had not been satisfied unboundedly in the Eurosystem liquidity providing operations, whether in its regular or longer-term operations (point I). We simulate the admittedly extreme case, in which the Eurosystem - in the context of variable rate tender procedures and in keeping with the pre-crisis practice - would have allowed the pre-set allotments at its liquidity providing operations to increase at the same pace as the estimated 'liquidity needs'. The latter aggregate quantifies the minimum volumes of liquidity borrowing that would have just enabled banks to fulfil their minimum reserve requirements and to cover for changes in the

54 The 10-year government bond yield used in the estimation is computed on the basis of the whole euro area.

55 Note that this scenario is generated on re-simulating the model conditioning on alternative paths for two state variables: the overnight rate and the spread. This is possible only by manipulating both the unexpected and the expected (signal) component of the monetary policy shock process, $\varepsilon_{t}$. 
public's demand for banknotes and for autonomous variations in the accounts held by some governments at their national central banks. In the pre-crisis period, such estimated 'liquidity needs' were the main reference statistic used to calibrate the pre-set volume of liquidity supply in the weekly refinancing operations.

Specifically, the implementation of the second counterfactual is designed as follows: (a) we assume that the structural non-policy shocks would have been the same as those identified under the new policies over the post-crisis period, as in the counterfactual described above; (b) unlike the exercise above, we re-simulate the model over the post-crisis period using the pre-crisis feed-back equation for the overnight interest rate. This, includes the positive and large elasticity, $\theta$, of the market interest rate to bank's liquidity demand conditions that characterised the feed-back in the years prior to the financial crisis (see Section 3); (c) we manipulate the policy shock process, $\varepsilon_{\mathfrak{v}}$, to generate an alternative path for the outstanding volumes of Eurosystem refinancing operations, which are counterfactually forced to grow at a constant rate reflecting the average growth rate of the 'liquidity needs' over the pre-crisis period. ${ }^{56}$

The results of the two scenarios are portrayed in Figure 4.8 and correspond to the dotted lines (former counterfactual) and the dashed lines (latter counterfactual) in the panels. In particular, the difference between the solid lines and the dashed lines is our measure of the impact of the shift to a fixed-rate-full-allotment procedure for auctioning liquidity. The difference between the solid lines and the dotted lines measures, instead, the pure impact of the lengthening of the maturities of monetary policy operations, under the assumption that, had the maturity spectrum not been expanded, the ECB would have provided liquidity in unlimited amounts in its weekly operations nonetheless.

According to the counterfactual exercises, the maximal impact of the non-standard policy interventions was associated with the switch to the fixed-rate-full-allotment tender procedure (the dashed lines). Given the large positive elasticity of the overnight interest rate in the counterfactual feed-back relationship underlying the dashed lines, and the constraint forced on the model that, under variable rate tenders, liquidity supply should satisfy no more than the banks' 'liquidity needs', this result is perhaps unsurprising. Note that these two features of our simulations mean that the unprecedented increase in the demand for liquidity observed in the quarters following the financial collapse would have exercised a strong upward pressure on the overnight interest rate. That upward pressure on the cost of borrowing and the lack of liquidity would have unleashed a severe de-leveraging process (see the credit panel) through which banks would have sought to align their liquidity needs to the size of their balance sheets by shrinking the latter. This process would have resulted in severe downside risks to price stability and in a deeper contraction than were actually observed. ${ }^{57}$

The institution of the 6-month and 12-month long-term operations also contributed to limiting the impact of the crisis, although their impact - given a policy of unlimited liquidity provision - was clearly less decisive.

On the basis of a third counterfactual we discuss the ECB's avoidance to enter commitments about the future course of policy. One way to interpret the ECB avoidance to enter commitments is related to exit

56 Note that forcing the Eurosystem supply of liquidity to follow a constant growth path would have had implications for the setting of the interest rate on the main refinancing operations (MRO) and/or for the behaviour of the EONIA rate within the monetary policy corridor, given the path actually followed by the MRO rate. Either the path of the MRO rate would have been different from the one actually followed by the ECB, or - given the historical path - the EONIA rate would have been occasionally capped by the rate on the marginal lending facility, which sets an upper bound to the fluctuations of the EONIA. In conducting our simulations, we assume the former case, which is admittedly very extreme.

57 Note that the model generates an endogenous upward adjustment in M3 growth in parallel to the shift in the demand for liquidity. This is due to the increase in the demand for short-term deposits included in M3 but not in MI. Unlike the overnight deposits included in the definition of $\mathrm{MI}$, these deposits are remunerated at an interest rate that is closely indexed to the EONIA rate. As the latter increases sharply in our model simulations, these other forms of deposits become an attractive form of wealth allocation, which explains the surge in M3 growth despite the sharp initial drop in credit. 
considerations. Quoting from President Trichet: "we designed technically the measures with their exit in mind" ${ }^{58}$. In designing non-standard measures the ECB has privileged measures that grant a large degree of flexibility to the central bank in addressing the risks to price stability going forward. Commitments about the future path of the policy rate do not seem to meet such a requirement. Within theoretical models it is easy to account for the conditionality of the commitment; instead, in reality, central banks may find it difficult to adequately communicate conditionality to the public. A communication campaign that tries to convince markets that the policy rate will be maintained low for longer than currently expected may be in itself easy to understand for the public. But the notion that the central bank will be patient in removing policy accommodation in the future notwithstanding inflation rates possibly rising above the numerical objective and that inflation will be expected to remain higher for an extended period may be difficult to convey and therefore judged as not credible. The major challenge for a central bank once inflation rates rise above the desired objective consists in managing inflation expectations. The central bank may need to take bold actions to regain control of inflation expectations. At that point it becomes hard to explain to the public that the very notion of conditional commitment implies that sharp increases in the policy rates are still perfectly consistent with the previously announced forward guidance that interest rates will be maintained lower than otherwise. Any misunderstanding on any of these points between the central bank and the markets will limit the flexibility of the central bank in that it may endanger its credibility. ${ }^{59}$ This may explain President Trichet's: "my oft-repeated statement at the ECB's monthly press conferences to the effect that the Governing Council 'never precommits'."

Figure 4.9 presents model simulations that allow to illustrate the hazards the central bank may face when it is bound by an explicit commitment about the future path of the policy rate. The simulations are carried out in incremental steps. First, it is assumed that at the outburst of the financial crisis following the collapse of Lehman the central bank fears that a very bad outcome may occur and that its actions may become constrained by the zero lower bound. To approximate such a worst case scenario, in the simulations the model is fed with a specific path of adverse 'demand' shocks that would lead (ex ante) to inflation outcomes that lie in the lowest percentile of the predictive distribution of inflation. ${ }^{61}$ We take here the vantage point of 2008Q4. In this first step monetary policy is let to evolve endogenously. The outcome is displayed in the upper panels of Figure 4.9 by the dotted line. The results show that indeed monetary policy would have incurred for some quarters the lower bound, defined for convenience as 0.25 percent on the EONIA. ${ }^{62}$ For comparison, the Figure displays also the historical path followed by EONIA in reality (see solid line).

Second, it is assumed that to counteract such adverse developments the central bank moves aggressively by enforcing immediately a zero policy rate, and generating expectations that the same level for the policy rate would prevail for some time after a macroeconomic recovery. This is implemented in the simulations by assuming that in $2009 \mathrm{Q}$ I the EONIA is brought down immediately to 0.25 percent and there is a promise to

58 See Trichet (2009b).

59 The challenge inherent in forward guidance is well described by Walsh (2009), who argues that instances in which central banks have made explicit use of forward guidance have been characterised by a mixed communication in which the central bank is "simultaneously promising to keep interest rates low for an extended period while also promising to prevent inflation from rising. ... In fact, the point of committing to low rates in the future is precisely because this will generate expectations of inflation. ... it is inconsistent to commit to low interest rates and stable inflation. " (see, p. 13). Thus, rather than promising higher future inflation, policymakers seem to be concerned that inflation expectations remain anchored. Mishkin (2009) strongly argues that even in a financial crisis it is imperative to maintain expectations well anchored.

60 See, Trichet (2009).

61 We make use of the same procedure as Section 3 to generate the predictive distribution and to identify the subset of shocks that we consider as 'demand' shocks.

62 For illustrative purposes, the zero bound is not enforced when simulating the dotted line. 
keep it low also after the rate prescribed by the standard policy reaction function has returned to positive values. The dashed line in the upper-right panel of Figure 4.9 illustrates the new policy path. Assuming that this commitment is fully credible, our results confirm the finding in the literature that forward guidance about the future path of interest rates can be very effective in forestalling deflationary risks and preserving macroeconomic stability in face of adverse demand shocks. ${ }^{63}$

In a third step we ask the question: What is going to happen in case, after a few quarters, the realisation of the non-policy shocks turned out to be less severe than initially expected? In practice, we assume that as of 2009 Q3 the realisation of shocks is exactly the same as the one that actually hit the euro area (as identified by the model) rather than the one used in the simulations in the second step above. Note that the historical shocks are strong and adverse, but less adverse than the ones used in the simulations behind the dotted line in the upper panels of Figure 4.9. The solid thick line in the lower panels of Figure 4.9 represents the outcome with historical shocks fed into the model starting in 2009Q3 and the policy commitment to low rates is maintained. This represents a case where commitment is "mis-understood" as an unconditional commitment: monetary policy maintains interest rates low despite a less adverse macroeconomic evolution in order to make good on past promises. The central bank sticks to its low policy rate to avoid "disappointing" expectations. The results show that the upward movement in inflation could have been dramatic. The disorderly surge in inflation is explained by the fact that the impact coming from less adverse shocks is compounded by the policy commitment to maintain rates low.

The final step of our simulations shows the outcome in case the central bank does not tolerate such a surge in inflation and reacts strongly to restore price stability. The outcome of this policy is shown by the dotted line in the lower panels. This leads to a long lasting recession making monetary policy an independent source of startstop dynamics that introduces high volatility in economic activity and may be detrimental for central bank credibility. Overall, the analysis suggests that possible complications arising at the time of exit are an essential dimension to factor in when designing the preferred types of non-standard measures to adopt in face of a financial crisis and increasing risks to price stability.

\section{Conclusion}

The financial crisis has led to a rethinking of monetary policy frameworks. In this paper, we investigate some features of the ECB's monetary policy strategy and the ECB's monetary policy response to the financial crisis against the background of economic and financial developments in the euro area over the last fifteen years. While the volatility of headline inflation and economic activity has increased quite dramatically over the past three crisis years, underlying inflation and medium-term inflation expectations have remained closely anchored to the ECB's definition of price stability, even during the financial crisis. During the decade prior to the financial crisis low and stable inflation and low volatility in economic activity co-existed with highly procyclical asset prices and money and credit developments. The low real and nominal volatility and the falling external finance premia led to secular rise in private debt, which itself contributed to the sharpness of the correction in the most recent recession. The strong anchoring of medium-term inflation expectations, on the other hand, contributed to limiting the consequences of the adverse financial shocks.

The boom-bust nature of the financial system over the past fifteen years and the high cost of the recent financial crisis have challenged the so-called Jackson Hole consensus that central banks should only react to asset prices and financial imbalances to the extent that they affect the short-term inflation forecast. Using the fully-specified structural model of Christiano, Motto and Rostagno (2010), we investigate this proposition. We first show that both supply side and financial developments have been important drivers of business cycle and

63 See, Eggertsson and Woodford (2003). Levin et al (2010) show however that even under commitment forward guidance may not be sufficient to preserve macroeconomic stability, depending on the persistence of the shocks and output elasticity to the interest rate. 
asset price fluctuations in the euro area. As argued by Christiano et al (20l0b), supply developments complicate the appropriate setting of monetary policy because they typically require a procyclical rise in the equilibrium real interest rate at a time when price developments point in the opposite direction. One lesson from the precrisis period is that an excessive focus on short-term inflation developments may exacerbate the boom-bust behaviour driven by expectations of productivity developments. This argues for a more medium-term orientation of monetary policy strategies focused on an analysis of the various sources of inflation developments and their medium-term implications. Using counterfactual policy simulations, we then argue that in line with the ECB's monetary policy strategy responding to credit developments helps stabilising both inflation and output. This is particularly true in the face of business cycle fluctuations that are driven by supply and financial developments. A second lesson is, therefore, that monetary policy strategies should allow for an enhanced role of the analysis of money and credit developments. One important remaining issue is how a monetary policy that leans against financial imbalances interacts with macro-prudential policies.

The great recession has led to an unprecedented use of non-standard monetary policy tools. In this paper, we discuss and evaluate some of the non-standard policy measures the ECB has taken to address the malfunctioning in financial markets. The measures taken under the "Enhanced Credit Support" umbrella aimed to overcome the financial market impairments which were constraining the process of credit creation in spite of the reduction in policy interest rates. We put these measures in the context of the academic literature and conduct a preliminary assessment of their effectiveness. We find that the ECB intervention was important to avoid disorderly de-leveraging in the banking sector and instrumental in sustaining credit creation and averting downside risks to price stability. Our results are also consistent with the hypothesis that the non-standard measures introduced by the ECB - which, notably, do not include entering commitments regarding the future path of the policy rate - contributed to provide support to the euro area economy. An important lesson from the financial crisis experience is therefore that by taking on a financial intermediation role in markets that are impaired, central banks can complement their more traditional interest rate policy and ensure its proper transmission. These non-standard policies are quite different from policies of quantitative easing which typically aim at substituting for the traditional interest rate policy in an environment where the latter is constrained by the lower bound. 


\section{References}

Adrian, T. and Shin, H.S. (2010), "Financial intermediaries and monetary economics", in Friedman, B. and Woodford, M. (eds.), Handbook Monetary Economics, forthcoming.

Altissimo, F., Ehrmann, M. and Smets, F. (2006), "Inflation persistence and price-setting behavior in the euro area - a summary of the IPN evidence", Occasional Papers Series, 46, European Central Bank.

Altunbas, Y., Gambacorta, L. and Marqués-lbañez, D. (2010), “Does monetary policy affect bank risk-taking?", Working Paper Series No. II66, European Central Bank.

Baumeister, C. and L. Benati (2010), "Unconventional monetary policy and the Great Recession”, mimeo, European Central Bank.

Bean, C., Paustian, M., Penalver, A. and Taylor, T. (2010), "Monetary Policy after the Fall", Federal Reserve Bank of Kansas City Annual Conference, Jackson Hole, Wyoming, August.

Beechey, M. Johansen, B. Levin, A. (2010), "Are Long-Run Inflation Expectations Anchored More Firmly in the Euro Area than in the United States?", Finance and Economics Discussion Series 2008-23, Board of Governors of the Federal Reserve System, May.

Bekaert, G., Hoerova, M. and Lo Duca, M. (2010), "Risk, Uncertainty and Monetary Policy", NBER Working Paper Series No 16397, February.

Benati, L. (2009), "Long-run evidence on money growth and inflation", Working Papers Series No. 1027, European Central Bank.

Benati, L. and Goodhart, C. (2010), "Monetary policy regimes and economic performance: the historical record, 1979-2008", in Friedman, B. and Woodford, M. (eds.), Handbook Monetary Economics, Elsevier, Amsterdam, forthcoming.

Bernanke, B.S. (2004), “The Great Moderation”, Remarks at the meetings of the Eastern Economic Association, Washington, DC.

Bernanke, B.S. and Gertler, M. (1995), "Inside the Black Box: The Credit Channel of Monetary Policy Transmission”, Journal of Economic Perspectives, American Economic Association, vol. 9(4), pages 27-48.

Bernanke, B.S. and Gertler, M. (200I), "Should Central Banks Respond to Movements in Asset Prices?", American Economic Review, 9 I (2), pp. 253-257.

Bernanke, B.S., Gertler, M. and Gilchrist, S. (1999), "The financial accelerator in a quantitative business cycle framework", in Taylor, J.B. and Woodford, M. (eds.), Handbook Macroeconomics, Elsevier, Amsterdam, pp. 1341-1393.

Bernanke, B.S. and I. Mihov (1998), "Measuring monetary policy", Quarterly Journal of Economics II3, pp. 869902.

Blanchard, O. and Simon, J. (200I), "The long and large decline in U.S. output volatility", Brookings Papers on Economic Activity, vol. 32(I), pp. 135-174.

Blinder, A. and Reis, R. (2005), "Understanding the Greenspan Standard", in Federal Reserve Bank of Kansas City, "The Greenspan Era: Lessons for the Future", Proceedings of the 2005 Jackson Hole Symposium, August, II-96.

Borio, C. and Lowe, P. (2002), "Asset prices, financial and monetary stability: exploring the nexus" BIS Working Papers No II4, July. 
Caballero, R., Hoshi, T. and Kashyap, A. (2005), "Zombie Lending and Depressed Restructuring in Japan", mimeo.

Cassola, N., Durré, A. and Holthausen, C. (2010), "Implementing monetary policy in the crisis times: the case of the ECB", ECB Central Banking Conference, Frankfurt, November.

Cecchetti, S.G. (1995), "Distinguishing theories of the monetary transmission mechanism", Proceedings, Federal Reserve Bank of St. Louis, issue May, pages 83-97.

Cecchetti, S. Genberg, H. Lipsky, J. and Wadhwani, S. (2000), "Asset Prices and Central Bank Policy", Geneva Report on the World Economy 2, CEPR and ICMB.

Christiano, L.J., Eichenbaum, M. and Evans, C. (2005), "Nominal rigidities and the dynamic effects of a shock to monetary policy”, Journal of Political Economy, Vol. I I3, pp. I-45.

Christiano, L.J., Motto, R. and Rostagno, M. (2003), "The Great Depression and the Friedman-Schwartz Hypothesis", Journal of Money, Credit and Banking, 35(6), pp. III9-II98.

Christiano, L.J., Motto, R. and Rostagno, M. (2007), "Shocks, structures or policies? The euro area and the US after 200I”, Journal of Economic Dynamics and Control, 32(8), pp. 2476-2506.

Christiano, L.J., Motto, R. and Rostagno, M. (2010), "Financial factors in economic fluctuations”, Working Paper Series, No I192, European Central Bank.

Christiano, L.J., Ilut, C., Motto, R. and Rostagno, M. (2010b), "Monetary policy and Stock Market Booms", NBER Working Paper Series, No 16402. Presented at Federal Reserve Bank of Kansas City Annual Conference, Jackson Hole, Wyoming, August.

Ciccarelli, M., Maddaloni, A. and Peydro, J.-L. (2010), "Trusting the bankers: a new look at the credit channel of monetary policy”, Working Paper Series No 1228, European Central Bank.

Cúrdia, V. and Woodford, M. (2010), "The Central-Bank Balance Sheet as an Instrument of Monetary Policy", NBER Working Papers 16208.

Detken, Gerdesmeier and Roffia (2010), "Interlinkages between money, credit and asset prices and their implications for consumer price inflation: recent empirical work”, in Papademos, L.D. and Stark, J. (eds.), Enhancing Monetary Analysis, European Central Bank, Frankfurt.

Detken, C. and Smets, F. (2004), "Asset price booms and monetary policy", Working Paper Series No 364, European Central Bank.

ECB (2003), "The Outcome of the ECB's Evaluation of its Monetary Policy Strategy”, Monthly Bulletin Article, June, pp. 79-92.

ECB (2004), “The Monetary Policy of the ECB”, European Central Bank, Frankfurt.

ECB (2005), “Asset Price Bubbles and Monetary Policy”, Monthly Bulletin Article, April, pp. 47-60.

ECB (2006), “Monetary Policy 'Activism”, Monthly Bulletin Article, November, pp. 67-8I.

ECB (2008), "The Eurosystem's open market operations during the recent period of financial market volatility", Monthly Bulletin Article, May, pp. 89-104.

Eggertsson, G.B. and Woodford, M. (2003), "Zero Bound on Interest Rates and Optimal Monetary Policy", Brookings Papers on Economic Activity 2003:I, pp. 139-233.

Ehrmann, M., Eijffinger, S. and Fratzscher, M. (2010), "The role of central bank transparency for guiding private sector forecasts”, Working Paper Series No I 146, European Central Bank.

Galati, G., Poelhekke, S. and Zhou, C. (2009), "Did the crisis affect inflation expectations?" DNB Working Papers 222, Netherlands Central Bank, Research Department. 
Gertler, M. and Kiyotaki, N. (2010), "Financial Intermediation and Credit Policy in Business Cycle Analysis", mimeo.

Gorton, G.B. (2009), "Information, liquidity and the (ongoing) panic of 2007", American Economic Review, 99(2), pp. 567-572.

Greenspan, A. (2004), "Risk and Uncertainty in Monetary Policy", American Economic Review, Papers and Proceedings, 94, 33-40.

Heider, F. and Hoerova, M. and Holthausen, C. (2009), "Liquidity Hoarding and Interbank Market Spreads: The Role of Counterparty Risk", Working Paper Series No I I26, European Central Bank.

Hördahl, P. and Tristani, O. (2010), "Inflation risk premia in the term structure of interest rates", Journal of the European Economic Association, forthcoming.

Hördahl, P., Tristani, O. and Vestin, D. (2006), "A joint econometric model of macroeconomic and termstructure dynamics", Journal of Econometrics, I3I, pp 405-444.

Issing, O. (2002), "Monetary Policy in a Changing Economic Environment", speech delivered at the symposium on 'Rethinking Stabilisation Policy' sponsored by the Federal Reserve Bank of Kansas City, Jackson Hole, Wyoming, August.

Jiménez, G., Saurina Salas, J., Ongena, S. R. G. and Peydro , J.-L., (2009), "Hazardous Times for Monetary Policy: What Do Twenty-Three Million Bank Loans Say about the Effects of Monetary Policy on Credit RiskTaking?", AFA 2009 San Francisco Meetings Paper.

Lenza, M., Pill, H. and Reichlin, L. (2010), "Monetary Policy in Exceptional Times”, CEPR Working Paper No 7669, January.

Levin, A., López-Salido, D., Nelson, E., and Yun, T. (2010), "Limitations on the Effectiveness of Forward Guidance at the Zero Lower Bound", International Journal of Central Banking, Vol. 6(I), March.

Lucas, R.E. (1995), “Monetary Neutrality”, Nobel Prize Lecture.

McConnell, M.M. and G. Perez-Quiros (2000), "Output Fluctuations in the United States: What Has Changed since the Early 1980's?", American Economic Review, American Economic Association, vol. 90(5), pages |464-|476, December.

Mishkin, F.S., "Monetary Policy Strategy: Lessons from the Crisis”, ECB Central Banking Conference, Frankfurt, November 2010.

Orphanides, A. (2010), "Monetary policy lessons from the crisis", colloquium in honour of Lucas D. Papademos, Frankfurt, May 2010.

Papademos, L.D. and Stark, J. (eds.), (2010), “Enhancing Monetary Analysis”, European Central Bank, Frankfurt.

Poole, W. (1970), "Optimal Choice of Monetary Policy Instruments in a Simple Stochastic Macro Model”, The Quarterly Journal of Economics, vol. 84(2), pages 197-216, May.

Rajan, R.G. (2005), “Has Financial Development Made the World Riskier?”, in The Greenspan Era: Lessons for the Future, 313-370, Federal Reserve Bank of Kansas City, Kansas City.

Reinhart, C. and Rogoff, K. (2008), "This time is different: eight centuries of financial folly", Princeton University Press.

Reinhart, C. and Rogoff, K., (2008), "This Time Is Different: Eight Centuries of Financial Folly", Princeton University Press.

Smets, F. (2010), "Comments on Geraats and Neumann", in Buti et al (eds.), The Euro - The First Decade, Cambridge University Press. 
Smets, F. and Wouters, R. (2003), "An estimated stochastic general equilibrium model of the euro area", Journal of the European Economic Association, Vol. I, pp. I I 23-I I 75.

Smets, F. and Wouters, R. (2007), "Shocks and frictions in US business cycles: A Bayesian DSGE approach", American Economic Review, 97(3), pp. 586-606.

Stark, J. (2010), “Enhancing the ECB's Monetary Analysis: What Have we Learnt?", Speech delivered at the conference 'The ECB and its Watchers X' Frankfurt am Main.

Stock, J. H. and Watson, M. W. (2003), "Has the Business Cycle Changed and Why?", NBER Chapters, in: NBER Macroeconomics Annual 2002, vol. 17, p. 159-230.

Trichet, J.-C. (2004), "Key issues for monetary policy: an ECB view", Keynote address at the National Association of Business Economics Philadelphia, October.

Trichet, J.-C. (2007), "The euro area and its monetary policy", keynote address at the conference 'The ECB and its Watchers IX' Frankfurt am Main.

Trichet, J.-C. (2008), "Risk and the Macro-economy", keynote address at the conference 'The ECB and its Watchers X' Frankfurt am Main.

Trichet, J.-C. (2009), "Credible Alertness Revisited", speech delivered at the symposium on 'Financial stability and Macroeconomic Policy' sponsored by the Federal Reserve Bank of Kansas City, Jackson Hole, Wyoming, August.

Trichet, J.-C. (2009b), "The ECB's Exit Strategy", Keynote address at the conference 'The ECB and its Watchers $X$ ', Frankfurt am Main.

van Ewijk, C., de Groot, H.L.F. and Santing, C. (2010), “A Meta-Analysis of the Equity Premium”, Tinbergen Institute Discussion Papers 10-078/3.

Walsh, C.E. (2009), “Inflation Targeting: What Have We Learned?", International Finance, vol. I2(2), pp. 195233.

White, W. (2006), "Is price stability enough?", BIS Working Papers No. 205, April.

Woodford, M. (2003), "Interest and Prices: Foundations of a Theory of Monetary Policy", Princeton University Press. 


\section{Annex}

\section{The DSGE Model and the Methodology}

The DSGE model used in the paper to interpret the data and carry out counterfactual simulations is taken from CMR (2010). The CMR model builds on the DSGE model developed by Christiano, Eichenbaum and Evans (2005) and Smets and Wouters (2003) and is extended by including the credit market, bankruptcies, money holding decisions and a liquidity-creating banking sector. The presence of a profit-maximising banking sector extending credit, operating a fractional-reserve-based transformation of base money into deposits and issuing short-term securities to finance capital formation allows for including a broad array of monetary aggregates and financial prices in the empirical analysis. The model is estimated using Bayesian methods on data spanning the 1985-2008 period for the euro area. In the estimation 16 variables are treated as observables, spanning from standard macroeconomic variables to monetary and financial variables such as the stock market, a measure of the external finance premium, credit, $\mathrm{MI}$ and $\mathrm{M} 3$, the outstanding stock of refinancing operations with the Eurosystem, ${ }^{64}$ and the spread between the ten-year bond rate and the short-term interest rate. CMR (2010) shows that the model is capable to reproduce the dynamic correlations of macroeconomic, monetary and financial variables existing in the data, and to be competitive in terms of out-of-sample performance.

The size and composition of banks' balance sheet, which is in itself the result of business decisions by banks interacting with households' and firms' demand for banks' assets and liabilities, can amplify or dampen macroeconomic fluctuations depending on the nature of shocks buffeting the economy. Another key finding is that shocks originating in the financial system and money creation activity of banks can become an independent source of macroeconomic fluctuations. In particular, three shocks that alter conditions in credit and liquidity markets are found to be important. The first shock represents exogenous changes to the cross-sectional dispersion of borrowers' returns. By making the uncertainty about the borrowers' worthiness vary over time, this shock plays an important role in generating positive correlation between economic activity, credit and other financial variables. The second shock alters directly the amount of net worth at the disposal of borrowers. Both shocks have a realised and an anticipated "signal" component. Each period economic agents observe the present realisation and receive signals that update their perceptions of the future evolution of these shocks. The realised and anticipated components have different macroeconomic implications. Anticipated shocks can generate expected excess returns that rise (or decline) in a sustained manner over time. The process of updating expectations has also the implication that new signals reinforce or counteract (depending on their sign) previously received signals. This sets in motion waves of accumulation and decumulation of capital, credit and money that resemble typical economic fluctuations.

The third type of shocks originating within the financial and liquidity side of the economy is related to banks' access to complementary forms of funding in the model: the issuance of checkable deposits included in MI, the issuance of other short-term deposits and marketable securities (M3-MI), and central bank refinancing. In particular, it is found that a shock changing banks' desire for safe assets in the form of central bank liquidity has exerted significant downward impact on economic activity over the recent financial crisis. In the model safe assets are held in banks' balance sheet to withstand unexpected withdrawals of funds, they thereby ensure continuity in banking activity and are productive for the banking sector. Figure A provides an illustration of the transmission mechanism of such a shock. A lower demand for liquidity buffers by banks generates an increased balance-sheet capacity and a greater scope for expanding loan supply. This exerts expansionary effects on real economic activity and upward pressure on inflation. This impulse is not triggered by central bank decisions to change the policy rate, but finds its source within banks' funding activity itself.

64 For the years 1985 to 1999, it uses an aggregation of bank reserves held with the central banks of Germany, France, Portugal, Spain, Italy, the Netherlands and Finland, appropriately rescaled. 


\section{Counterfactual simulations}

Structural models can be used to construct policy scenarios and counterfactuals that try to assess the impact of alternative hypothetical policy actions. Counterfactuals centred around the financial crisis require models that can trace out the transmission mechanism of shocks originating in the financial sphere and that propagate to the rest of the economy. This is a further motivation for the use of the specific DSGE model described above.

The counterfactuals are constructed by using a two-stage approach. In the first stage, the model is used as a filter (two-sided) to recover the underlying shocks in the sample. In case the sample-period relevant for the analysis extends beyond the available historical data and includes a projection horizon, the historical data can be augmented by model-based conditional or unconditional forecasts, or simply by treating forecasts produced outside the model as if they were "data" in sample. Having obtained an estimate of the underlying shocks, in a second stage it is imposed that a given variable, e.g. the policy rate, follows a different path from the historical one. This amounts to carrying out a conditional forecast where the conditioning assumption is met by manipulating the relevant shock. The relevant shock is chosen according to the source of uncertainty that the counterfactual is trying to understand. Then, the time series of all shocks that have been recovered in the first stage is kept unchanged, with the exception of the one for the relevant shock that is adjusted in order to meet the conditioning assumption. Finally, the model is used to trace out the implications of such altered shock path for the other endogenous variables. Counterfactuals are generally carried out by assuming that the altered path of the shock materialises in an unexpected manner. This practice is followed in some of the counterfactuals presented in the paper. However, the paper presents also some simulations based on the assumption that agents know in advance about the new path for the shock. 


\section{Figures}

\section{Section 2}

Figure 2.I. Stable Inflation and Inflation Expectations

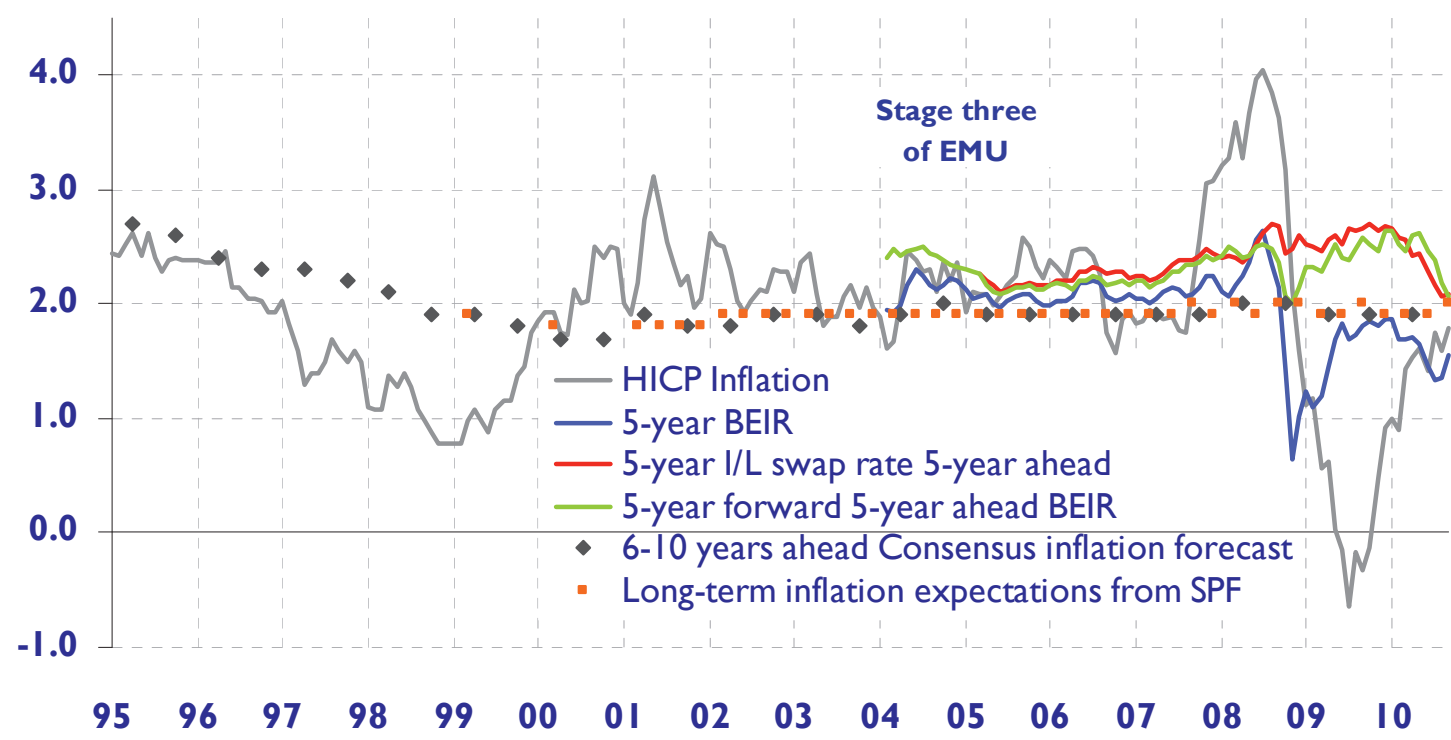

Sources: Consensus, ECB Survey of Professional Forecasters, Eurostat, Reuters, ECB calculations.

Notes: BEIR is Break-Even Inflation Rate from comparison of inflation indexed to conventional sovereign bonds Last observation: September 2010.

Figure 2.2. Inflation Expectations in the euro area and the US
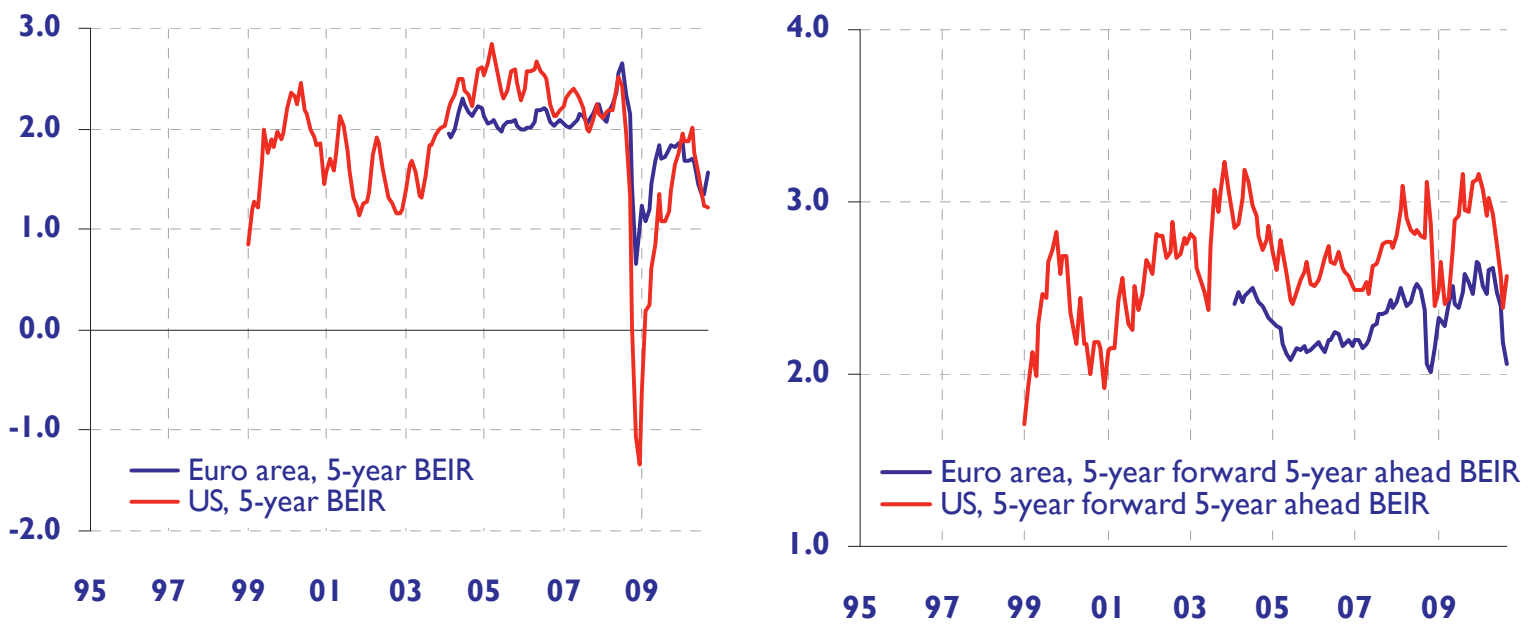

Sources: Federal Reserve, Reuters, ECB calculations.

Notes: BEIR is Break-Even Inflation Rate from comparison of inflation indexed to conventional bonds. 
Figure 2.3. Variance decomposition of Inflation

Euro area

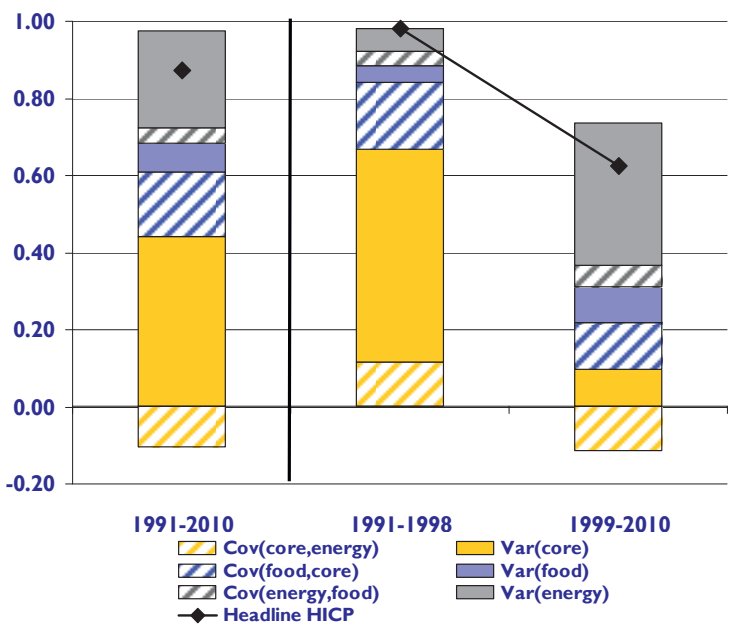

United States

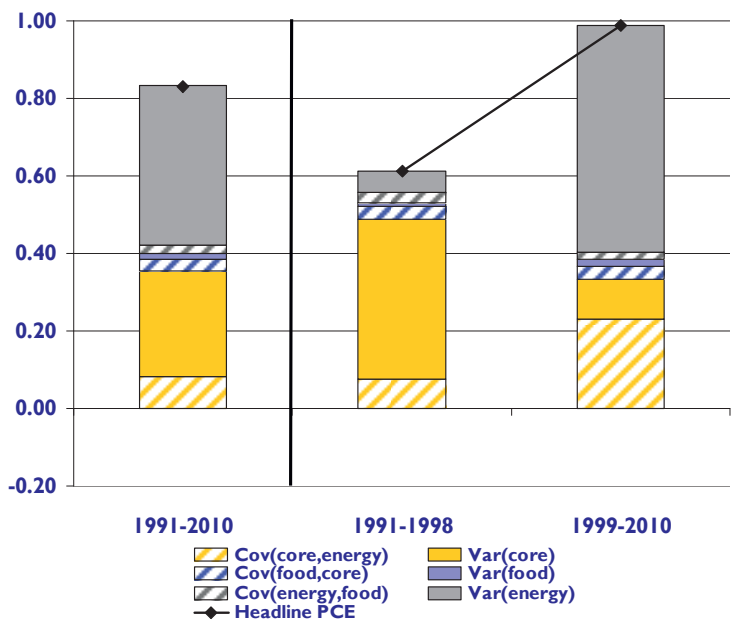

Sources: $B E A, E C B$, Eurostat, Federal Reserve, ECB calculations.

Notes: Inflation refers to HICP inflation for the Euro area and Personal Consumption Expenditure (PCE). Core refers to headline inflation excluding food and energy. Var is variance, Cov is twice the covariance between the respective measures in order to sum up to overall variance of the headline measure.

Figure 2.4. Variance decomposition of inflation over time

\section{Euro area}

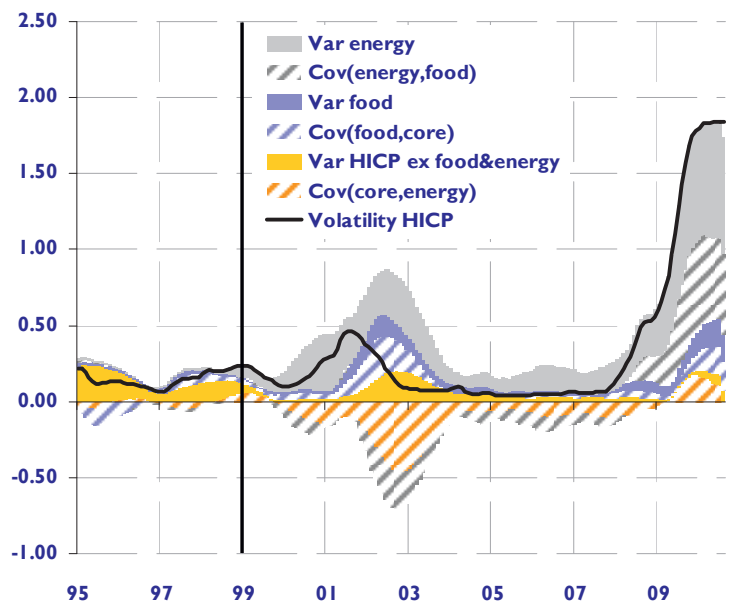

United States

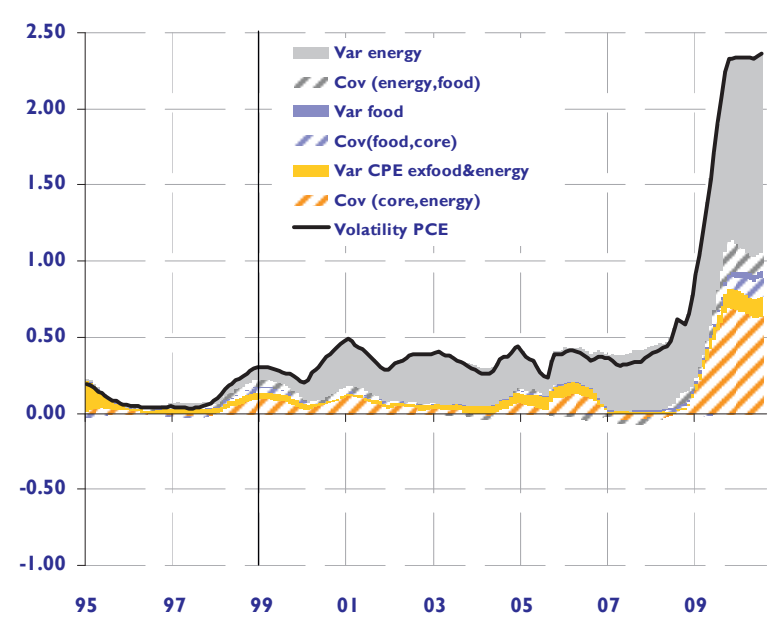

Sources: BEA, ECB, Eurostat, Federal Reserve, ECB calculations.

Notes: The variance is computed as 36-month moving windows. Inflation refers to HICP inflation for the Euro area and Personal Consumption Expenditure (PCE) deflator for the US. Core refers to headline inflation excluding food and energy. Var is variance, Cov is to two times the covariance between the respective measures in order to sum up to overall variance of the headline measure. 
Figure 2.5. Output per capita performance
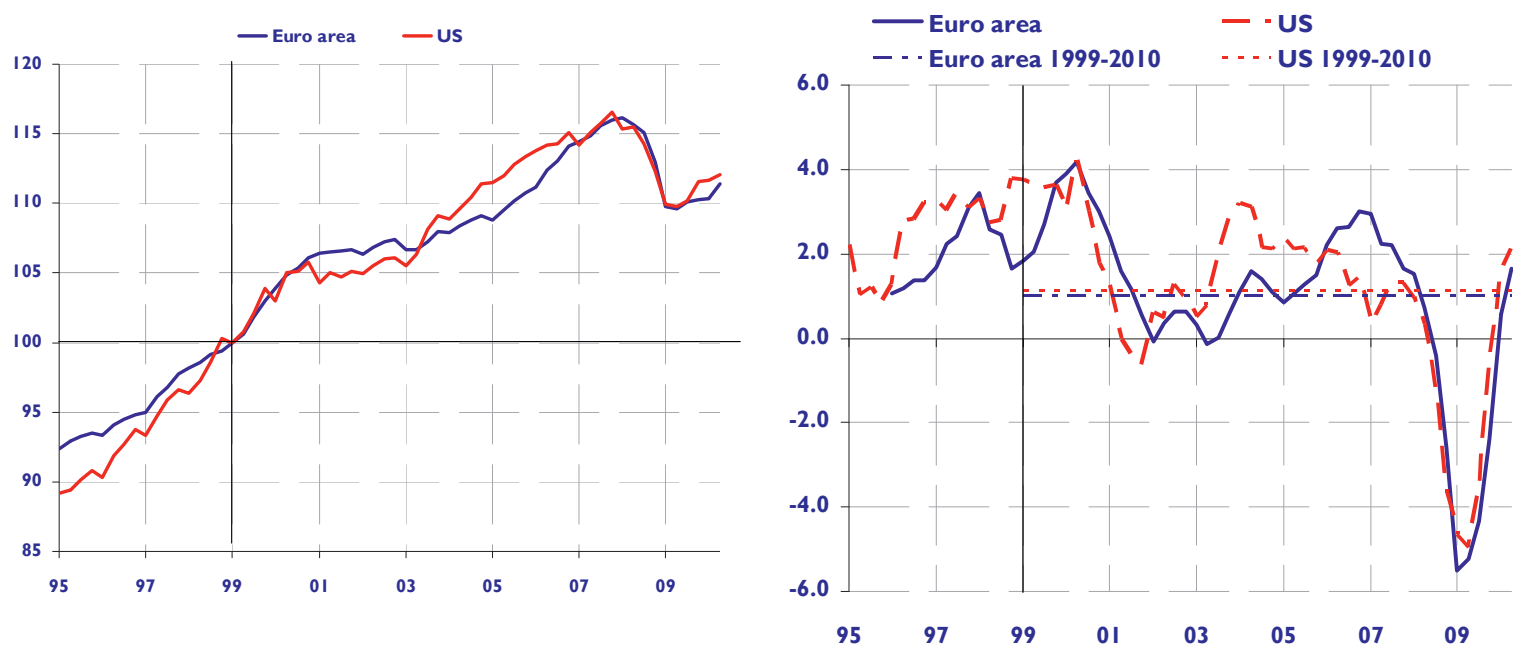

Sources: $B E A$, Eurostat, $E C B$ calculations.

Notes: Output per capita is real GDP divided by total population. Left panel $1999 \mathrm{Q} I=100$, right panel annual percentage changes. Last observation: 2010 Q2.

Figure 2.6. Total Factor Productivity

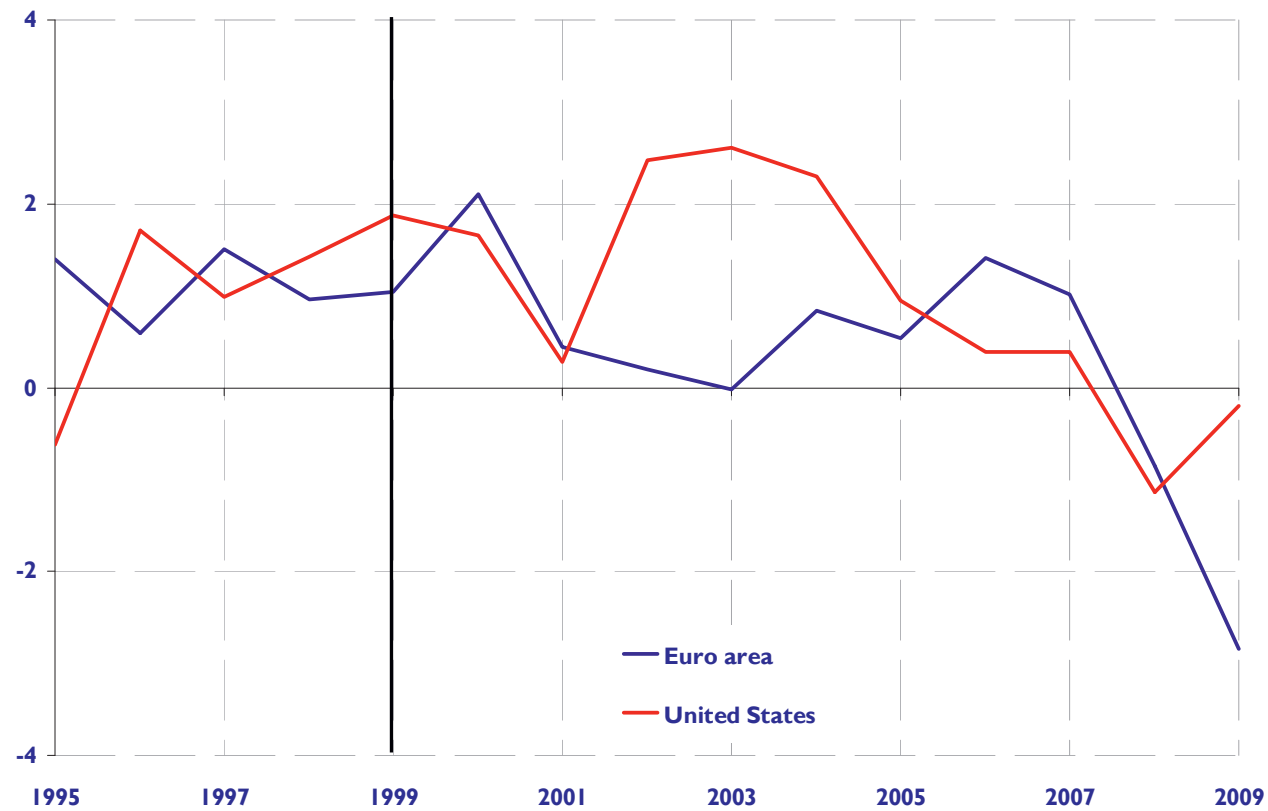

Sources: Basu and Fernald (2009), ECB calculation.

Notes: Total Factor Productivity is obtained from growth accounting taking into account labour and capital quality. 
Figure 2.7. Macro-economic volatility 1999-2010

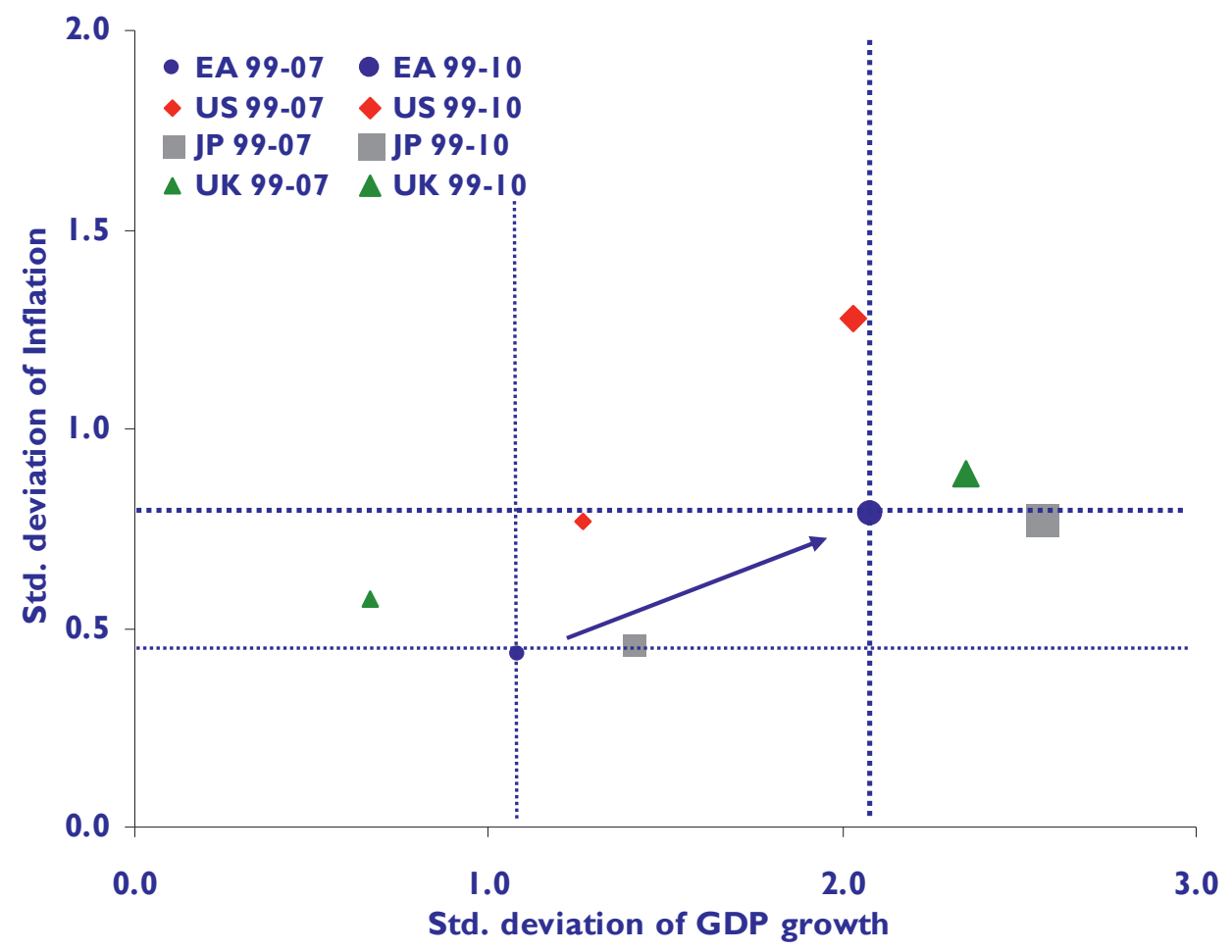

Sources: OECD. Adapted from Benati and Goodhart (2010).

Notes: Inflation is annual CPI inflation, GDP growth is annual real GDP growth.

Figure 2.8. Similar Phillips curves across the euro area and the US

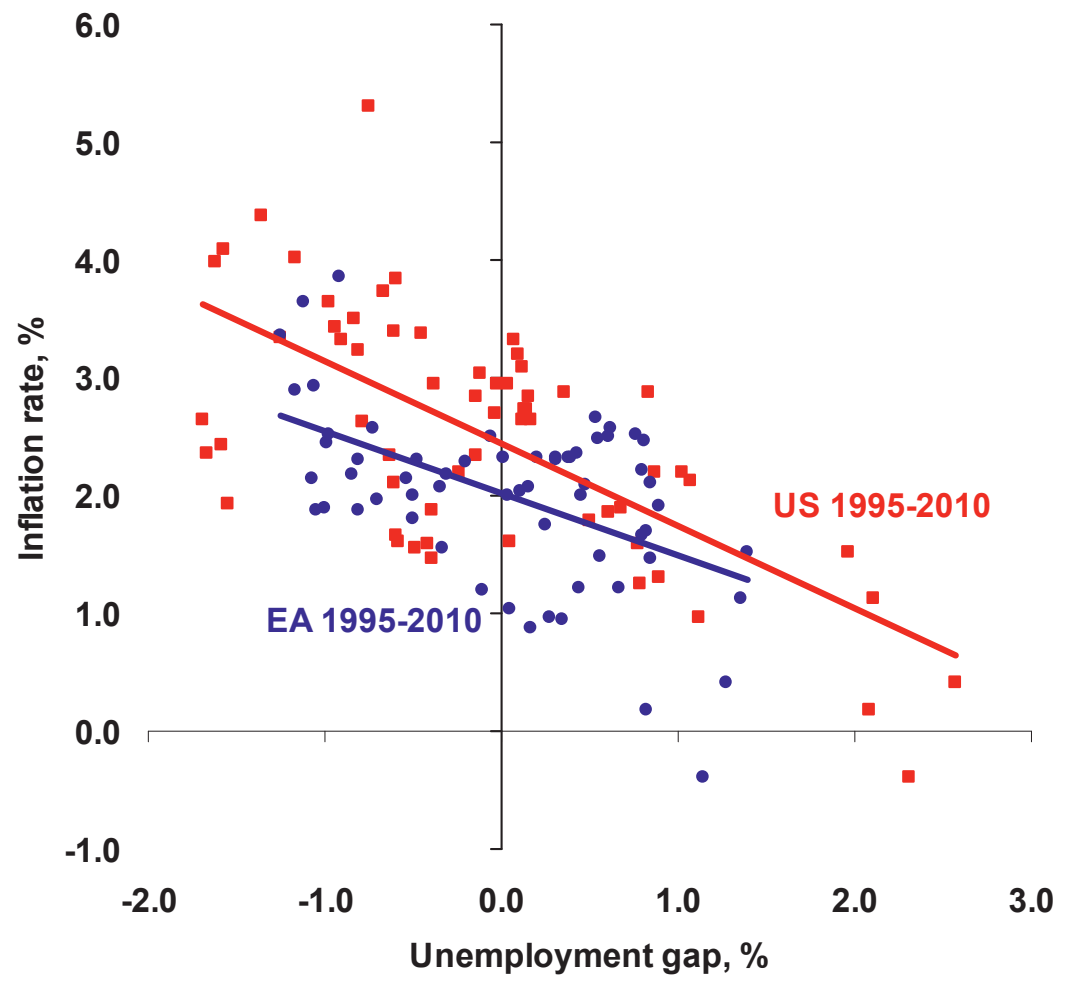

Sources: AWM database (see Fagan et al., 200I), BLS, Eurostat, ECB calculations. Adapted from Anderton and Hiebert (2009)

Note: Inflation is computed using HICP inflation for the euro area and CPI inflation for the US. Unemployment gap computed as difference between unemployment rate and trend unemployment using HP filter(20000). 
Figure 2.9. Macro-economic volatility over time

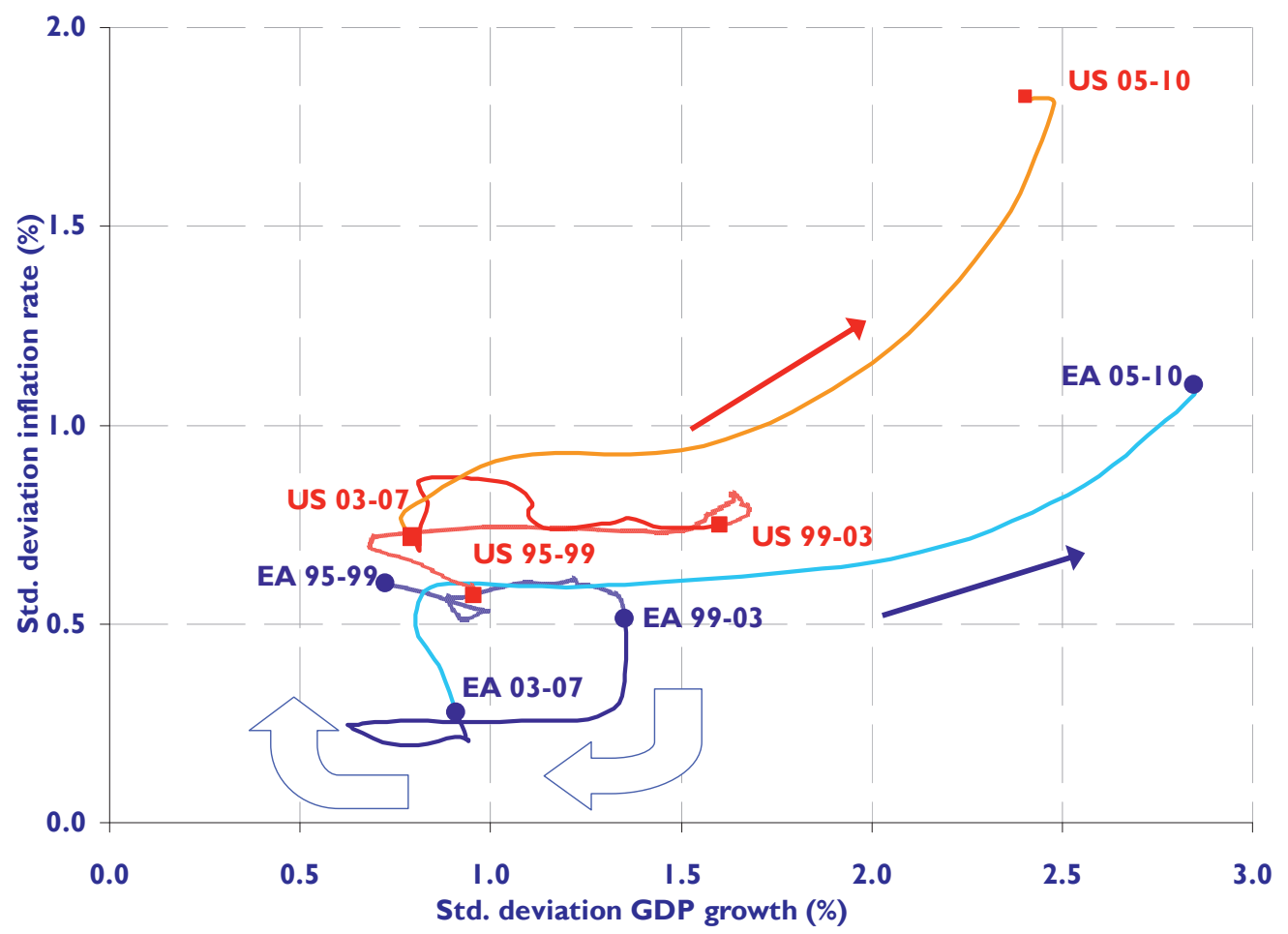

Sources: BEA, BLS, Eurostat.

Note: inflation is HICP for the euro area and CPI for the US.

Figure 2. I0. Aggregate asset prices over nominal GDP

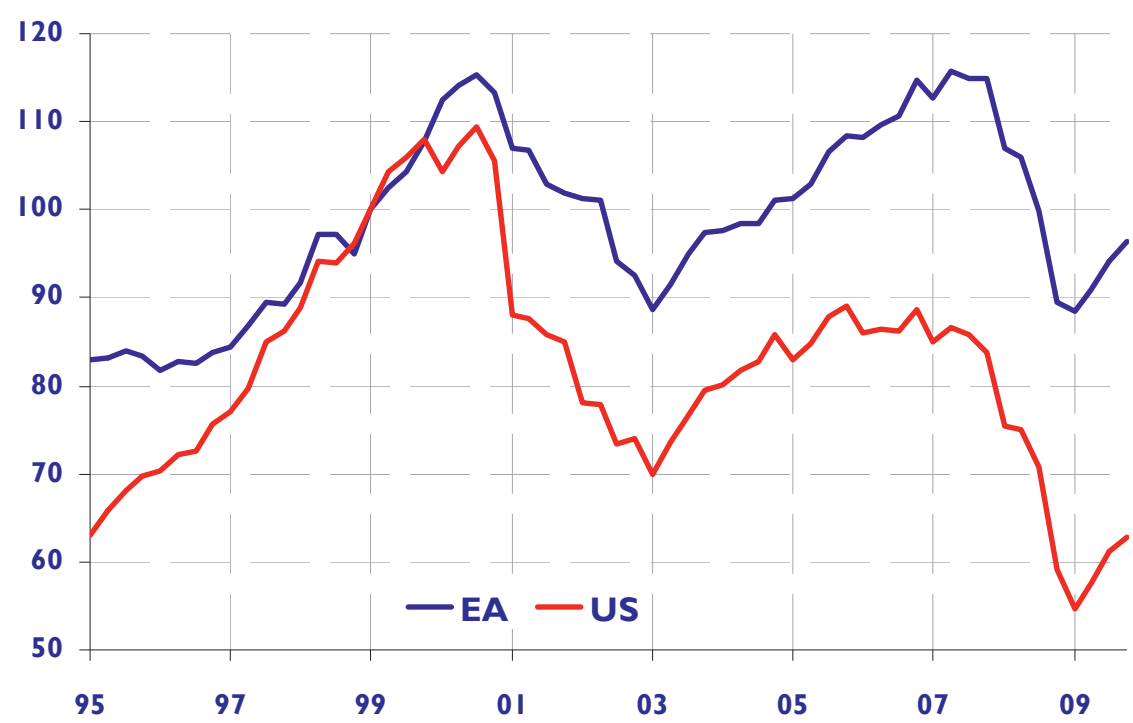

Sources: BEA, BIS calculations based on national data, Eurostat, ECB calculations.

Note: 1999QI=100. The Quarterly Aggregate Asset Price Index encompasses prices for equity, residential real estate and commercial real estate. The euro area index is composed from national series of the eight largest countries (DE, $F R, I T, E S, N L, B E, F I, I E)$ and weighted by their relative real GDP. 
Figure 2.II. Spreads of corporate securities

Euro Area Non-Financial Ccorporations
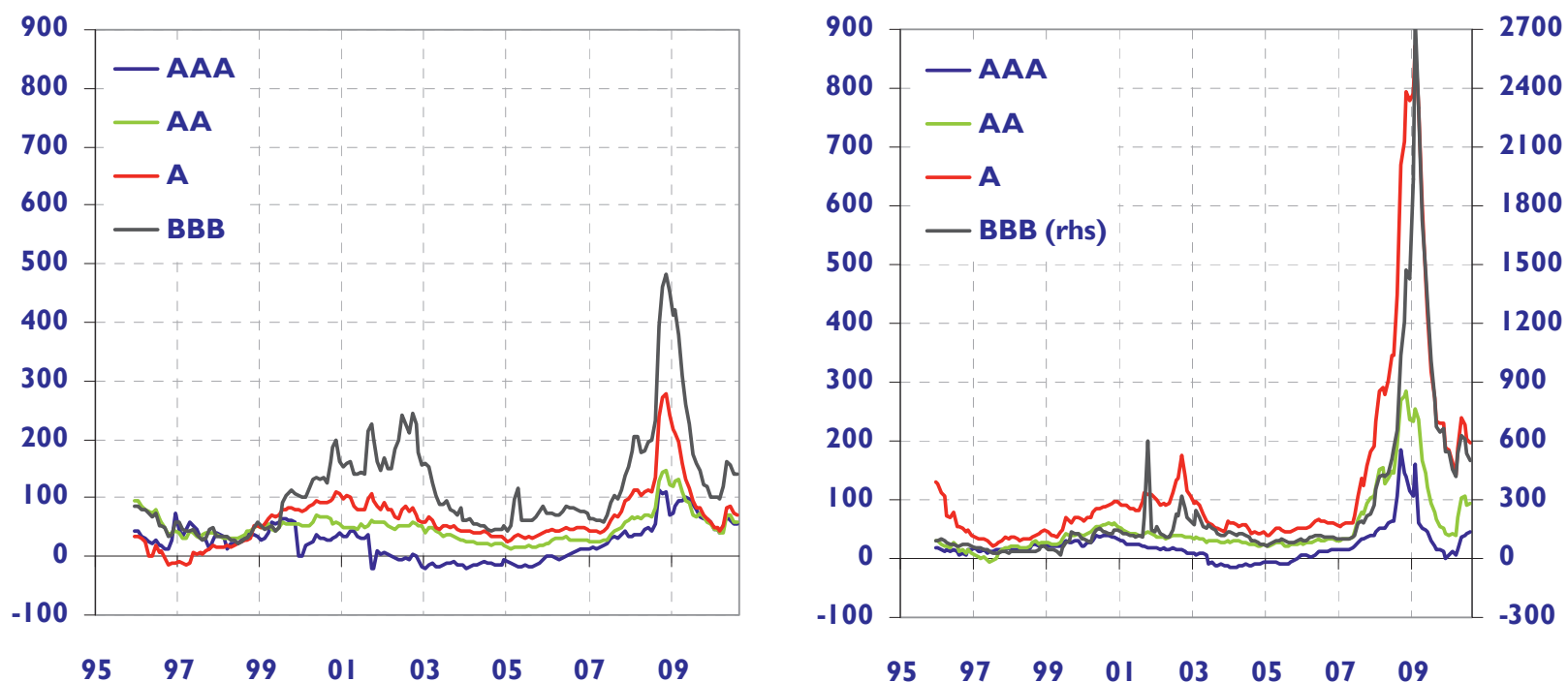

Sources: Thompson Financial Datastream.

Notes: In basis points. Spreads are difference to EMU benchmark AAA government bond index by Merill Lynch.

Figure 2.12. Pro-cyclicality of the financial sector in the euro area

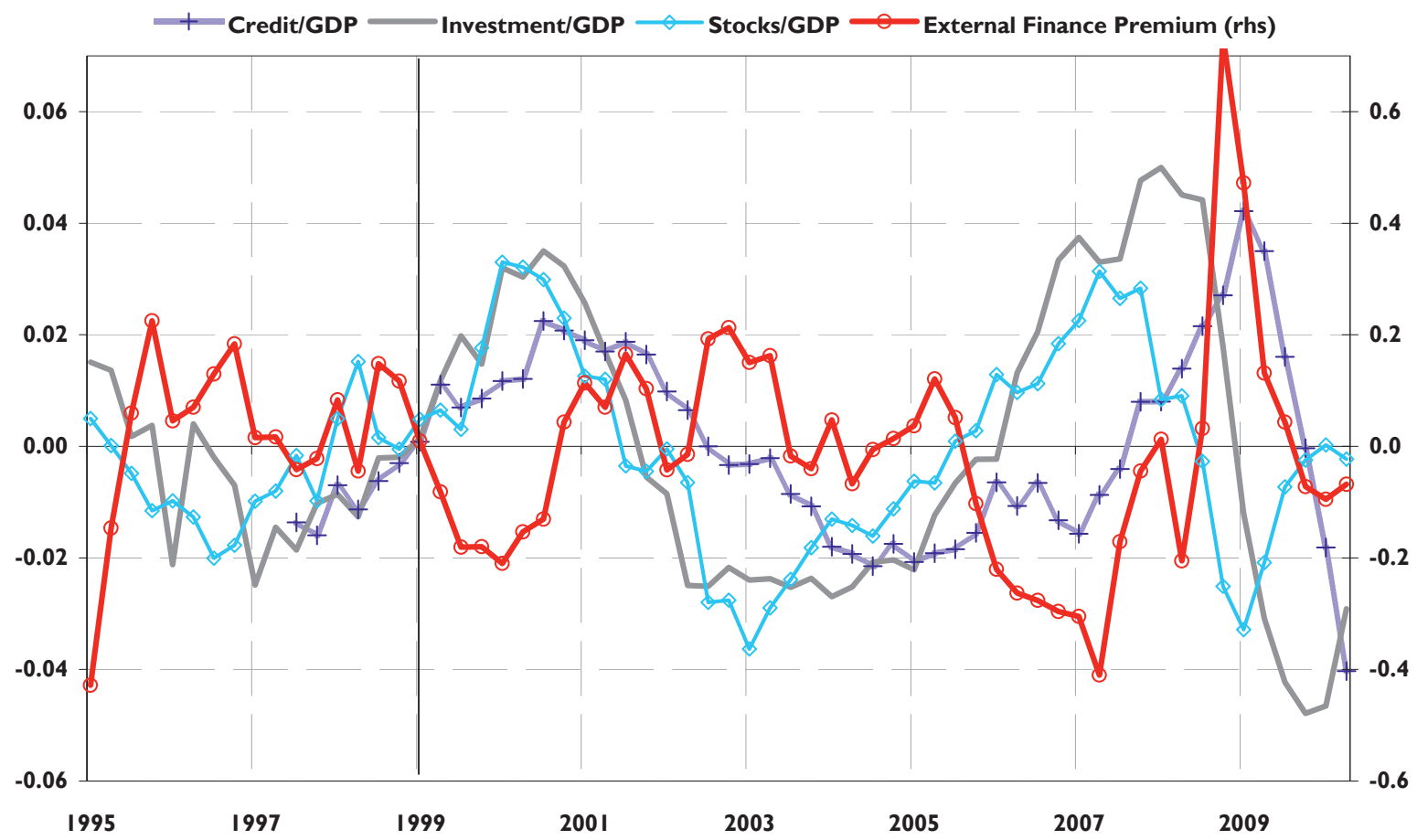

Sources: BSI, Dow Jones, Eurostat, ECB calculations.

Note: All series in percentage deviations from HP(I600)-trend, stocks/GDP rescaled. Credit defined as total MFI loans and securities to NFCs, investment is total private investment, stocks is Dow Jones Euro Stoxx 600 index. The external finance premium is measured as an average of spreads between lending rates, including corporate bond yields, and measures of risk-free rates of corresponding maturities. 
Figure 2.13. Money and external finance premium

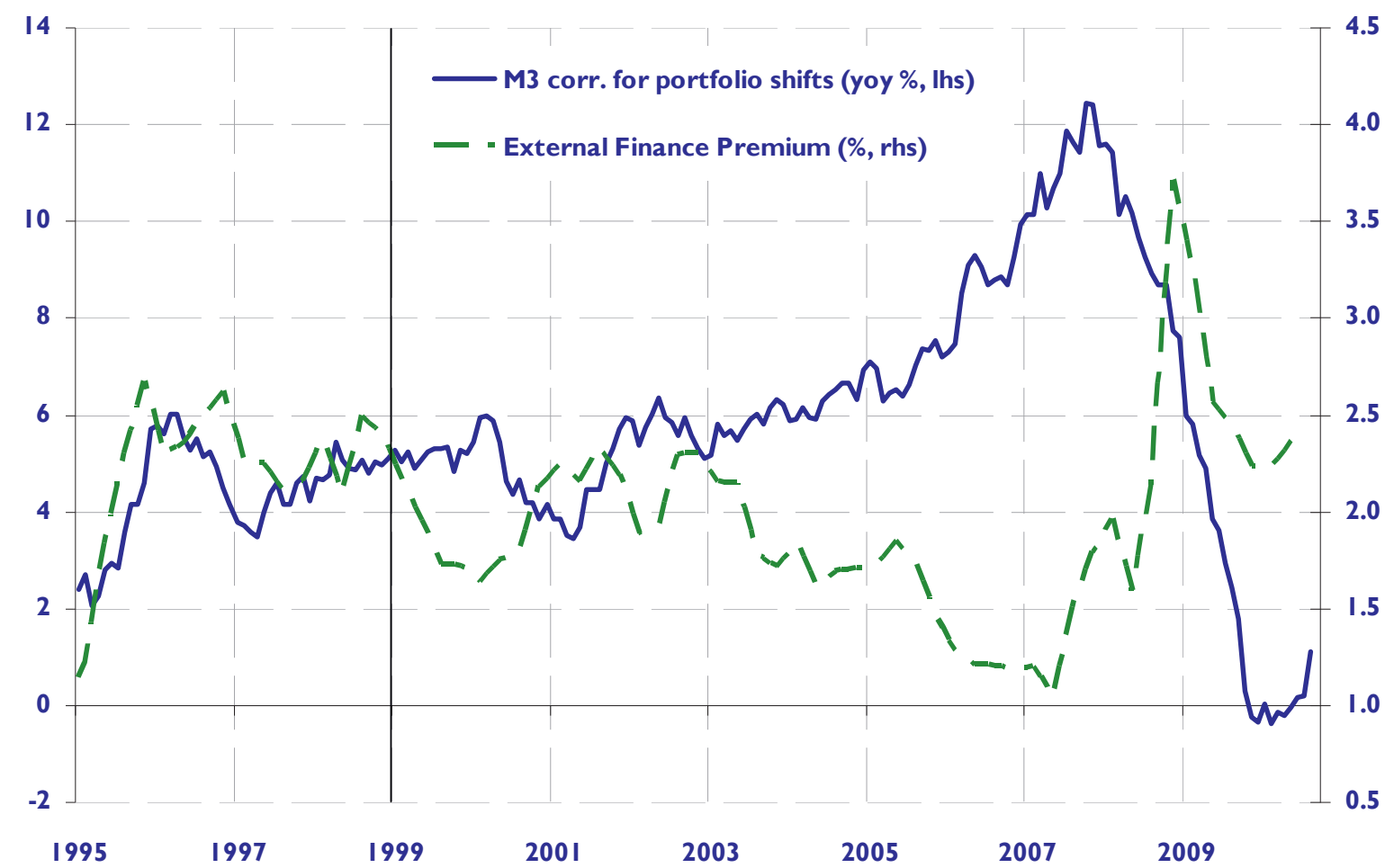

Sources: $B I S, E C B$, Dow Jones, $E C B$ calculations.

Notes: M3 refers to annual growth rates of M3, corrected for portfolio shifts; The external finance premium is measured as an average of spreads between lending rates, including corporate bond yields, and measures of risk-free rates of corresponding maturities, in percentage points.

Figure 2.14. Debt by sector (in percent of GDP)

Euro area (1999-2010)

\section{United States (1950-20 I0)}

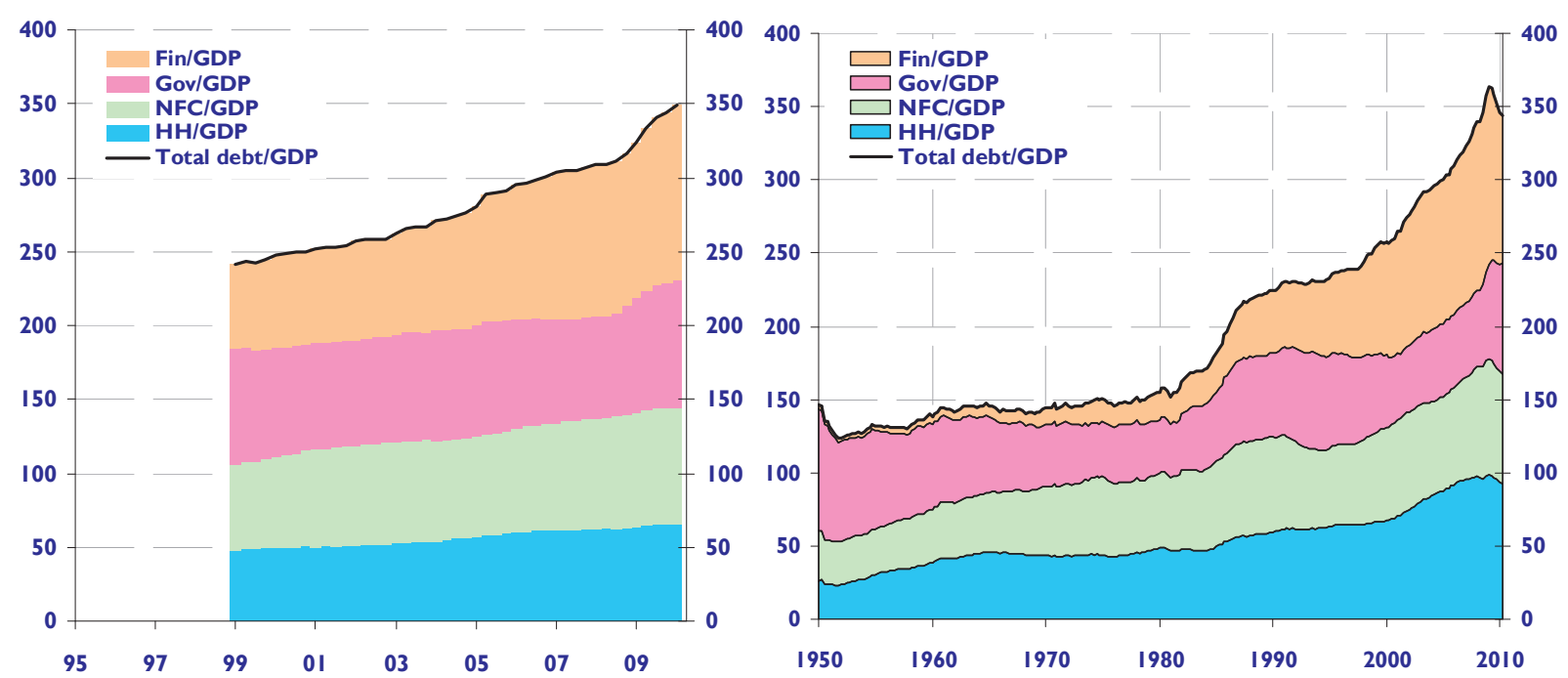

Sources: Quarterly Euro Area Accounts Eurostat, Flow of Funds Federal Reserve, BEA.

Notes: Debt is defined as loans for euro area households (credit market instruments in the US), for NFCs and financial corporations debt is credit, securities excluding equity, and pension liabilities, net of inter-company loans (credit market instruments in the US), debt by governments are loans and securities. 


\section{Section 3}

Figure 3.I Shock Decomposition: GDP Growth (year-on-year percentage change)
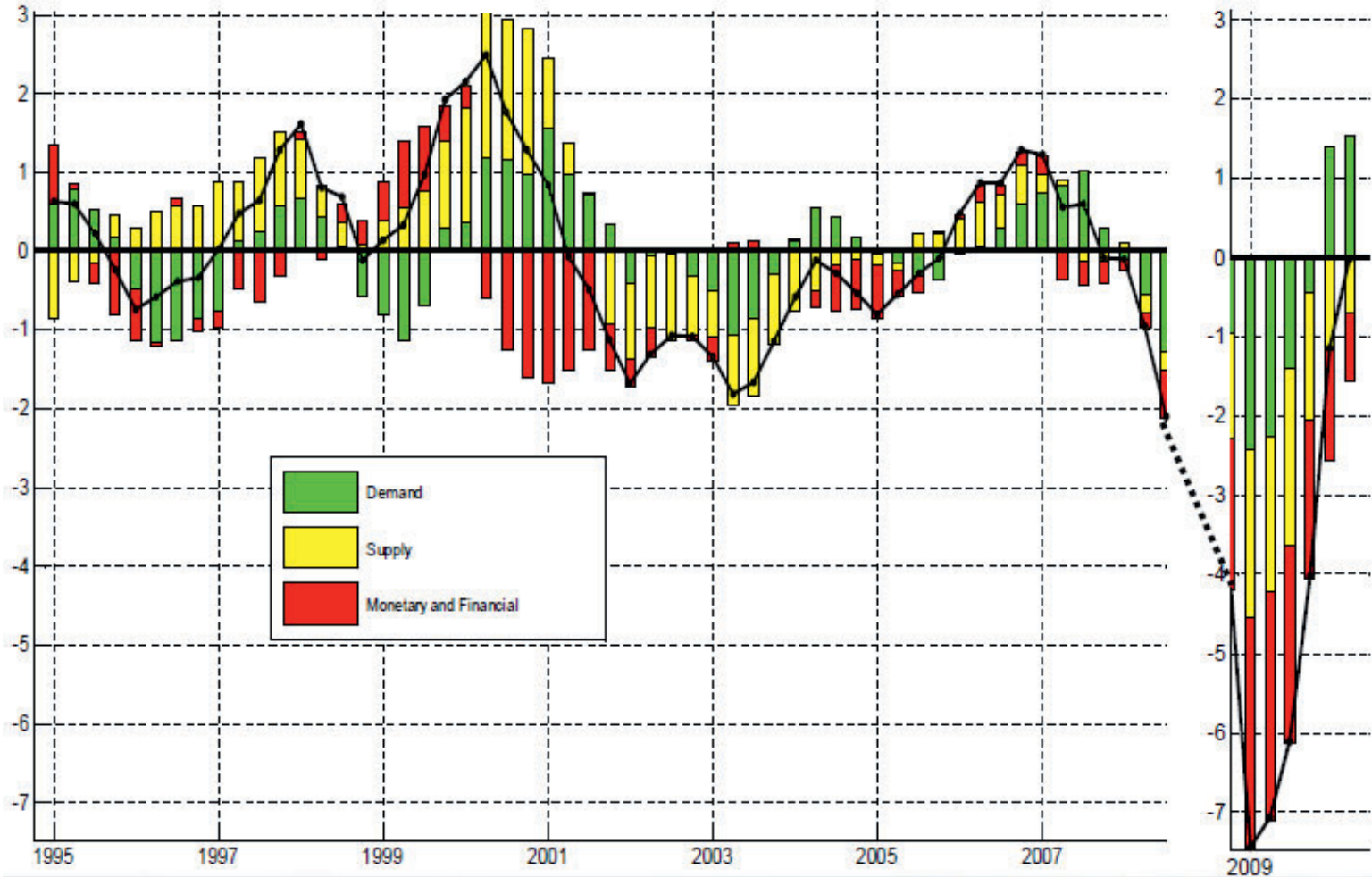

Note: The solid line indicates the deviation of the year-on-year GDP per capita growth rate from its long-run growth path (I.5\%). Each data point is broken down into the contribution from the shocks identified by the model.

Figure 3.2 Shock Decomposition: Inflation (year-on-year percentage change)

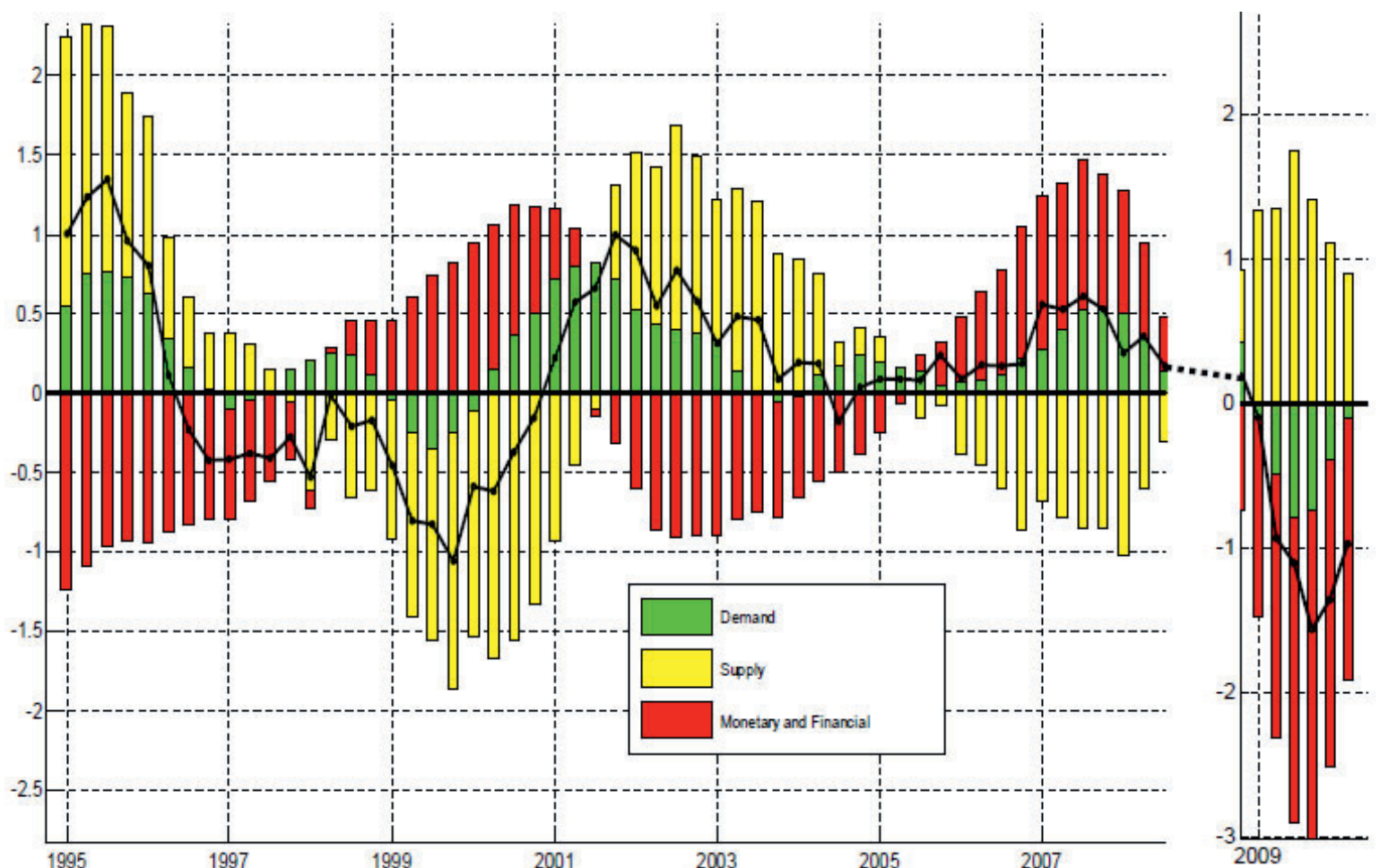

Note: The solid line indicates the deviation of the year-on-year GDP inflation from a point numerical definition of price stability (I.9\%). Each data point is broken down into the contribution from the shocks identified by the model. 
Figure 3.3 Shock Decomposition: Ten-Year Bond / EONIA Spread (percent p.a.)
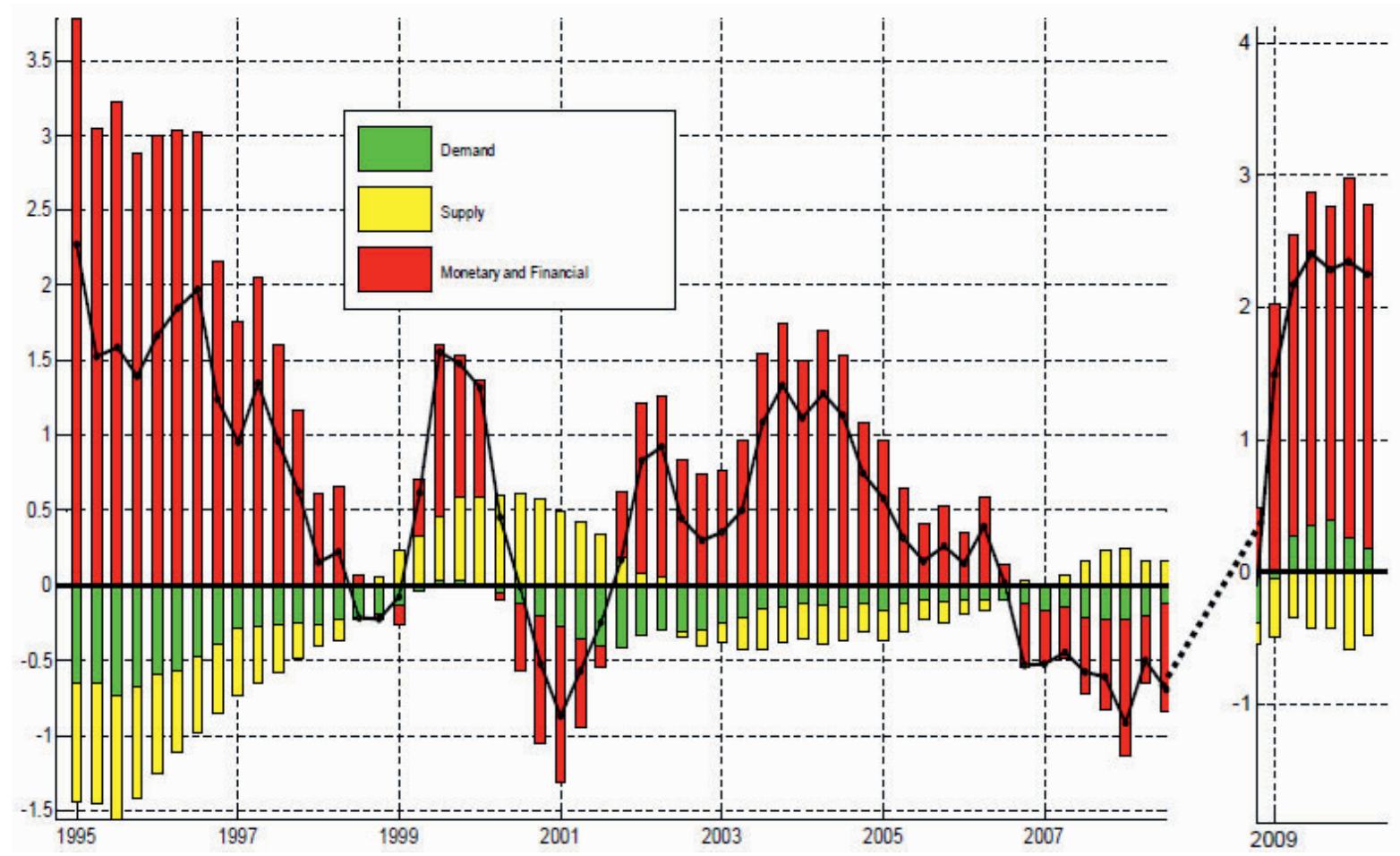

Note: The solid line indicates the deviation of the spread between the ten-year bond rate and the EONIA rate from its long-run average. Each data point is broken down into the contribution from the shocks identified by the model.

Figure 3.4 Shock Decomposition: Credit Risk Premium (percent p.a.)
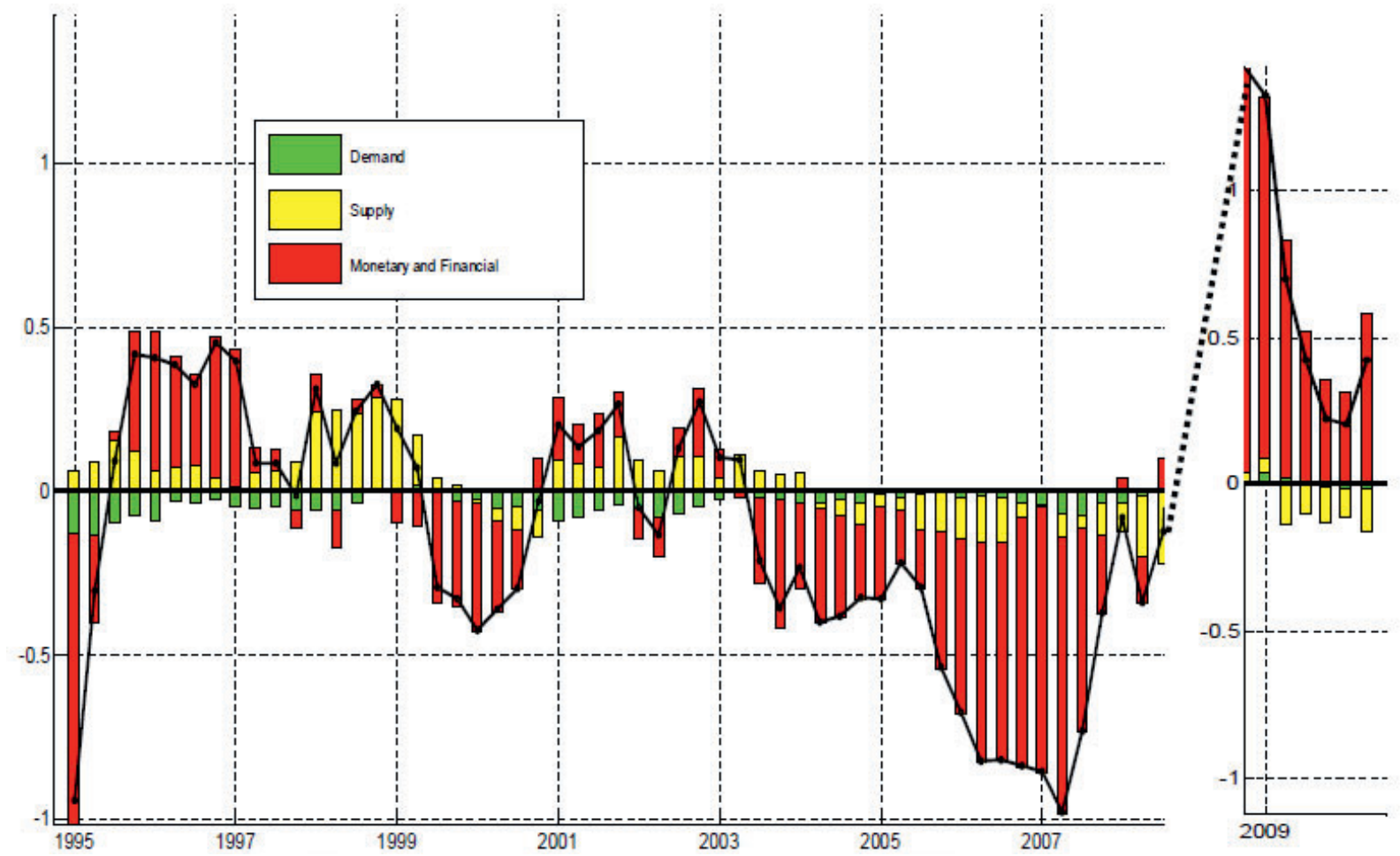

Note: The solid line indicates the deviation of the an average premium paid by borrowers on loans with different maturities over and above the risk-free interest rate with the same maturity from its long-run average. 
Figure 3.5 Stochastic Simulations: Inflation Looking Forward (year-on-year percentage changes)
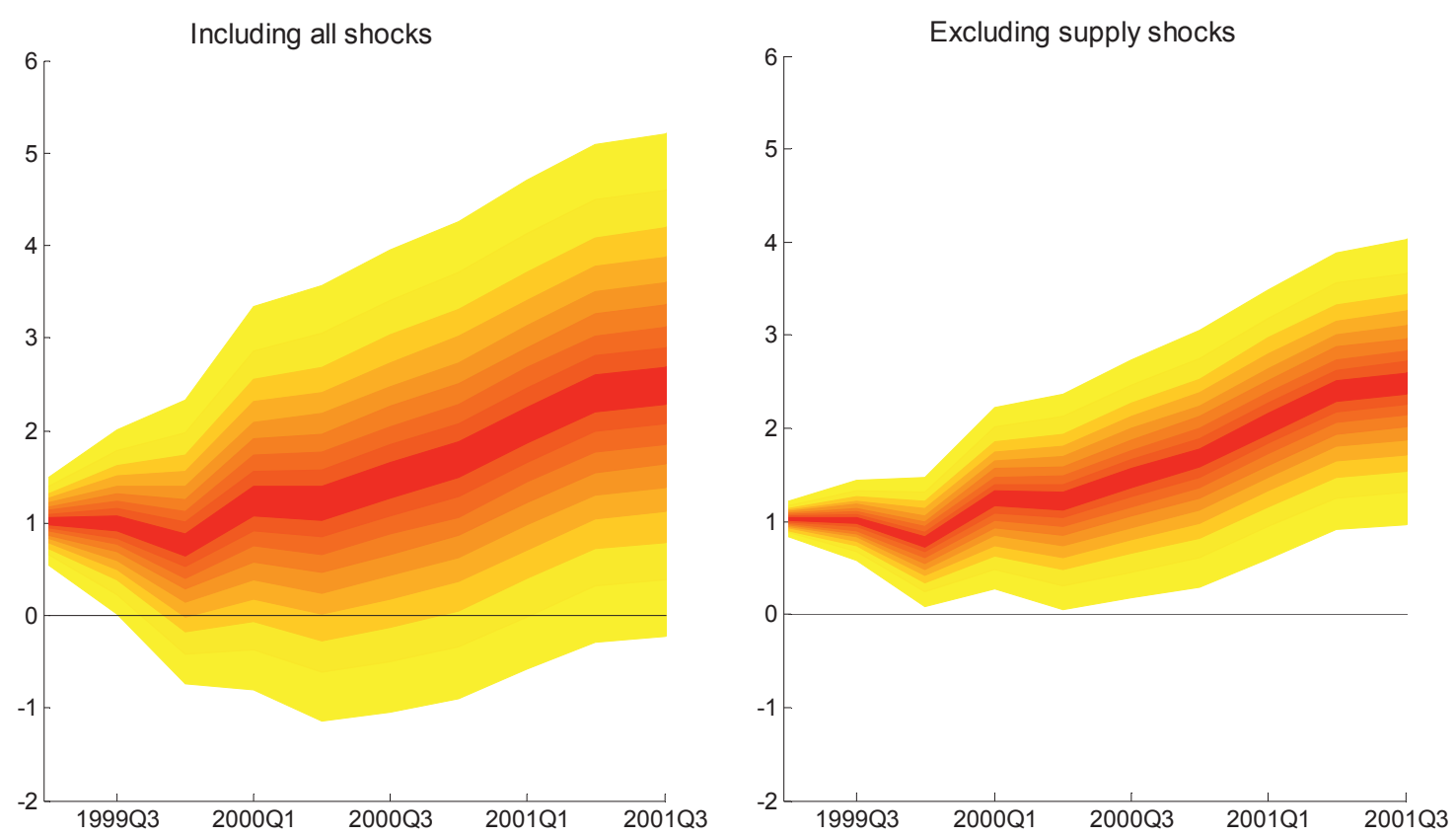

Note: Predictive distributions for inflation as could have been generated in $1999 Q 2$ by projecting the CMR model forward on the basis of all shocks (left-hand figure) or all shocks excluding temporary TFP shocks, permanent labour-augmenting productivity shocks, oil price shocks, price mark-up shocks (right-hand figure).

Figure 3.6 A 1999 Policy Counterfactual: Taking out Insurance Against Deflation
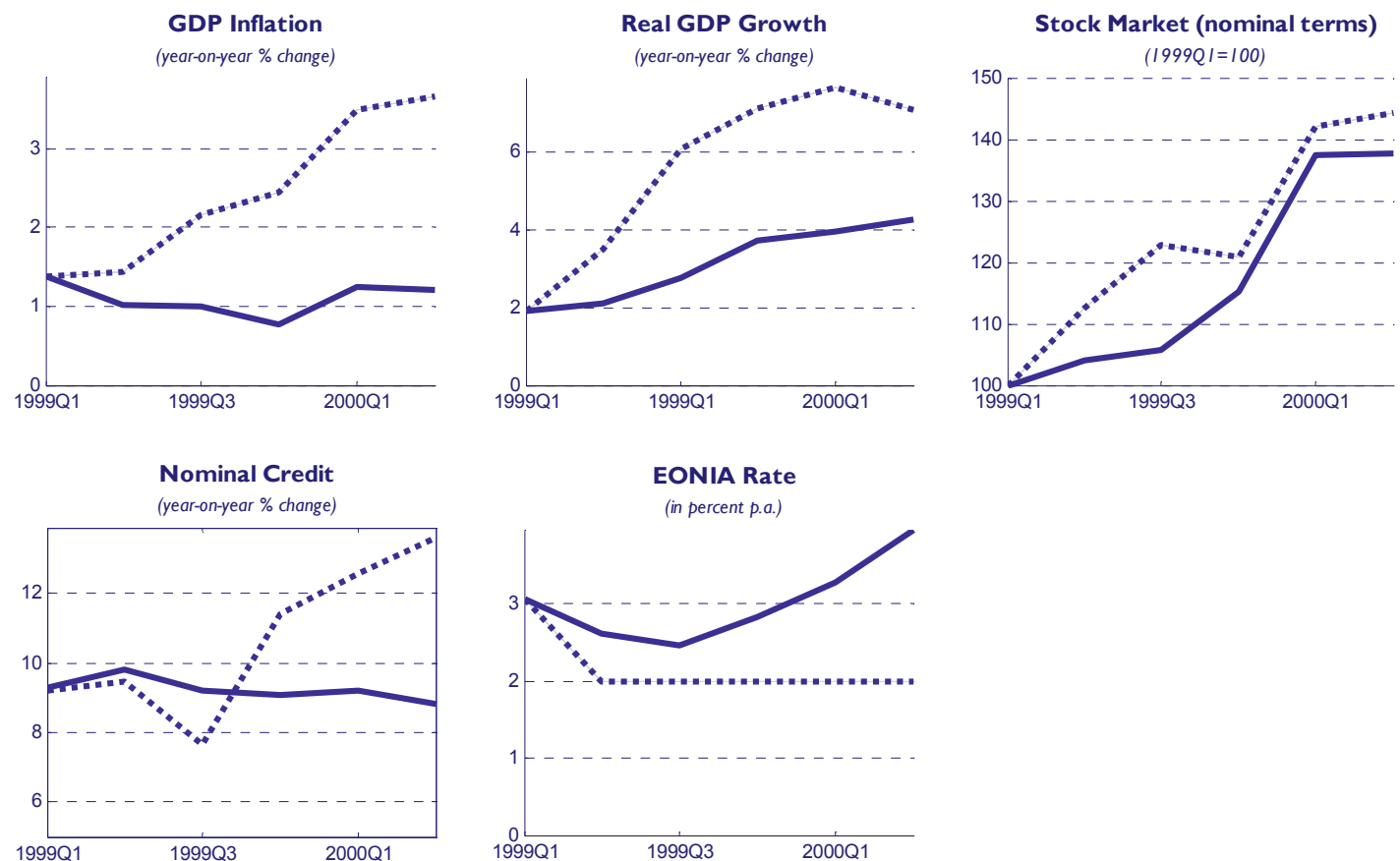

Note: In each panel the solid line indicates history. The dotted line indicates the counterfactual associated with the following policy experiment:: the central bank reacts to the risks of deflation displayed in Figure 3.5 by cutting the policy rate to 2 percent in I999QI and signalling its intention to keep it at that level until 2000Q2. 
Figure 3.7 Money, Underlying Money and Credit Growth (Percent p.a.)

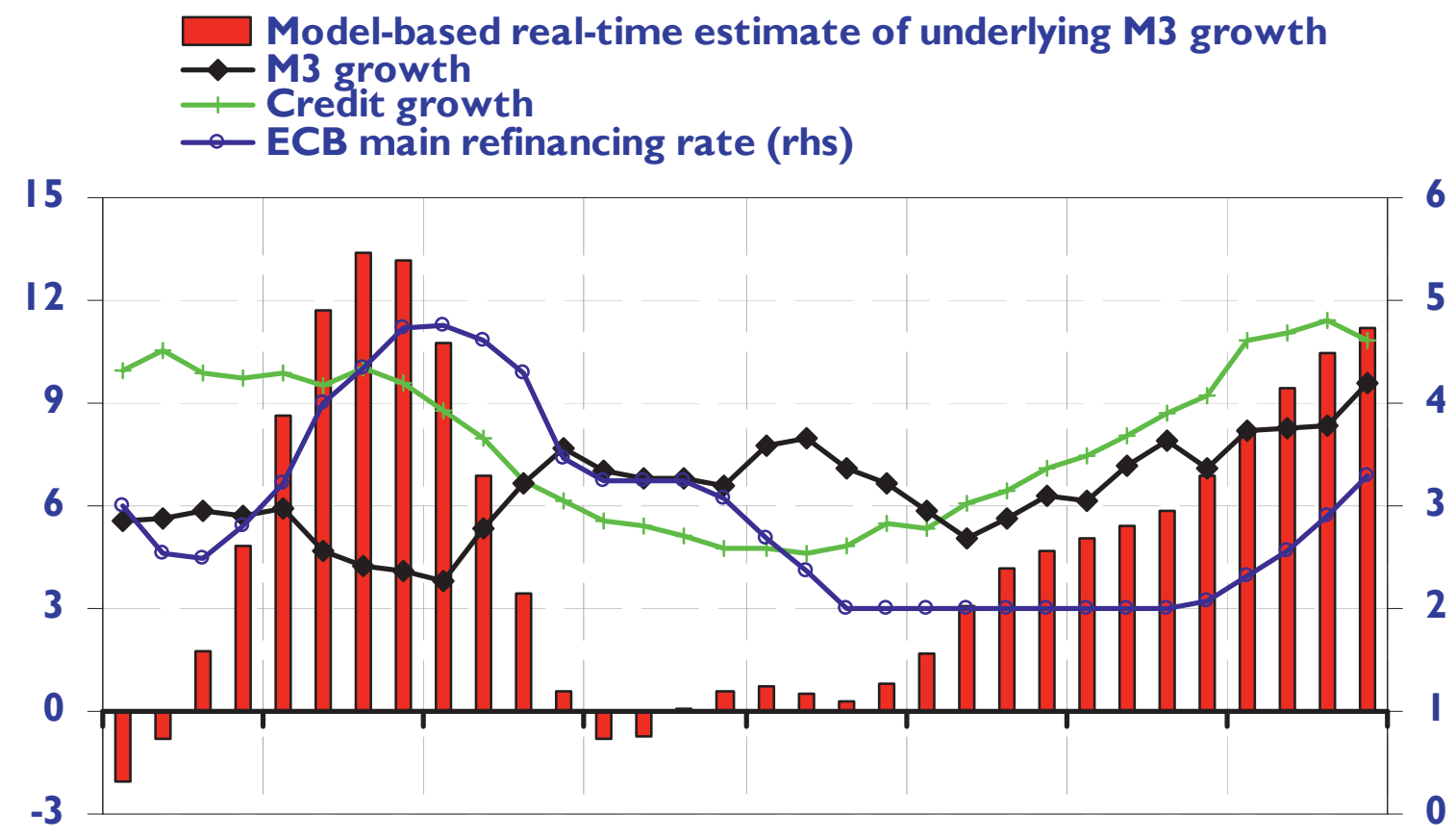

\section{I999QI 2000QI 200IQI 2002QI 2003QI 2004QI 2005QI 2006QI}

Notes: The red bars correspond to the annualised rates of money growth in the CMR model, after purging headline money growth of the impact of shocks shifting the demand for money.

Figure 3.8 Counterfactual: History without the Monetary Pillar
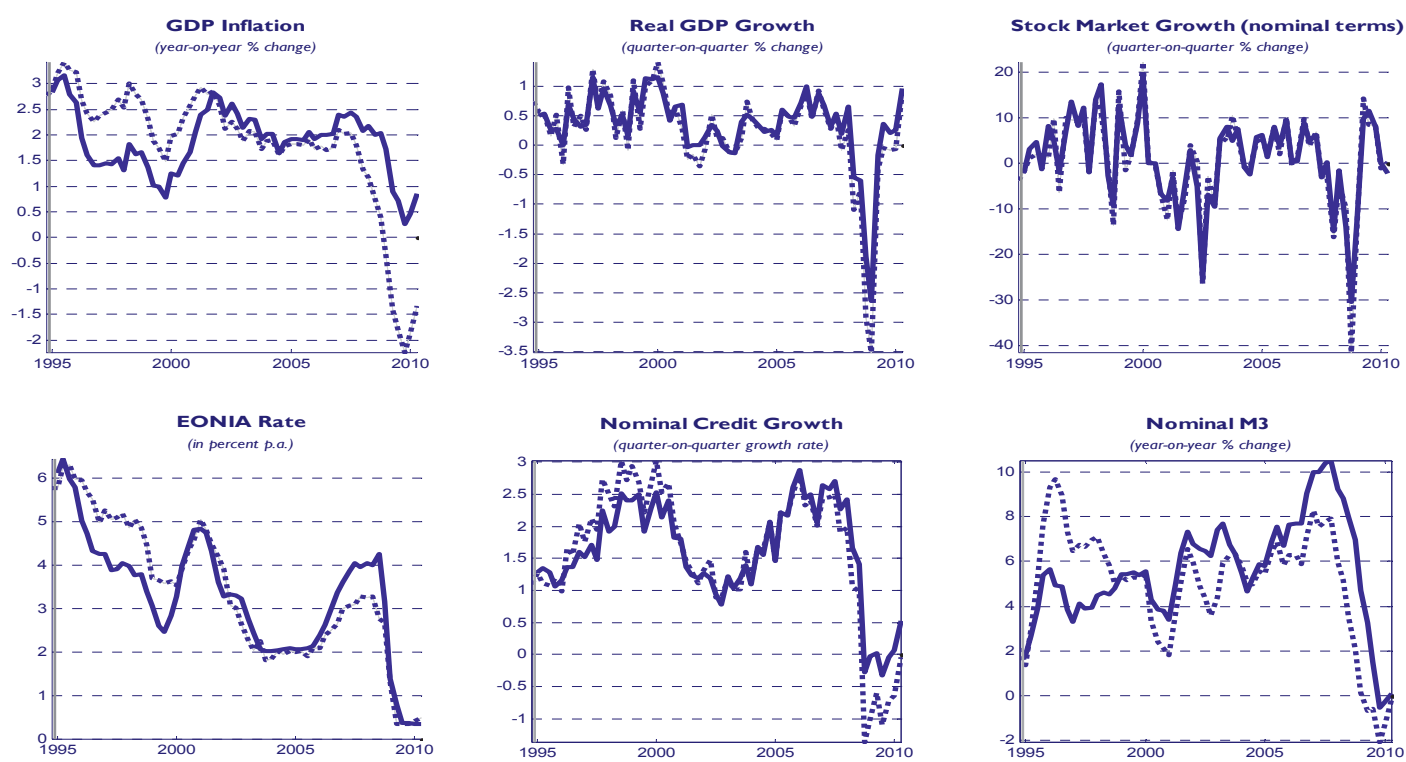

Notes: In each panel the solid line indicates history. The dotted line indicates the counterfactual associated with a money market feed-back relationship $(I)$ in which the monetary policy reaction coefficient, $\gamma$, is set equal to zero. 
Figure 3.9 The Taylor Frontier With and Without the Monetary Pillar

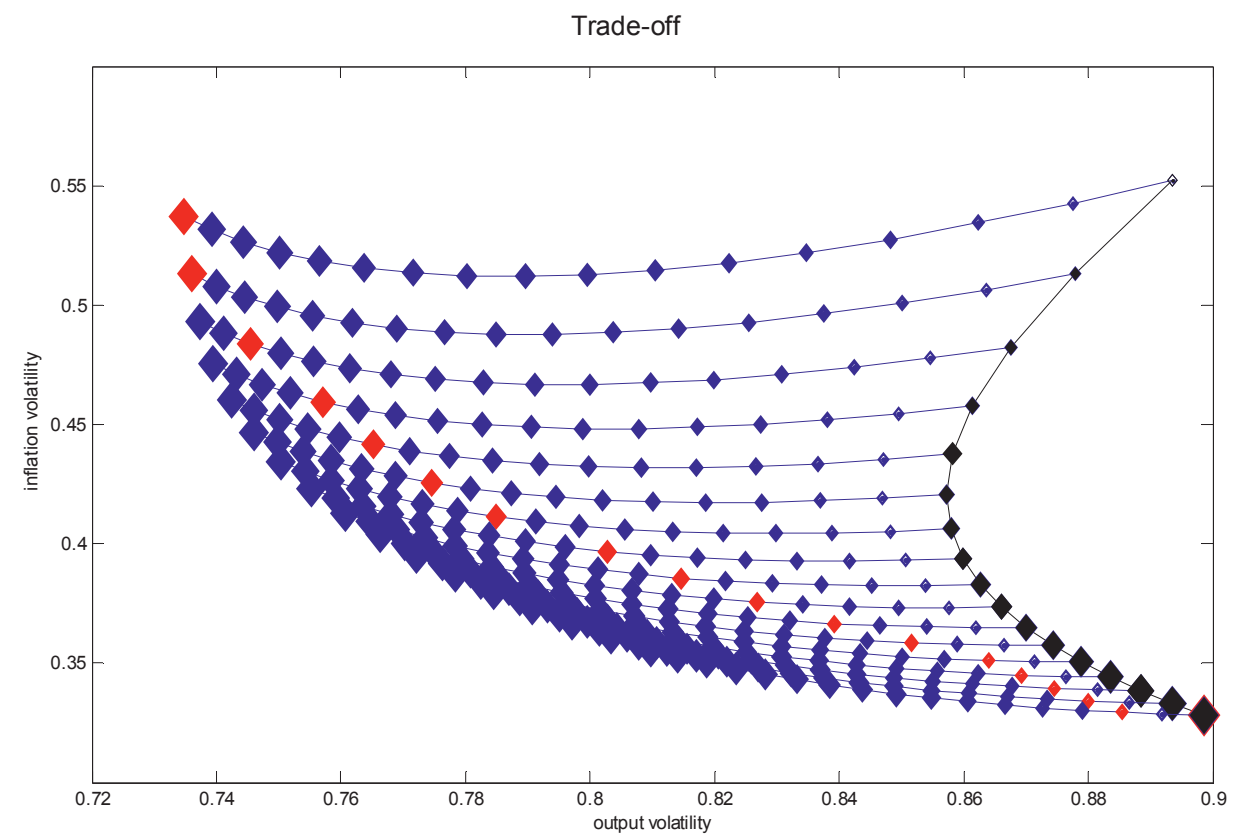

Notes: Taylor frontiers with a reaction to credit (blue lines) and without a reaction to credit (black lines). Black (blue) diamonds of increasing size indicate reaction to inflation (credit) of increasing intensity. Red diamonds represent the maximal reaction to credit consistent with a trade-in. 


\section{Section 4}

Figure 4.I. Turmoil in the money market

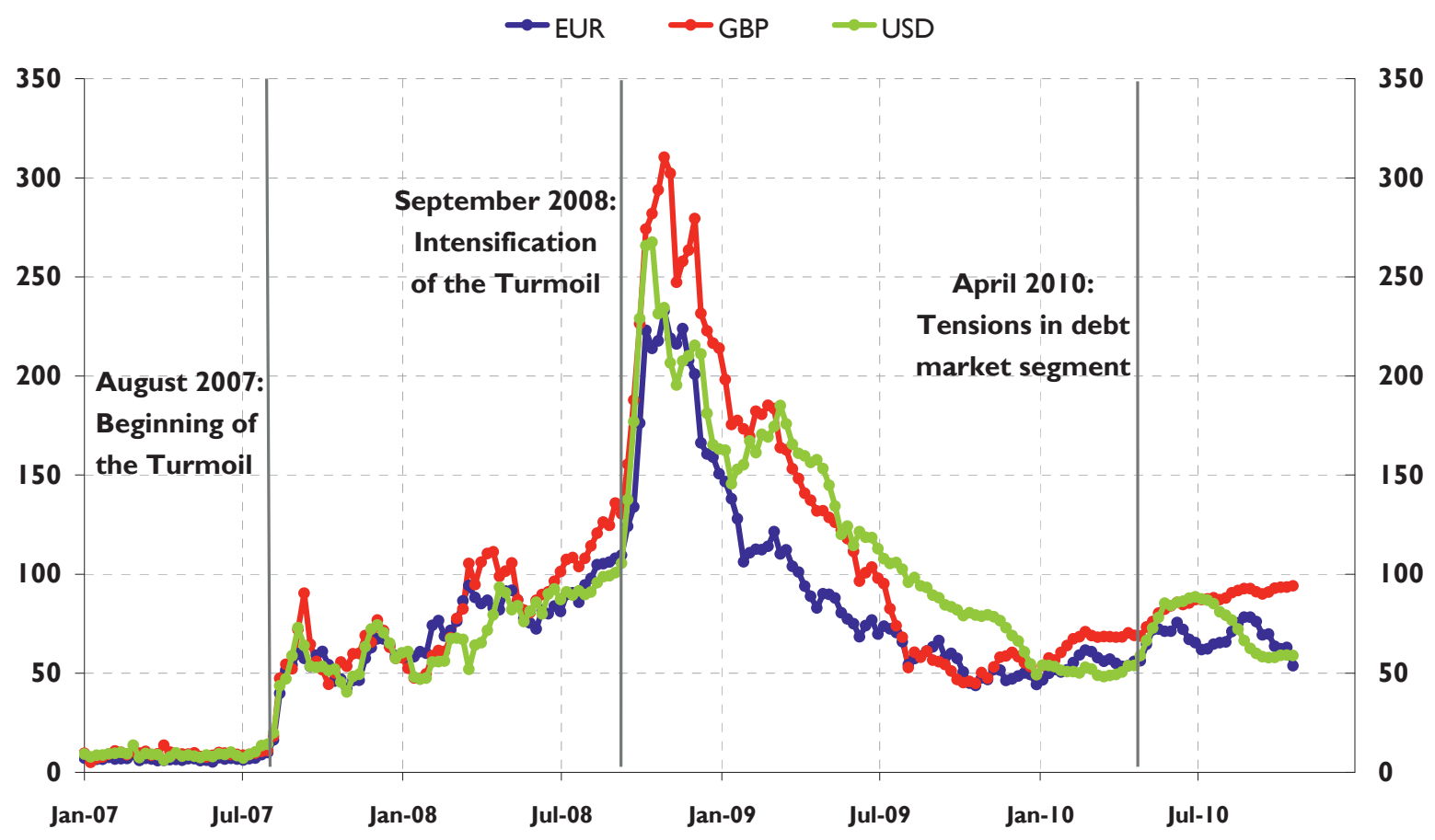

Sources: Bloomberg and ECB calculations.

Note: Spreads are the difference between 12-month Euribor/Libor and Overnight Index Swap rates, in basis points. Last observation 22 October 2010.

Figure 4.2. ECB interest rates and money market rates

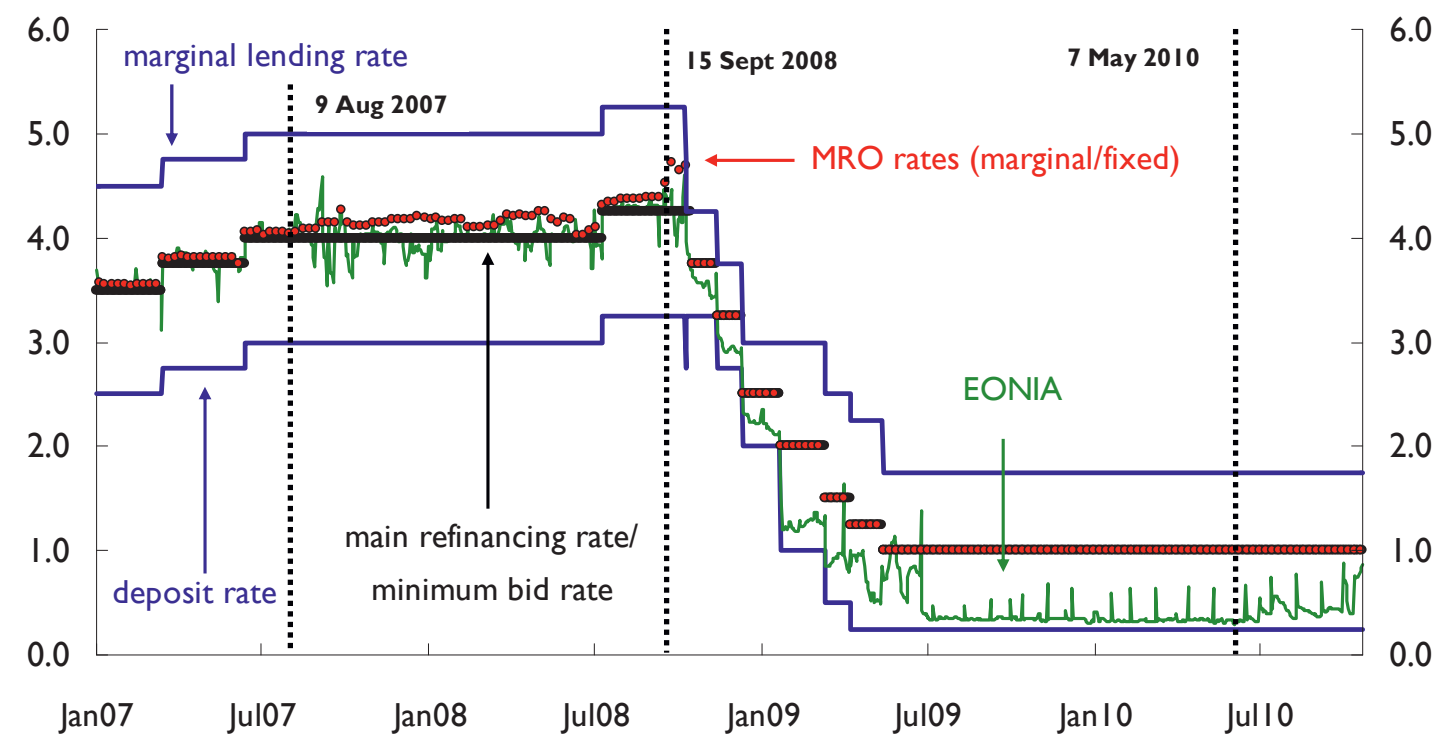

Sources:ECB. Note: Last observation 21 October 2010. 
Figure 4.3. ECB balance sheet during the financial crisis

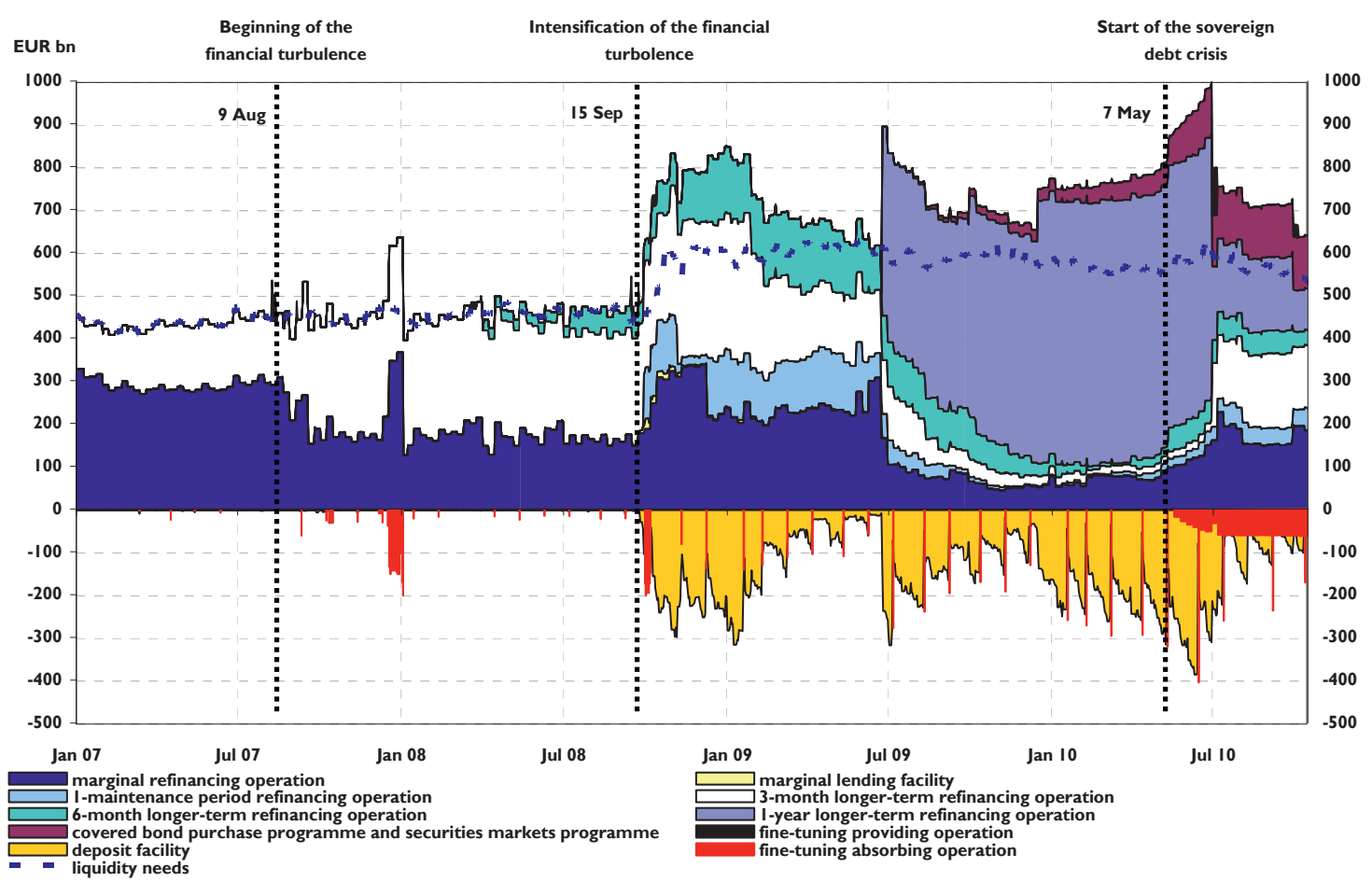

Sources: ECB. Note: Last observation 15 October 2010.

Figure 4.4. Impulse responses to a $I \%$ increase in the interbank spread
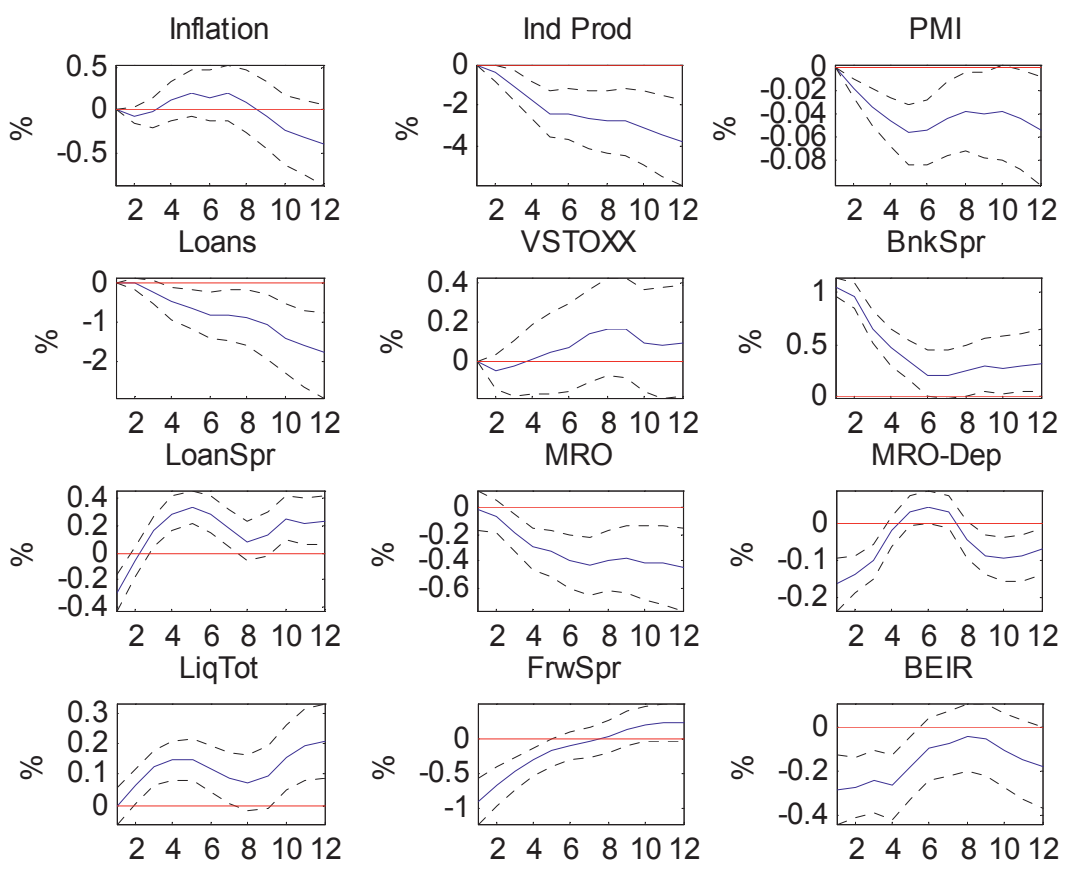

Note: In each panel the solid line indicates the median response, the dotted lines refer to the $16^{\text {th }}$ and $84^{\text {th }}$ percentile of the posterior distribution of the impulse responses. Legend: "Inflation" is the year-on-year log-difference of the HICP; "Ind Prod" is logindustrial production in deviation from a quadratic trend; "PMl" is the Purchasing Managers Index (in logs); "Loans" is the annual growth rate of loans adjusted for sales and securitisation; "VSTOXX" is implied stock market volatility (in logs); "BnkSpr" is the spread between the 3-month EURIBOR and the 3-month overnight index swap rate; "LoanSpr" is the spread between the rate on bank loans to non-financial corporations and the 3-month EURIBOR; "MRO" is the MRO rate; "MRO-Dep" is the spread between the MRO rate and the rate on the deposit facility; "LiqTot" is the outstanding amount of ECB liquidity-providing operations (in logs); "FrwSpr" is the spread between the overnight rate in I year and the MRO rate; "BEIR" is the I0-year break-even inflation rate. 
Figure 4.5. Impulse responses to a standard expansionary policy shock
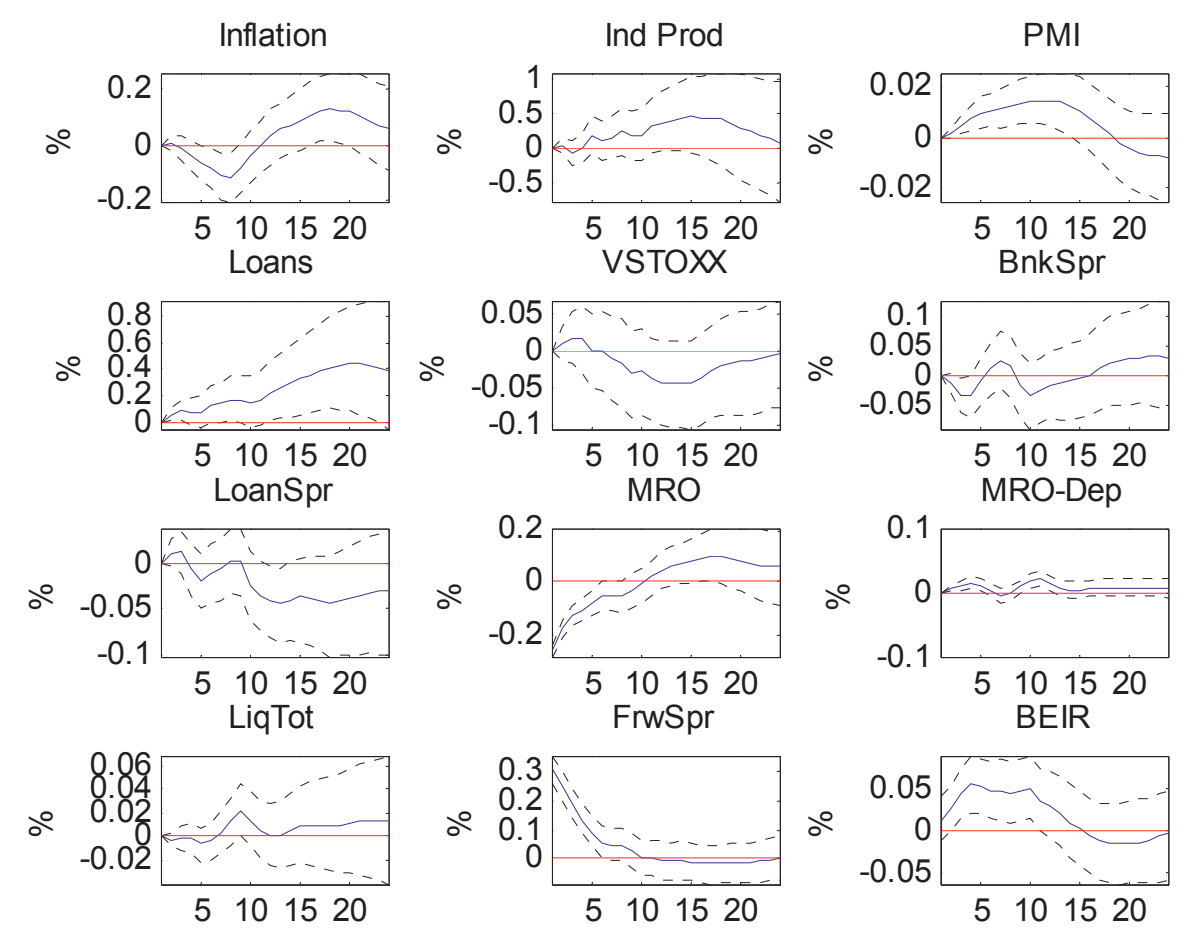

Note: In each panel the solid line indicates the median response, the dotted lines refer to the $16^{\text {th }}$ and $84^{\text {th }}$ percentile of the posterior distribution of the impulse responses. Legend: see Figure 4.4.

Figure 4.6. Impulse responses to an exogenous fall in the rate on the deposit facility
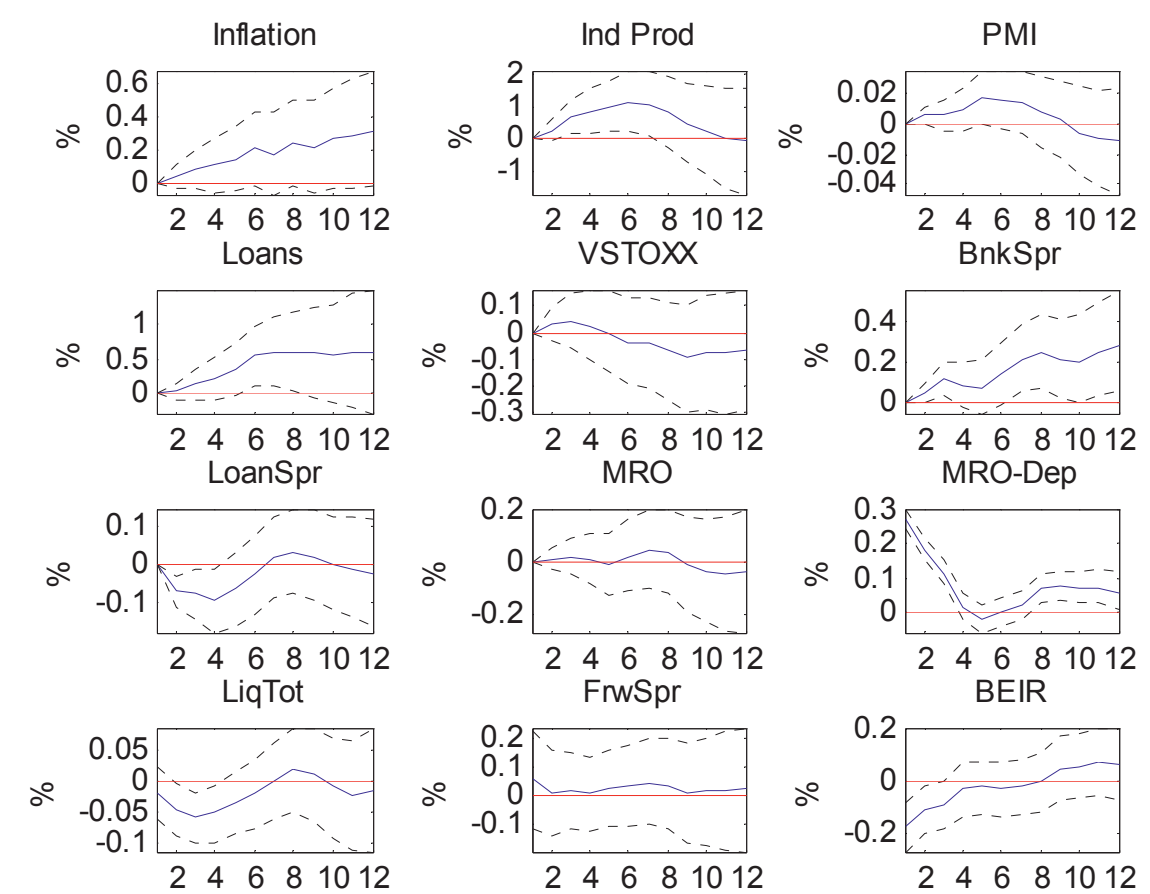

Note: In each panel the solid line indicates the median response, the dotted lines refer to the $16^{\text {th }}$ and $84^{\text {th }}$ percentile of the posterior distribution of the impulse responses. Legend: see Figure 4.4. 
Figure 4.6b. Impulse responses to a fall in the rate on the deposit facility: extended model
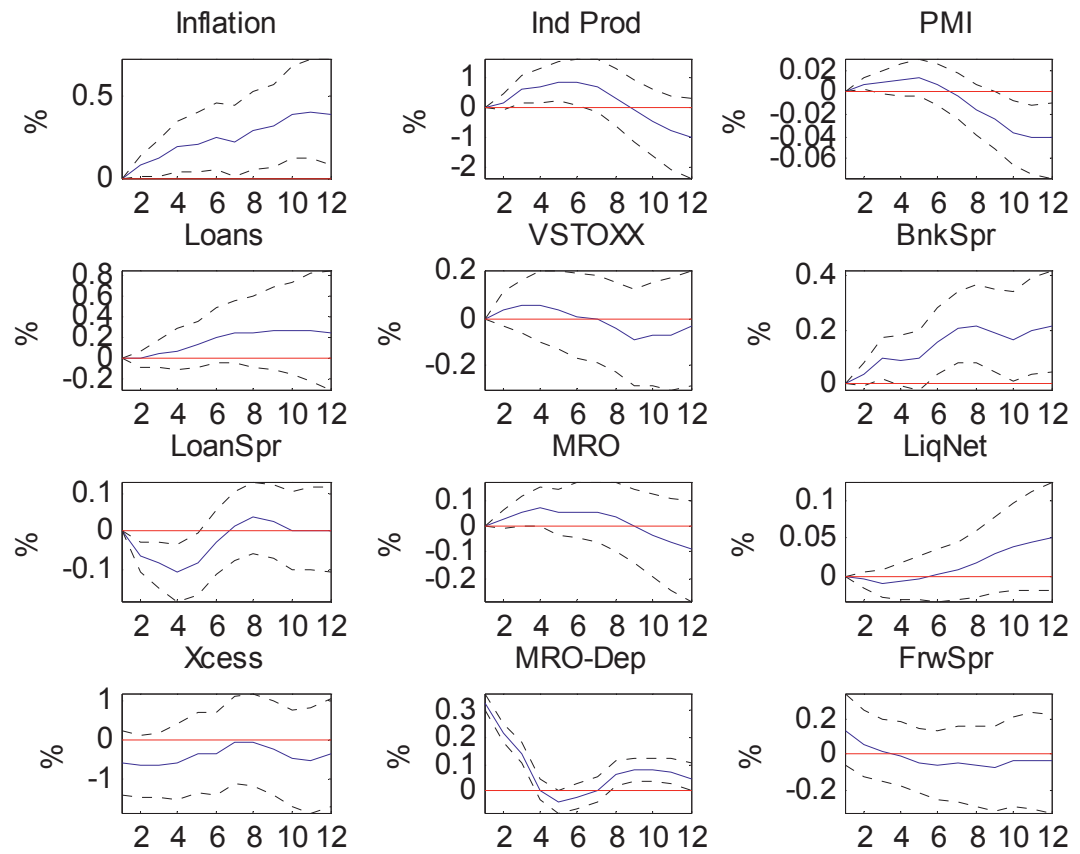

Note: In each panel the solid line indicates the median response, the dotted lines refer to the $16^{\text {th }}$ and $84^{\text {th }}$ percentile of the posterior distribution of the impulse responses. Legend: "LiqNet" is the difference between total liquidity-providing operations and the recourse to the deposit facility (in logs); "Xcess" is the recourse to the deposit facility (in logs); for the other variables, see Figure 4.4.

\section{Figure 4.7. Impulse responses to a liquidity demand shock}
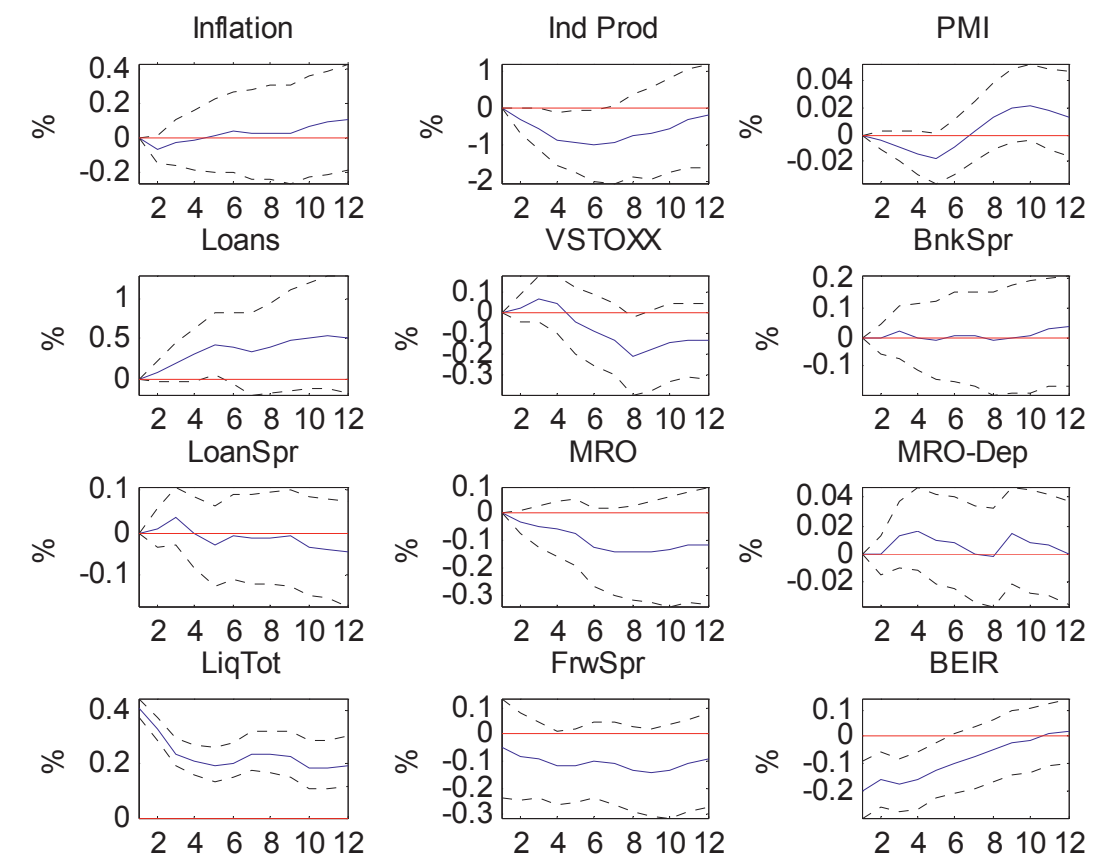

Note: In each panel the solid line indicates the median response, the dotted lines refer to the $16^{\text {th }}$ and $84^{\text {th }}$ percentile of the posterior distribution of the impulse responses. Legend: see Figure 4.4 . 
Figure 4.7b. Impulse responses to a demand shock for excess liquidity: extended model
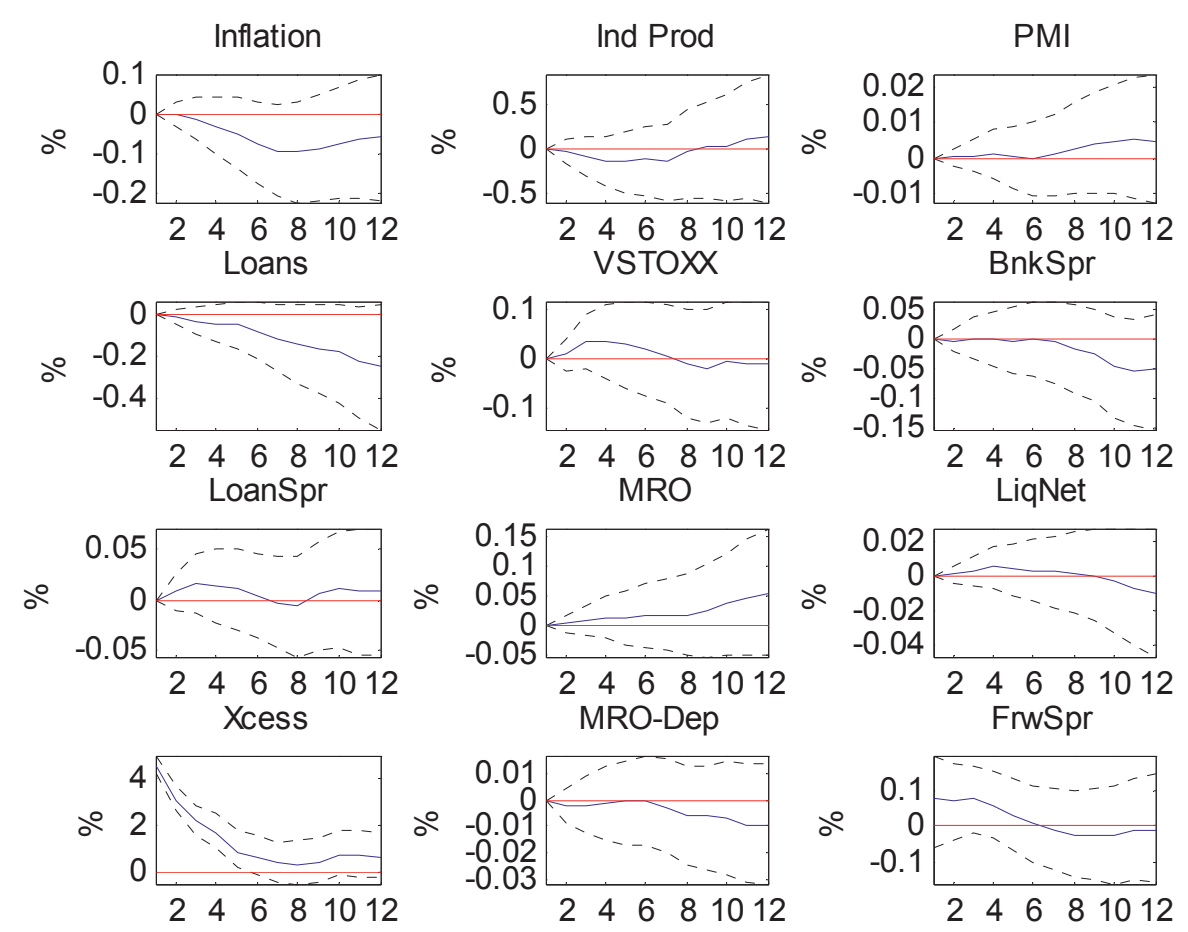

Note: In each panel the solid line indicates the median response, the dotted lines refer to the $16^{\text {th }}$ and $84^{\text {th }}$ percentile of the posterior distribution of the impulse responses. Legend: see Figure 4.66. 
Chart 4.8. Post-Crisis Counterfactual: FRFA and Long Term Refinancing Operations

History . . . FRFA, No LTRO
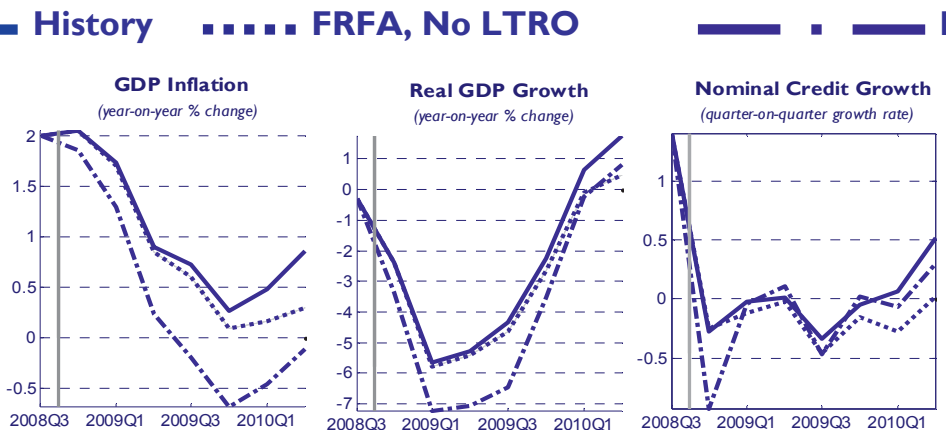

No FRFA
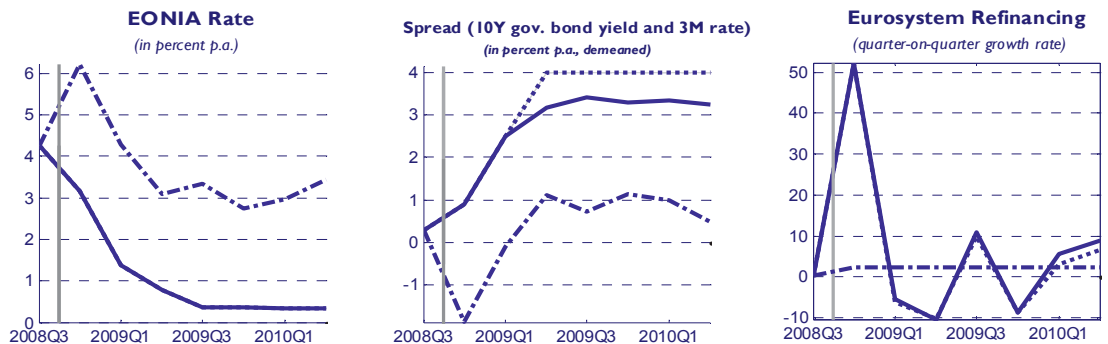

Note: In each panel the solid line indicates history. The dotted line indicates the counterfactual associated with a fixed-rate-fullallotment policy in the main refinancing operations, but no longer-term operations. The dashed line indicates the counterfactual associated with a variable-rate-tender policy in all refinancing operations.

\section{Chart 4.9. Post-Crisis Counterfactual: Too Low For Too Long}

\section{History}

Worst Case Scenario

- - - - Low EONIA Commitment

Historical Shocks \& Commitment

Historical Shocks, Commitment \& Surprise
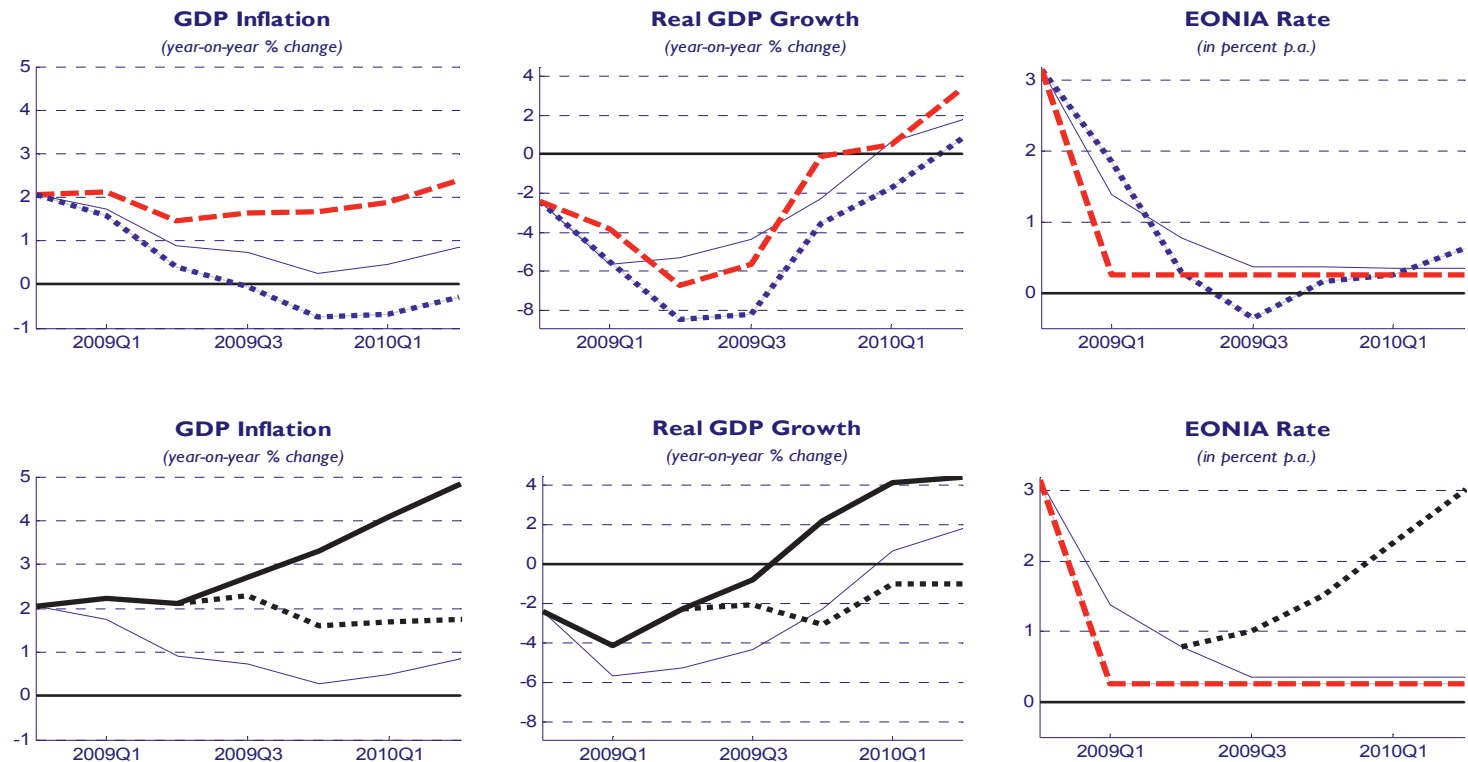

Note: In the panels the solid thin blue line indicates history. In the upper panels the dotted blue line indicates the counterfactual associated with assuming that adverse shocks in the lowest percentile of the predictive distribution would have occurred. The dashed red line indicates the counterfactual associated with bringing immediately the EONIA down to low levels and committing to maintain it there for some time. In the lower panels the solid black line is the outcome in case the shocks that have actually occurred do materialise but the policy commitment is maintained. The black dotted line is the outcome in case there is a policy "surprise", i.e. the tightening occurs earlier than originally expected by markets. 


\section{Appendix}

Figure A. Impulse Response Function to a Bank's Liquidity Demand Shock
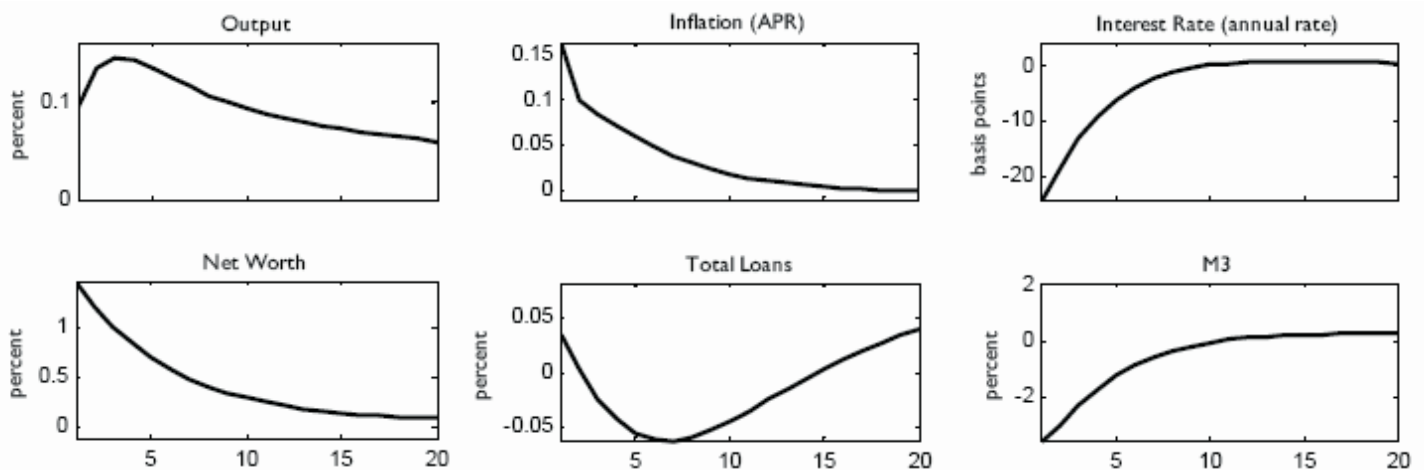

Note: Reproduced from Christiano, Motto and Rostagno (2010), "Financial Factors in Economic Fluctuations", ECB WP No. I/92. 
